\title{
Wind Turbine Trailing-Edge Aerodynamic Brake Design
}

Gene Quandt

NREL Technical Monitor:

Paul Migliore

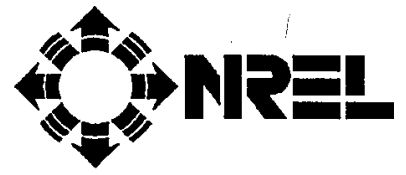

National Renewable Energy Laboratory 1617 Cole Boulevard

Golden, Colorado 80401-3393

A national laboratory of the U.S. Department of Energy Managed by Midwest Research Institute for the U.S. Department of Energy under contract No. DE-AC36-83CH10093

Prepared under Subcontract No. TAD-3-13400 January 1996 


\section{NOTICE}

This report was prepared as an account of work sponsored by an agency of the United States govemment. Neither the United States govemment nor any agency thereof, nor any of their employees, makes any warranty, express or implied, or assumes any legal liability or responsibility for the accuracy, completeness, or usefulness of any information, apparatus, product, or process disclosed, or represents that its use would not infringe privately owned rights. Reference herein to any specific commercial product, process, or service by trade name, trademark, manufacturer, or otherwise does not necessarily constitute or imply its endorsement, recommendation, or favoring by the United States govemment or any agency thereof. The views and opinions of authors expressed herein do not necessarily state or reflect those of the United States govemment or any agency thereof.

Available to DOE and DOE contractors from:

Office of Scientific and Technical Information (OSTI)

P.O. Box 62

Oak Ridge, TN 37831

Prices available by calling (423) 576-8401

Available to the public from:

National Technical Information Service (NTIS)

U.S. Department of Commerce

5285 Port Royal Road

Springfield, VA 22161

(703) $487-4650$ 


\section{Foreword}

The Wind Technology Division of the National Renewable Energy Laboratory (NREL) is conducting exploratory research on aerodynamic devices that are intended to enhance wind-turbine rotor performance and attenuate structural loads. Desired properties of these devices include simplicity, reliability, maintainability, low cost, and fail-safe design. Initial efforts have focused on the use of trailing-edge aerodynamic brakes for overspeed protection. Long-term efforts will address more aggressive and innovative strategies that have the potential to significantly advance the state of the art.

This report touches on the work performed in two projects: Subcontract No. TAD-3-13400 entitled "Wind Turbine Trailing-Edge Aerodynamic Brake Design" performed by Gene A. Quandt, and Subcontract No. XAD-3-133365 entitled "Aerodynamic Devices for Wind Turbine Performance Enhancement" performed by Wichita State University (WSU). These two projects progressed in parallel, with considerable interaction between the principal investigators.

The WSU Phase 1 Report discussed the configurations studied and the attempts to identify promising alternatives through the analysis of the wind tunnel test data. The Phase 2 Report presented windtunnel results for "spoiler-flaps" of $30 \%, 40 \%$ and $50 \%$ chord; for various leading-edge lip extensions; for different venting arrangements; and for different device hinge locations. Gene Quandt's subcontract report, the document you are presently reading, focuses on aerodynamic and structural design, and includes preliminary design calculations for a centrifugally actuated aerodynamic brake.

As is often the case with exploratory research, these projects have spawned additional follow-on studies. Wind-tunnel tests are planned at Ohio State University in which a pressure-tapped S809 airfoil model will be tested with three trailing-edge devices: the spoiler-flap, a plain flap ("unvented aileron") and a vented plain flap ("vented aileron"). Rotating-blade tests of these same configurations will be conducted at the National Wind Technology Center (NWTC), with the goal of quantifying the effects of unsteadiness, blade rotation, and aspect ratio, so that corrections can be applied to windtunnel test data for use by wind-turbine designers in the future.

Alue \& Miglcare 


\section{Preface}

The report was funded by the National Renewable Energy Laboratory (NREL), for that I am thankful. I also want to thank the NREL staff for their help and untiring technical assistance. A special thanks to the projects technical monitor, Paul Migliore, for allowing ideas to become models. Thanks also must be paid to Wichita State University (WSU), L.S. Miller, and his team for their test support and all of their help with the post test analysis. 


\section{Abstract}

This report describes the design of a centrifugally actuated aerodynamic-overspeed device for a horizontal-axis wind turbine. The device will meet the following eriteria:

- It will be effective for airfoil angles of attack $0^{\circ}$ to $45^{\circ}$.

- It will be stowed inside the blade profile prior to deployment.

- It will be capable of offsetting the positive torque produced by the overall blade.

- Hinge moments will be minimized to lower actuator loads and cost.

- It will be evaluated as a potential power modulating active rotor-control system.

A literature review of aerodynamic braking devices was conducted. Information from the literature review was used to conceptualize the most effective devices for subsequent testing and design. Wind-tunnel test data for several braking devices are presented in this report. Using the data for the most promising configuration, a preliminary design was developed for a MICON 65/13 wind turbine with Phoenix 7.9-m rotor blades. 


\section{Table of Contents}

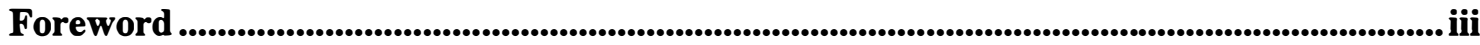

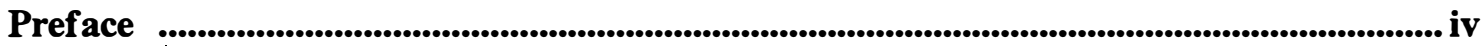

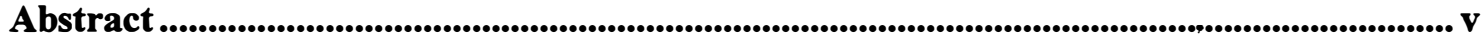

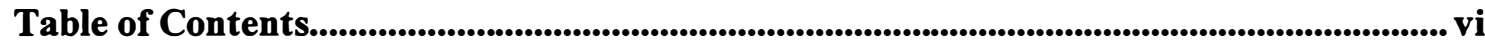

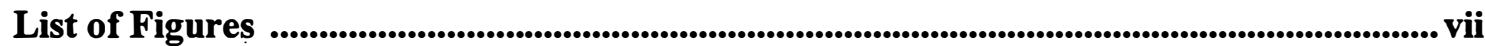

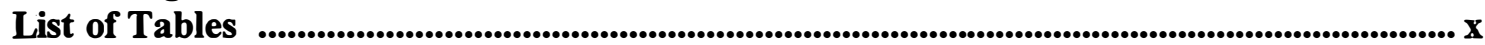

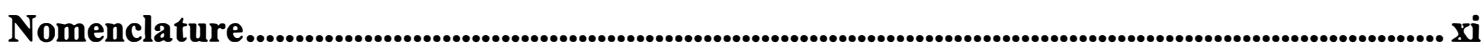

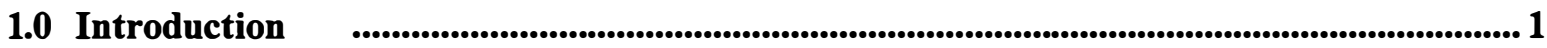

1.1 Wind Turbine Power Modulation and Overspeed Protection......................................... 1

1.2 Low Cost Wind Turbine Aerodynamic Overspeed Control Device................................... 3

1.3 Wind Turbine Aerodynamics ............................................................................................................... 4

2.0 Literature Survey

2.1 HAWT Aerodynamic Devices ..................................................................................................... 7

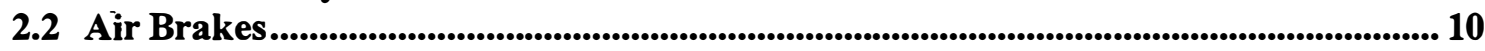

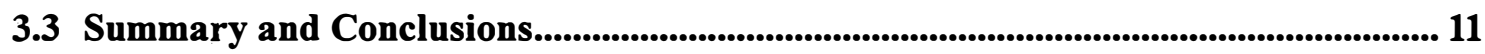

3.0 Investigation Procedures $\quad$....................................................................................................................... 12

3.1 Geometry Considerations............................................................................................................... 12

3.2 Aerodynamic Considerations............................................................................................................. 12

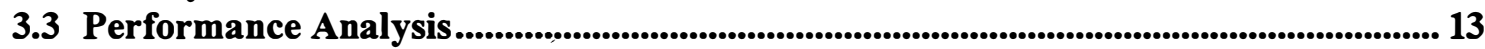

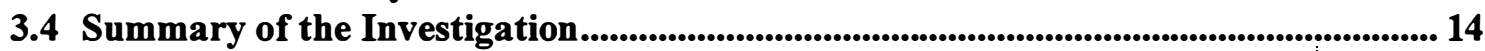

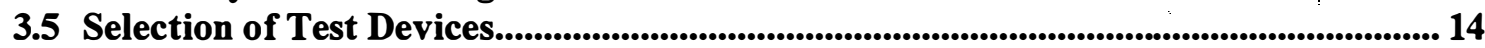

4.0 Wind Tunnel Testing $\quad$...................................................................................................................... 16

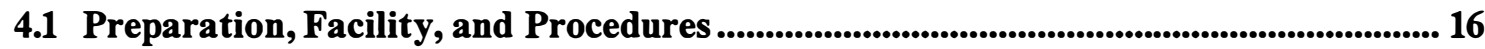

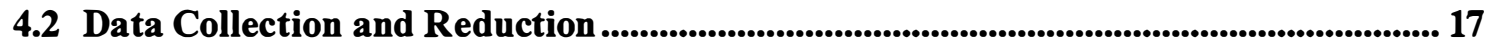

4.3 Data Summary and Performance Analysis ........................................................................... 24

4.4 Pressure Data Measured on the Spoiler-Flap .............................................................. 31

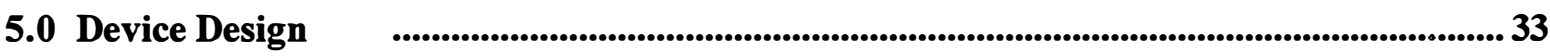

5.1 Aerodynamic Braking Requirements ......................................................................................... 33

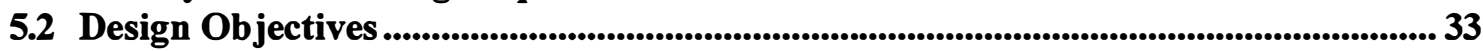

5.3 Preliminary Design for the Phoenix 7.9-m blade .................................................................. 38

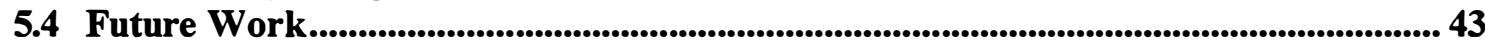

6.0 Summary $\quad$.................................................................................................................................................................. 45

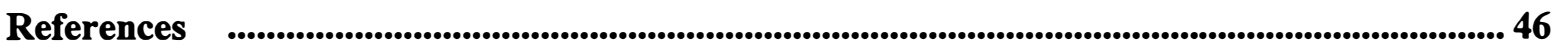

Appendix A Wind Tunnel Aerodynamic Data

Appendix B Phoenix 7.9-M Blade Spoiler-Flap Loads Data 


\section{List of Figures}

$\underline{\text { Page }}$

1-1 Blade segment angle of attack for a 26-m-diameter turbine at 60 RPM .............................. 3

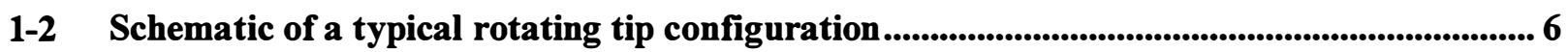

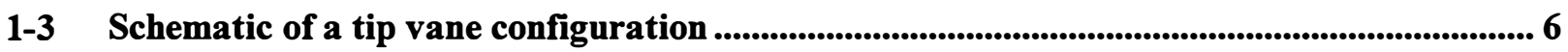

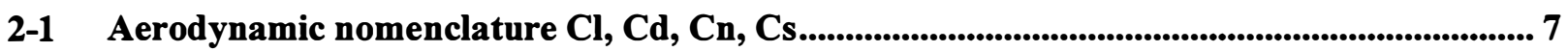

3-1 Blade with a (typical) trailing edge braking device configuration ......................................... 12

3-2 Basic airfoil section used for the wind-tunnel test ............................................................ 14

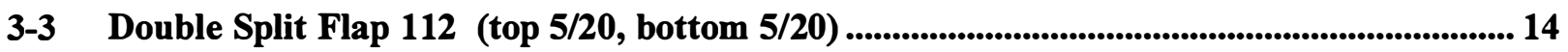

3-4 Double Split Flap 60 (top 10/30, bottom 10/30) ............................................................... 15

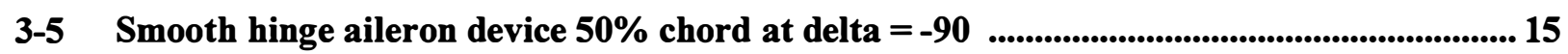

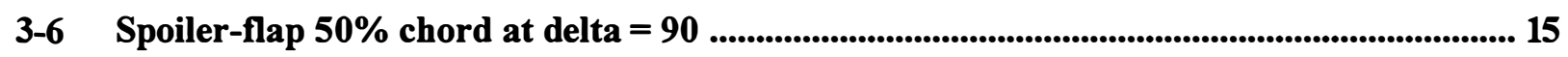

4-1 Suction coefficient for all NACA DSF 112 tested variations.............................................. 19

4-2 Suction coefficient for the first four symmetric NACA DSF 60 tested chord and

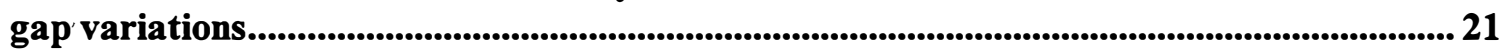

4-3 Suction coefficient for the typical $20 \%$ chord NACA DSF 60 tested gap variations............ 22

4-4 Suction coefficients for the $50 \%$ chord aileron with smooth hinge..................................... 23

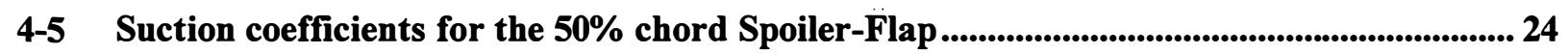

4-6 Typical NACA DSF rotor aerodynamic brake torque profiles.............................................. 25

4-7 Typical NACA DSF rotor aerodynamic brake torque profiles.............................................. 26

4-8 Smooth-hinge aileron rotor aerodynamic brake torque profiles.......................................... 26

4-9 Smooth-hinge aileron rotor aerodynamic brake torque profiles............................................. 27

4-10 Spoiler-Flap rotor aerodynamic brake torque profiles .............................................................. 27

4-11 Spoiler-Flap rotor aerodynamic brake torque profiles ........................................................... 28

4-12 Spoiler-Flap and DSF 112 (top 5/20, bottom 5/20) comparison of aerodynamic brake torque profiles. 


\section{List of Figures (Continued)}

4-13 Spoiler-Flap and DSF 60 (top 10/30, bottom 10/30) comparison of aerodynamic brake torque profiles.

4-14 Comparison of Spoiler-Flap and smooth-hinge aileron aerodynamic brake torque profiles.

4-15 Typical Spoiler-Flap pressure distribution for AOA 18 and delta $=60$

4-16 Typical Spoiler-Flap pressure distribution for AOA 30 and delta $=60$.......................... 32

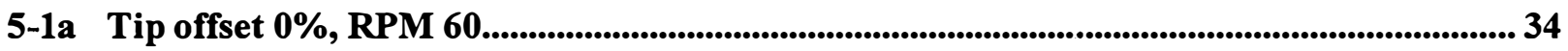

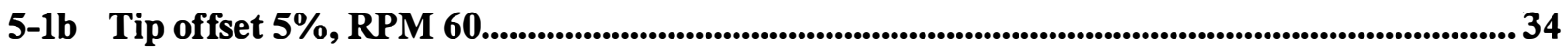

5-1c Tip offset 10\%, RPM 60............................................................................................................. 34

5-1d Tip offset 15\%, RPM 60........................................................................................................ 34

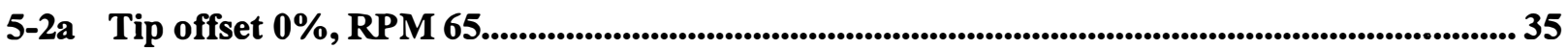

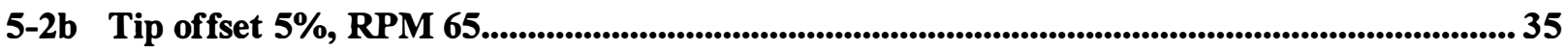

5-2c Tip of fset 10\%, RPM 65....................................................................................................................... 35

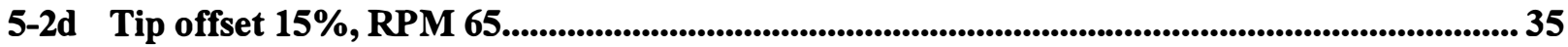

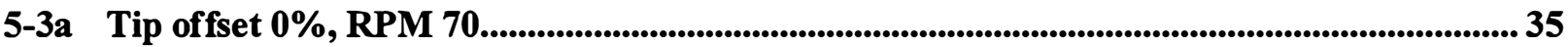

5-3b Tip offset 5\%, RPM 70

5-3c Tip offset 10\%, RPM 70....................................................................................................................................... 36

5-3d Tip of fset 15\%, RPM 70................................................................................................................................. 36

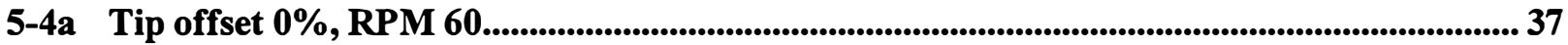

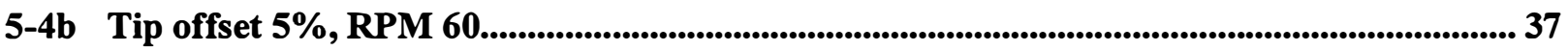

5-4c Tip offset 10\%, RPM 60................................................................................................................................ 38

5-4d Tip offset 15\%, RPM 60........................................................................................................... 38

5-5 Plan view of a 25\% span Spoiler-Flap device for the Phoenix 7.9 meter blade ...................... 38

5-6 Outboard Spoiler-Flap floating hinge and rib fittings ....................................................... 39 


\section{List of Figures (Concluded)}

5-7 Inboard Spoiler-Flap translating revolute hinge and rib fittings.............................................. 40

5-8 Magnet fittings laid out on the blade .................................................................................... 40

5-9 Plan view of Phoenix 7.9-m blade with a 25\% span Spoiler-Flap device showing load analysis segments.

5-10 Plan view of a 25\% span Spoiler-Flap device showing segments, air loads,

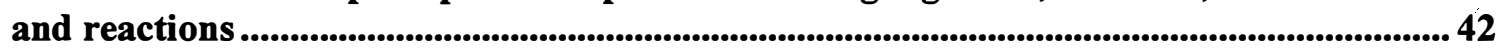

5-11 Plan view of a 25\% span Spoiler-Flap device showing device inertial loads and reactions 


\section{List of Tables}

$\underline{\text { Page }}$

1 Configuration (1) NACA DSF 112 two dimensional wind tunnel data.................................... A-2

2.1A Configuration (6) NACA DSF 60 two dimensional wind tunnel data ................................... A-3

2.2A Configuration (6) NACA DSF 60 two dimensional wind tunnel data ................................... A-4

2.3A Configuration (6) NACA DSF 60 two dimensional wind tunnel data .................................. A-5

3.1A Configuration (4) round shoulder two dimensional wind tunnel data................................... A-6

3.2A Configuration (4) round shoulder two dimensional wind tunnel data.................................. A-7

4.1A Configuration (2) spoiler-flap two dimensional wind tunnel data ........................................ A-8

4.2A Configuration (2) spoiler-flap two dimensional wind tunnel data ........................................ A-9 


\section{Nomenclature}

\begin{tabular}{|c|c|c|c|}
\hline 2-D & - & two dimensional & \\
\hline $\mathrm{AOA}$ & - & angle of attack & \\
\hline AR & - & aspect ratio & \\
\hline AWT & - & advanced wind turbine & \\
\hline B & - & number of blades & \\
\hline BS & - & blade station (inches from blade hub interface) & \\
\hline c & - & local chord & Drag \\
\hline$c_{d}$ & - & drag coefficient & $\begin{array}{l}\left(\frac{1}{2}\right) \cdot \rho \cdot V^{2} \cdot c \cdot(1) \\
\mathrm{C}_{\mathrm{L}}{ }^{2} \\
\end{array}$ \\
\hline $\mathrm{C}_{\mathrm{di}}$ & - & induced drag & $\begin{array}{l}\pi \cdot \mathrm{AR} \\
\text { Lift }\end{array}$ \\
\hline$c_{1}$ & - & lift coefficient & $\begin{array}{l}\left(\frac{1}{2}\right) \cdot \rho \cdot V^{2} \cdot c \cdot(1) \\
\quad \text { Lift }\end{array}$ \\
\hline $\mathrm{C}_{\mathrm{L}}$ & - & three dimensional lift coefficient & $\begin{array}{r}\left(\frac{1}{2}\right) \cdot \rho \cdot V^{2} \cdot S \\
M_{.25}\end{array}$ \\
\hline $\mathrm{c}_{\mathrm{m}(1 / 4)}$ & - & moment coefficient at the quarter chord & $\begin{array}{l}\left(\frac{1}{2}\right) \cdot \rho \cdot V^{2} \cdot c \cdot(1) \\
\text { normal } \cdot \text { force } \\
\end{array}$ \\
\hline $\mathrm{C}_{\mathrm{n}}$ & - & normal-force coefficient & $\begin{array}{l}\left(\frac{1}{2}\right) \cdot \rho \cdot V^{2} \cdot c \cdot(1) \\
\text { suction } \cdot \text { force } \\
\end{array}$ \\
\hline $\mathrm{C}_{\mathrm{s}}$ & 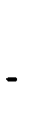 & suction force coefficient & $\left(\frac{1}{2}\right) \cdot \rho \cdot V^{2} \cdot c \cdot(1)$ \\
\hline$C_{x}$ & - & $\left(C_{1} \sin \phi-C_{d} \cos \phi\right)$ & \\
\hline $\mathrm{C}_{\mathrm{y}}$ & - & $\left(C_{1} \cos \phi+C_{d} \sin \phi\right)$ & \\
\hline delta & - & device deflection angle & \\
\hline DOE & - & Department of Energy & \\
\hline Drag & - & aerodynamic force in the direction of the flow & \\
\hline DSF 60 & - & double split flap deflected to $60^{\circ}$ & \\
\hline DSF 112 & - & double split flap deflected to $112^{\circ}$ & \\
\hline
\end{tabular}




\section{Nomenclature (continued)}

\begin{tabular}{|c|c|c|}
\hline $\mathrm{ECN}$ & - & Energieonderzoek Centrum Nedeland \\
\hline EMF & - & electromotive force \\
\hline FBD & - & free body diagram \\
\hline IEC & - & International Electrotechnical Commission \\
\hline Lift & - & aerodynamic force normal to the direction of the flow \\
\hline $\mathbf{M}_{.25}$ & - & aerodynamic moment about the $.25 \mathrm{c}$ of the airfoil \\
\hline No Device & - & truncated airfoil without a device \\
\hline normal-force & - & force normal to the chord local cchord plane \\
\hline NREL & - & National Renewable Energy Laboratory \\
\hline NPS & - & Northern Power Systems \\
\hline PROP93 & - & wind turbine performance code \\
\hline $\mathbf{r}$ & - & radial position on the blade \\
\hline $\mathbf{R}$ & - & rotor blade radius \\
\hline $\operatorname{Re}$ & - & Reynolds number \\
\hline REF & - & reference information \\
\hline $\mathrm{RPM}$ & - & revolutions per minute \\
\hline S & - & area length ${ }^{2}$ \\
\hline suction force & - & force parallel with the local chord plane \\
\hline TSR & - & tip speed ratio \\
\hline $\mathrm{V}$ & - & incoming flow velocity \\
\hline $\mathbf{w}$ & - & swirl velocity of the air incoming to the blade element length/sec \\
\hline wrt & - & with respect to \\
\hline $\mathrm{W}$ & - & $(\mathrm{r} \Omega+\mathrm{w}) / \cos \phi$ \\
\hline WER & - & Wind Energy Report \\
\hline WSU & - & Wichita State University \\
\hline WTGS & - & wind turbine generating systems \\
\hline$\phi$ & - & AOA relative wind wrt rotor plane \\
\hline$\Omega$ & - & angular velocity $(\mathrm{rad} / \mathrm{sec})$ \\
\hline$\Delta \mathrm{P}$ & - & incremental power \\
\hline$\Delta \mathrm{Q}$ & - & incremental torque \\
\hline$\Delta \mathrm{T}$ & - & incremental thrust \\
\hline$\Delta r$ & - & incremental radial section \\
\hline
\end{tabular}




\section{Nomenclature (concluded)}

$\rho \quad-\quad$ density of air mass $/$ length $^{3}$

(Subscripts)

$\max \quad-\quad$ maximum value of a variable

(Superscripts)

$\circ$

degrees 


\subsection{Introduction}

\subsection{Wind Turbine Power Modulation and Overspeed Protection}

Horizontal-axis wind turbines (HAWTs) are machines that extract mechanical energy from the wind and convert it, in most cases, to electrical energy. Constant-speed HAWTs come in two basic configurations: stall-controlled and actively controlled rotors. Stall-controlled rotors use aerodynamic tailoring to dissipate the power-producing forces once the rated power of the turbine is exceeded. The stall-control process can be defined as a rotor blade progressively stalling (losing lift) from the hub to the tip, thereby decreasing the spanwise percent of the blade that is producing significant power. Actively controlled rotors use some control action to dissipate power once the rated power and wind speed are exceeded. Regardless of which method of power modulation is used, the HAWT will still require an emergency braking system in case of loss of the line electromotive force (EMF) or some mechanical failure resulting in an overspeed condition.

\subsubsection{Aerodynamic Considerations}

There are two main aerodynamic factors that determine the potential energy capture from a HAWT; the control method, stall or active, and the swept area of the rotor. The wind turbine extracts a finite amount of energy from the wind that passes through the rotor swept area or "disc of rotation." It logically follows that as the disk gets larger, the amount of energy that can be extracted also gets larger. This is why the swept area is considered one of the primary variables in determining the amount of energy that can be extracted by a turbine.

The wind-turbine modeling method that will be used is called the Glauert Momentum Vortex Theory. This theory is used to calculate power, torque, and thrust on radial blade segments and then sum up the loads on the segments to determine the overall loading of the wind-turbine blade.

\subsubsection{Active Control}

An actively controlled rotor is capable of capturing larger amounts of energy than a stallcontrolled rotor. The National Aeronautics Space Administration (NASA) and the U.S. Department of Energy (DOE) studied some actively controlled HAWTs in the 1980s. These were large megawatt turbines in which the rotor blade or blade segment pivoting was actively controlled to limit the peak power once the rated wind speed was exceeded. The drawback of this configuration was that the mechanisms required for actuating the blade segments were large, expensive, and prone to failure. 


\subsubsection{Stall control}

The advantage of a stall-controlled rotor is that it contains no moving control devices, minimizing the cost of rotor installation. For a HAWT designed to use a stall-controlled rotor, the swept area is determined by the allowable maximum power. However, in wind speeds beyond that rated for the turbine, the blade's aerodynamics must be tailored to dissipate power. This is done by progressive blade stall from the center of the swept area (the hub) to the outermost section of the swept area (the blade tip). The progressive blade stall controls the power output of the rotor. The drawback of this control strategy is that much of the blade is operating in a post-stall regime during normal operation. This regime is aerodynamically unstable and results in high fatigue loads. One common requirement for actively controlled and stall-controlled turbines is an overspeed protection device. The design of this device is outlined briefly below and is described in more detail in Section 2.2 .

\subsubsection{Mechanical Design Considerations}

This overspeed protection device can be either a purely mechanical disk brake-type device or an aerodynamic device. The aerodynamic device can be a rotating tip, tip vane, spoiler, flap, blade tip, entire blade, or aileron. To this point, the most popular methods in production are the tip vanes, rotating tips and rotating blades.

Aerodynamic overspeed control devices have been used on nearly all of the modern wind turbines. On turbines without a separate device, a portion of the blade is generally rotated to accomplish the aerodynamic overspeed control effect. The aerodynamic control can be electrically or inertia-load activated. The initial design for this project will be an inertia-load-activated aerodynamic overspeed control device.

The primary consideration is locate the device as close to the tip as possible for maximum aerodynamic effectiveness and minimum overall weight. In the tip region of curent optimized stall-controlled rotor blades there is little space and structure. This makes device location a compromise between aerodynamic and structural concerns.

\subsubsection{Safety Issues}

The interesting and difficult part of designing an aerodynamic braking device for a HAWT application is the blade's angle of attack (AOA) range. The braking device must be effective for 
blade angles of $0^{\circ}$ to $45^{\circ} \mathrm{AOA}$ to enable a wind turbine to limit its operating RPM in a freewheeling condition at wind speeds up to $140 \mathrm{mph}$. There are some variations in the operating range. The plot of AOA data for a 26-m-diameter turbine at $60 \mathrm{RPM}$ and three wind velocities is shown in Figure 1-1. The data are shown to emphasize the AOA variation on the spanwise blade segments for braking analysis.

The actuation should be fail-safe. That is, if an actuation component fails, the device should deploy, resulting in a safe condition. It should be noted that making the actuating system fail-safe does not make the entire installation fail-safe. If a single component failure could result in the loss of device effectiveness, then the system is not fail-safe. In an effort to minimize the inertial loads, the mass of the device and actuating system should be as small as possible.

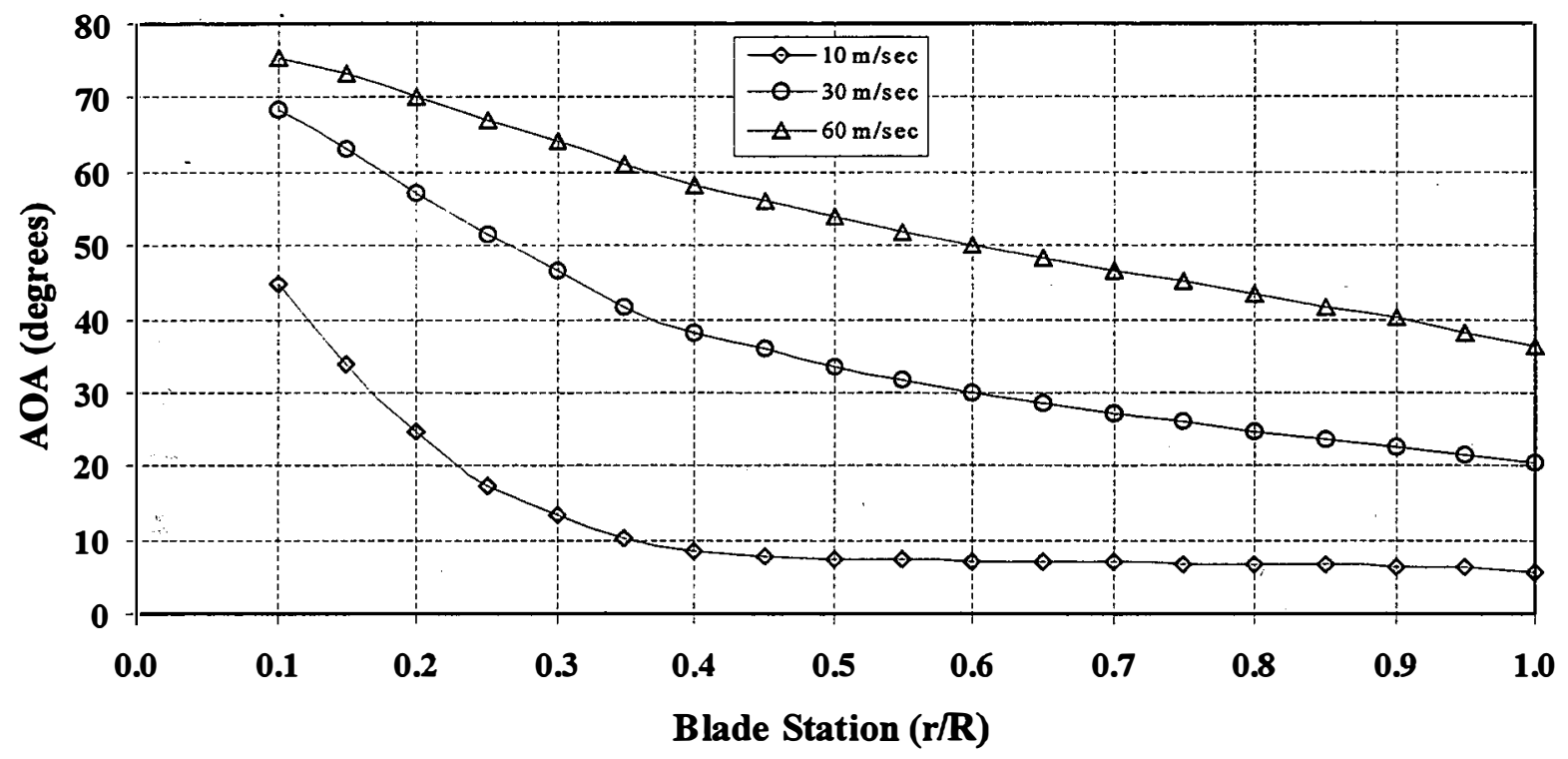

Figure 1-1. Blade segment angle of attack for a 26-m-diameter turbine at 60 RPM.

\subsection{Low Cost Wind Turbine Aerodynamic Overspeed Control Device}

This report describes the process of designing a reliable, passively actuated, inexpensive HAWT aerodynamic braking device. The device will be capable of being stowed inside or nearly inside the standard airfoil shape prior to deployment. This design will eliminate the operating drag caused by tip vane devices. The device will not be designed to carry large normal operating loads. This overspeed control device design is, first and foremost, an alternative to turbine rotor blade tip vanes or rotating tips for aerodynamic braking. Another potential use for the device would be as a power modulator in an active aerodynamic control system. 
A wind-turbine aerodynamic braking device will be configured based on data obtained in windtunnel tests performed at Wichita State University (WSU) between November and December 1993 L.S. Miller (1995). The most critical aerodynamic characteristic for HAWT control is the Coefficient of Suction (Cs). For the aerodynamic device to be entirely effective, the relationship between device deflection and $\mathrm{Cs}$ should be continuous and predictable. The Cs should be highly negative for a blade AOA range between $0^{\circ}$ and $45^{\circ}$; this would ensure a tip-speed ratio of 1 or less while free-wheeling in a 140-mph wind.

Several configurations of aerodynamic brakes that were tested on World War II-era fighter airplanes might have potential as wind-turbine aerodynamic brakes. These configurations will be evaluated to determine the most aerodynamically efficient designs. A preliminary design will be developed for an overspeed control device. Once a device is chosen, its performance will be evaluated on an Advanced Wind Turbine (AWT) using PROP93 Glauert Momentum Theory.

\subsection{Wind Turbine Aerodynamics}

Development of new technology requires some compromise. The type and quantity of data that can be gathered to evaluate device effectiveness is limited. The devices evaluated here were all tested in a two-dimensional wind tunnel at WSU. The relative effectiveness of the devices in a twodimensional wind tunnel experiment should predict their relative effectiveness on a wind-turbine rotor blade. Future work will identify the relationship of two-dimensional and three-dimensional aerodynamic data by analyzing the selected device on a rotor blade in atmospheric tests.

As the swept area, wind speed, and density of the flow are increased, the power available for the rotor also increases. The power rating of a turbine is the power generated at the rated wind speed. A wind turbine will generate most of its energy above the cut-in wind speed but below rated wind speed. The cut-in wind speed is the wind speed at which the turbine will generate enough power to offset the frictional losses produced by the rotor's rotation. This is the wind speed at which the turbine begins to rotate and generate power. For constant-speed turbines the machine rotates slightly above syncronous rpm for all wind speeds above cut-in wind speed and below cut-out wind speed. The cut-out wind speed is the wind speed beyond which the rotor should not operate because the turbine may produce power and high loads in excess of the rated. Therefore, control must be exerted to prevent the turbine from damaging components.

A wind-turbine aerodynamic control device must be able to effectively control overspeed or modulate power. The device must be capable of controlling the local blade aerodynamics enough 
to counter the rest of the blade that is still producing power. Wind speeds and typical rotor rotational speeds require the aerodynamic control device to function at a high blade AOA.

\subsubsection{Glauret Momentum Vortex Theory}

Performance codes used to evaluate braking device effectiveness are based on the Glauret Momentum Theory, modified for tip and hub effects. The code, PROP93 McCarty (1993), is a graphically enhanced version of the PROPPC code Tangler (1987). The analysis uses twodimensional wind-tunnel aerodynamic data. The aerodynamic performance of the tested devices will be used to predict the relative performance of each device on a wind-turbine rotor blade. The device will be required to meet the effectiveness requirements of the Energieonderzoek Centrum Nederland (ECN) or the International Electrotechnical Commission (IEC), or NREL.

With or without a braking device installed, the rotor will produce a certain amount of power, torque, thrust, and bending loads. These loads will be used for the device design. The primary variable for determining a device's effectiveness is its torque ( $Q$ ). Expressions for torque, power, and thrust are provided below.

$$
\begin{array}{r}
\text { Torque: } \Delta \mathrm{Q}=\frac{1}{2} \cdot \rho \cdot \mathrm{W}^{2} \cdot \mathrm{r} \cdot\left(\mathrm{C}_{\mathrm{x}}\right) \cdot \mathrm{B} \cdot \mathrm{c} \cdot \Delta \mathrm{r} \\
\text { Power: } \Delta \mathrm{P}=\Omega \cdot \Delta \mathrm{Q}=\Omega \cdot \frac{1}{2} \cdot \rho \cdot \mathrm{W}^{2} \cdot \mathrm{r} \cdot\left(\mathrm{C}_{\mathrm{x}}\right) \cdot \mathrm{B} \cdot \mathrm{c} \cdot \Delta \mathrm{r} \\
\text { Thrust: } \Delta \mathrm{T}=\frac{1}{2} \cdot \rho \cdot \mathrm{W}^{2} \cdot \mathrm{r} \cdot\left(\mathrm{C}_{\mathrm{y}}\right) \cdot \mathrm{B} \cdot \mathrm{c} \cdot \Delta \mathrm{r}
\end{array}
$$

\subsubsection{Design Philosophy for Devices and Systems}

The design should be mechanically simple, aerodynamically effective, entirely storable, reliable, and capable of minimizing the hinge moments in order to lower actuator load requirements. This report focuses on the design of a passively actuated aerodynamic braking device to improve the state of the art in wind-turbine aerodynamic braking.

A current method of aerodynamic braking for many wind turbines is the so-called rotating tip (similar to U.S. Patent 2,074,149). The device is relatively simple and aerodynamically clean, with only one chordwise interface seal as shown in Figure 1-2. It is centrifugally actuated at a specified blade rotational speed. The mass of the device provides the impetus for deployment. This device 
rotates on and is supported by a small shaft. The shaft must carry power-producing loads during normal operation as well as the large dynamic loads of a braking event. The stress concentration required to transfer all loads via the shaft results in a heavy tip region. This device could be improved by reducing its weight.

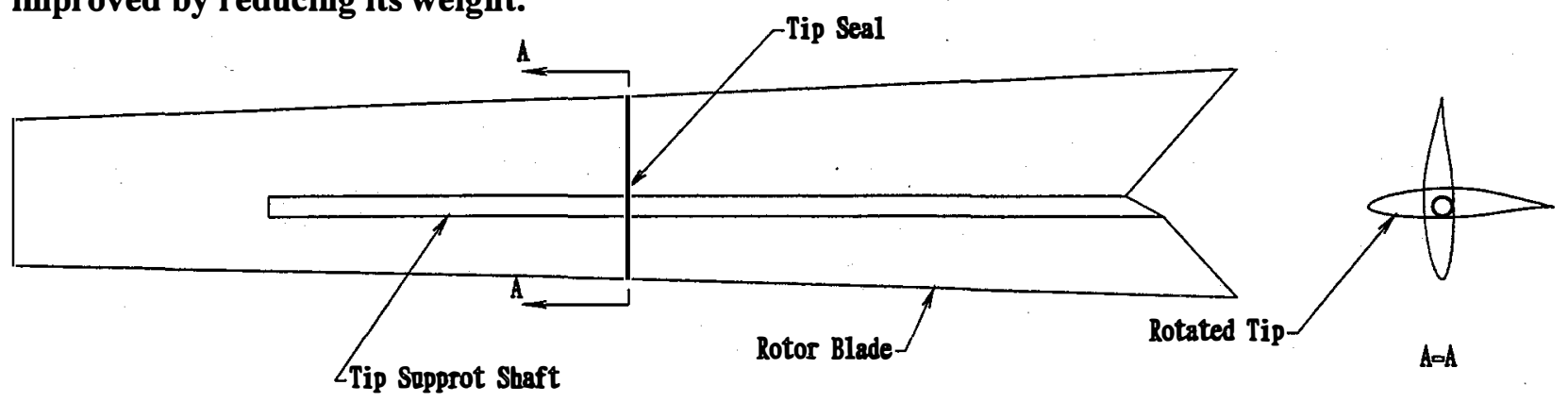

Figure 1-2. Schematic of a typical rotating tip configuration.

Another current method of aerodynamic braking for wind-turbine blades is the tip brake (similar to U.S. Patent 4,180,372). The device is relatively simple and may enhance performance in some wind conditions if properly designed, but it is aerodynamically exposed, creating drag in all powerproducing conditions, as shown in Figure 1-3. The device is centrifugally or electrically actuated at a specified blade rotational speed. The mass of the device can provide the impetus for deployment. This device could be improved by minimizing interference drag at the junction during normal power-producing operation.
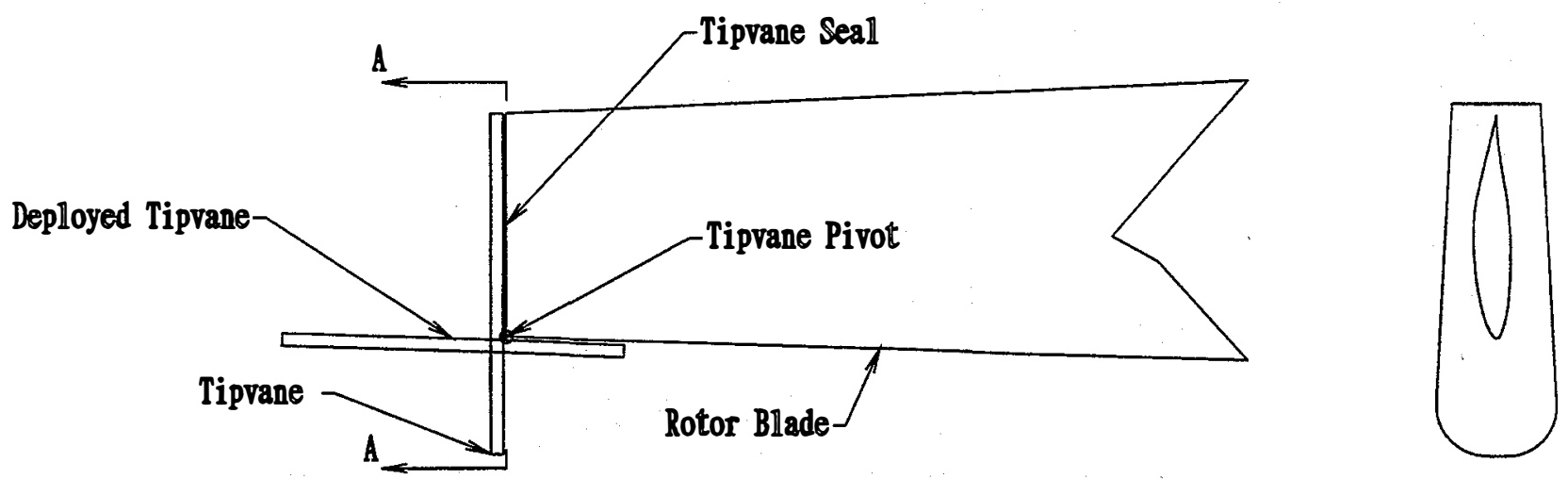

Figure 1-3. Schematic of a tip vane configuration.

In designing a passively actuated aerodynamic braking device, a major goal is to reduce the weight of the current rotating tip and the drag of the tip brake. The device must be completely storable and must not carry the power production loads. Predictable loads and control trends will be desirable characteristics of the selected device. 


\subsection{Literature Survey}

\subsection{HAWT Aerodynamic Devices}

The effectiveness of the control or braking device is defined by its ability to effect a change in the magnitude of the chord force. Figure 2-1 shows the standard aerodynamic force coefficients, lift (Cl) and drag (Cd), and the significant wind-turbine force coefficients, chord force or suction force (Cs) and normal force (Cn).

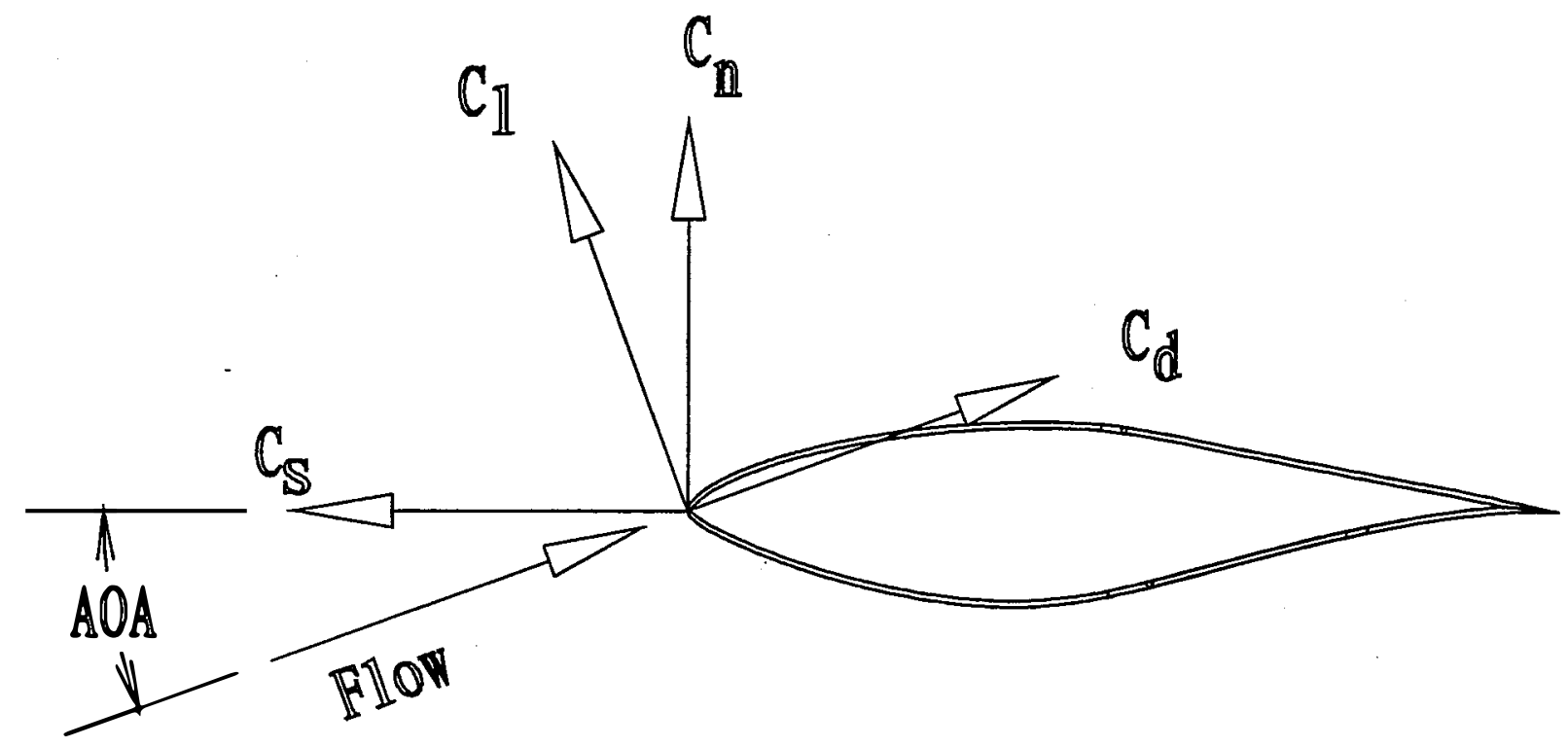

Figure 2-1. Aerodynamic nomenclature $\mathrm{Cl}, \mathrm{Cd}, \mathrm{Cn}, \mathrm{Cs}$.

The suction force and normal force are oriented in the chordwise and normal-to-chordwise direction. Equations 4 and 5 show the relationship between lift, drag, suction, and normal aerodynamic forces. The airfoil section on a HAWT blade may be twisted for aerodynamic reasons; the angle of twist would result in a slight modification for the analysis of rotor torque and thrust.

$$
\begin{aligned}
& C s=C l \cdot \sin (A O A)-C d \cdot \cos (A O A) \\
& C n=C l \cdot \cos (A O A)+C d \cdot \sin (A O A)
\end{aligned}
$$

\subsubsection{Ailerons}

Aileron control devices for HAWTs have been studied for both power modulation and aerodynamic braking potential. 


\subsubsection{Control (Power Modulation)}

Wentz and Snyder (1980) first investigated the use of ailerons as potential power modulators. Additional studies by Gregorek (1984) focused on pressure distributions for three aileron configurations: a $30 \%$ chord plain, a $38 \%$ chord plain, and a $38 \%$ chord balanced aileron. Gregorek studied ailerons as power modulators for the NACA 64-621 airfoil.

Miller (1986) has presented a summary of the work done by NASA and DOE. Miller's presentation focused on the highlights of wind-tunnel and full-scale atmospheric tests conducted prior to 1986 . In 1983 , a full-scale test of a $20 \%$ chord aileron proved that a $20 \%$ chord, $30 \%$ span aileron would not effectively control power on the MOD-0 wind turbine over its full range of operational wind speeds. A device with more control authority was needed, so the next logical step was to increase the chord of the aileron. Another MOD-0 test was conducted with a $38 \%$ chord aileron. Testing of this aileron was conducted between December 1983 and June 1984. The device regulates power over all operational wind speeds of the MOD-0 and worked better as an aerodynamic brake than did the $20 \%$ chord device.

Corrigan et al. (1987) assessed the performance and power regulation of two aileron-controlled rotors and a pitchable tip-controlled rotor on the Mod-0 turbine. The study used a $20 \%$ chord and a $38 \%$ chord aileron at $30 \%$ span, along with a $30 \%$ span pitchable tip. Corrigan found the $38 \%$ chord aileron to be the best power regulator of the three configurations tested. Both Gregorek's and Corrigan's results indicate that the $38 \%$ chord aileron is best suited for turbine control of the ailerons tested. Based on these reports, the $38 \%$ chord aileron also is most suitable for use as an aerodynamic braking device.

\subsubsection{Braking (Overspeed Control)}

Almost all of the control studies mentioned included analysis of aerodynamic braking with ailerontype devices. These braking devices have had difficulty in the $25^{\circ}$ to $40^{\circ}$ range due to reduction in the Cs. Gregorek (1984) concluded that the aileron devices work well as aerodynamic brakes for an $\mathrm{AOA}$ of less than $30^{\circ}$. The devices tested showed a positive Cs excursion beyond $30^{\circ}-$ not a desirable characteristic of an aerodynamic brake. Miller's (1986) data show that as the device chord increases, its braking effectiveness increases, and that in the limit you have a rotating tip. Analytical studies (Miller 1986) on the MOD-2 wind turbine with a simulated 30\% span, 38\% chord aileron predicted adequate braking potential. However, this conclusion is tempered by the fact that the Re modeled for the tip was 1 million, while the MOD-2 operating Re was 5 million. 
. The difference could have affected the answer. Savino et al. (1985) has reported reflection plane tests of aileron braking devices. The results were similar to previous findings (Gregorek 1984) in that the Cs went positive in the blade $\mathrm{AOA}$ range of $30^{\circ}$ to $50^{\circ}$.

\subsubsection{Other Devices}

Control and aerodynamic braking devices are usually one and the same for HAWTs. To limit the number of system components, devices are engineered to perform both functions on the rotor blade. This puts considerable restrictions on the deployment characteristics for proposed devices. The pitchable blade, pitchable tip, Sledge, and Fledge are devices that have been or could be used as both peak power controls and aerodynamic braking systems.

Many of the turbines studied in the 1980s used rotating blade tip devices of poor structural design that were prone to failure. For lower cost and improved reliability there has been increased interest in other methods of aerodynamic control.

\subsubsection{Control}

Active control of a HAWT may have potential to reduce the cost of energy. The primary control parameter for a wind turbine is the Cs. Therefore, the ability to effect the Cs is a significant measure of device effectiveness. A simulation study performed by Jamieson and Agius (1990) compared pitchable tips, ailerons, spoilers, Fledges, and Sledges. The study evaluated the ef fectiveness per unit span of actuated control, or braking device performance. The Sledge and the pitchable tip had similar span effectiveness characteristics, these were more than twice as effective as an aileron device.

\subsubsection{Braking}

The two most frequently used aerodynamic braking devices are the tip vane and the rotating tip. The tip vane is a mounted externally to the blade (similar to U.S. patent 4,180,372). Braking results from the drag of the deployed device, and deployment is controlled by the manufacturer's criteria. The rotating tip is a segment of the load-bearing rotor blade (similar to U.S. patent $\mathbf{2 , 0 7 4 , 1 4 9 ) . ~ B r a k i n g ~ o f ~ t h e ~ r o t a t i n g ~ t i p ~ a l s o ~ i s ~ d u e ~ t o ~ t h e ~ d r a g ~ o f ~ t h e ~ d e p l o y e d ~ d e v i c e . ~ M a n y ~ s t u d i e s ~}$ have been conducted to determine if an aerodynamic device can modulate power and control overspeed conditions. The results have not been convincing enough for turbine manufactures to incorporate aerodynamic devices into their turbine designs as power modulators. The devices that 
have been tested include, but are not limited to, ailerons, spoilers, flaps, and leading edge devices. Many other types of aerodynamic braking devices have been studied, installed on the wings of World War II-era fighter airplanes.

\subsection{Air Brakes}

\subsubsection{Airplanes}

An air brake study conducted by Toll and Ivey (1945) evaluated 20\% chord split-flap-type devices situated aft of the $60 \%$ chord. Toll and Ivey experimented with changing the position of the split flap from $60 \%$ to $90 \%$ chord in $10 \%$ chord increments. The flap gap was varied $5 \%$ to $20 \%$ chord, and the flap deflection angle was tested at $30^{\circ}, 60^{\circ}, 90^{\circ}$, and $120^{\circ}$. A wartime report by Rogallo (1941) analyzed one air brake configuration consisting of a $10 \%$ chord spoiler located at $\mathbf{7 3 \%}$ of the blade chord. This was used in conjunction with a $26 \%$ chord slotted flap. The Rogallo study produced aerodynamic data that provided insight into the potential of the devices as dive brakes on fighter airplanes. A significant finding was that when the $10 \%$ chord spoiler was deflected to $60^{\circ}$, the flap could be deflected to $50^{\circ}$ without a significant increase in $\mathrm{C}_{\mathrm{I} \text { max}}$. This led researchers to conclude that a spoiler-flap-type device would be worthy of investigation.

\subsubsection{HAWT}

Tip brakes are the simplest type of aerodynamic brake available today. However, they are always exposed to three-dimensional aerodynamic forces due to their location at the tip of the rotor. Tip brakes are positioned for minimum drag during normal power-generating operation. When the tip brake is required to perform, it will rotate into a high drag configuration. This can be for either emergency or normal stopping.

Rotating tips are entire blade segments that generate power and transfer it to the remaining blade structure. However, when aerodynamic braking is required, the blade tip extends and rotates into a high drag configuration similar to a tip brake. The benefit of the rotating tip is that the rotor need not carry a drag-producing tip device during normal power generation. There is a weight penalty associated with the rotating tip due to the required load transfer of all braking and tip power-generated loads through a single shaft. 


\subsection{Summary and Conclusions}

Current-generation wind turbines use stall-controlled rotor blades and tip brakes, or an active aileron for control and braking. Blades being manufactured for the 65- to 150-kW market still use rotating tip devices.

It is clear that the most important factor in determining the capability of an aerodynamic braking device at low AOA is the amount of drag produced. The most important factor in determining continued good performance is the device's ability to dump lift as the local AOA approaches $45^{\circ}$.

Wentz (1984) showed that a $20 \%$ chord flap deflected at $60^{\circ}$ and positioned at $80 \%$ of chord aft of the leading edge would be an effective braking device beyond the point of blade stall. The problem with this design is in the low to moderate blade $\mathrm{AOA}$ range from $0^{\circ}$ to $20^{\circ}$ where the device produces positive Cs. This is due to the increased $\mathrm{Cl}_{\max }$ caused by the flap. If the $\mathrm{Cl}_{\max }$ increment could be reduced, the flap device would be effective and simple.

Toll and Ivey (1945), Rogallo (1941), and Wentz (1984) developed the most important configurations for testing and evaluation. Wentz' test of double split flaps and flaps showed that beyond $30^{\circ}$, lower surface projection is important. Toll and Ivey suggested that performance would be improved by positioning the devices as far forward as possible. Rogallo indicated that small spoilers and gapped flaps can be effective because the flap creates high drag and because the spoiling effect of the small spoiler deployment causes virtually no increase in lift. Toll and Ivey revealed a clear trend that as the AOA increases, the flap drag increases. This is an important characteristic of a wind-turbine aerodynamic braking device over a wide range of blade AOA up to approximately $10^{\circ}$ to $40^{\circ}$. The characteristics of this type of device make it a potentially good brake for wind turbines. NASA double-split flaps will be tested in the wind-tunnel testing phase of this study. The data also showed that the influence of a spoiler-type device decreased constantly from $0^{\circ} \mathrm{AOA}$ through the extreme tested AOA of $18^{\circ}$.

Rogallo pointed out the significance of the lift spoiling aspect of a braking device in the AOA range between $5^{\circ}$ to $15^{\circ}$. This led to the development of the Spoiler-Flap device (refer to Figure 3-6). This type of device yields the characteristics of the Rogallo study and has the high AOA behavior of the Wentz flap device in WER 23. A positive feature of the Spoiler-Flap is that it uses only one moving aerodynamic surface, limiting the number of moving parts. 


\subsection{Investigation Procedures}

\subsection{Geometry Considerations}

Wind-turbine aerodynamic brakes must have a large portion of their chord projecting below the lower surface of the normal blade section. The significant shadowing effect of the blade must be eliminated by positioning the device so it acts more like a flap than a spoiler. The device must remain effective from $0^{\circ}$ to $45^{\circ} \mathrm{AOA}$ to ensure that the rotor will not exceed operating $\mathrm{RPM}$ in a no-load 140-mph or 60-meters-per-second (mps) wind. All but one of the devices to be tested will have a $20 \%$ chord or larger lower-surface projection. The device without a lower-surface projection will have another potential method for making the lower surface work; attached flow to a rounded trailing edge. The design will be as simple as possible because one moving aerodynamic surface is better than two.

\subsection{Aerodynamic Considerations}

The ability of a braking device to maintain a negative Cs through a blade AOA between $0^{\circ}$ to $90^{\circ}$ would be a significant advantage. This is because the braking device is attached to only a small segment of the blade, and the rest of the blade may be generating positive Cs. Thus, the small blade segment must balance the other segments. A typical device configuration is shown in Figure 3-1. If the turbine requirements are to maintain operating RPM at $140-\mathrm{mph}$ wind with a free-wheeling turbine, then the device's effective AOA need only be from $0^{\circ}$ to $45^{\circ}$ and need not go all the way to $90^{\circ}$. Aerodynamic capability is the most important characteristic of a potential braking device. The Phase 1 two dimensional aerodynamic testing will assist in designing a stateof-the-art device. The tested devices will be evaluated on their ability to create negative coefficients of suction.

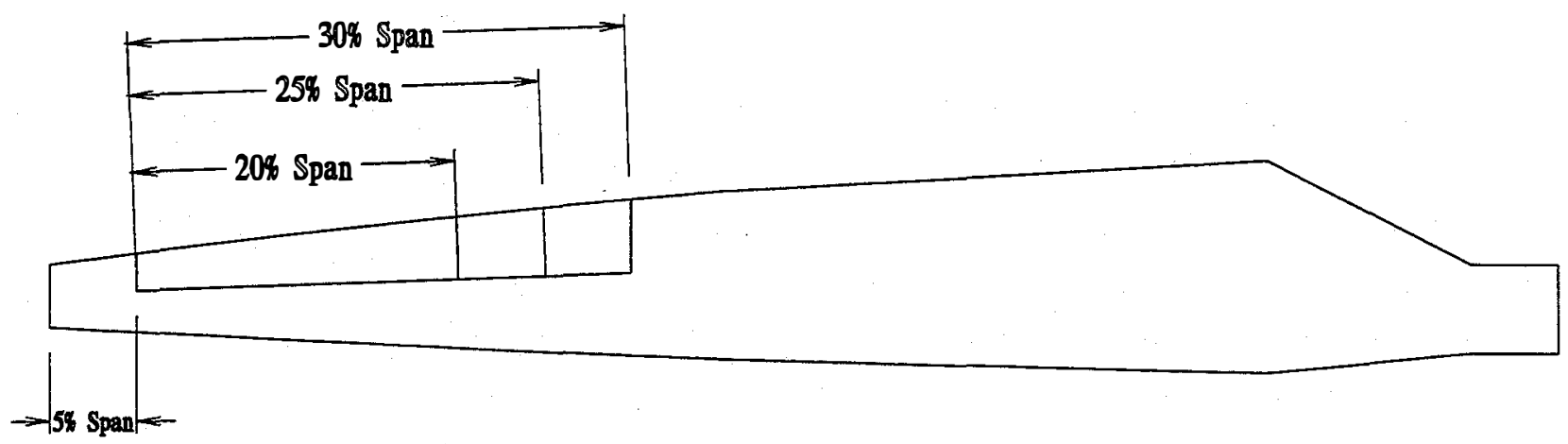

Figure 3-1. Blade with a (typical) trailing edge braking device configuration. 


\subsection{Performance Analysis}

Aerodynamic data collected for all of the devices tested at WSU will be used to characterize their braking potential. The simplest way to evaluate the various devices is to maintain a constant span for each and then compare the amount of braking torque for each of the configurations. This information will be used to help choose a candidate for further study and to develop a point design.

\subsection{Summary of the Investigation}

The devices will be aerodynamically tested and optimized using two-dimensional wind-tunnel testing. A device will be structurally sized for a specific turbine application, and its performance will be analyzed using PROP93 HAWT performance code. Based on the literature review and the required range of device effectiveness, the test matrix covers five main configurations. Three of the device configurations can be deflected with respect to the blade segment; the other two will allow only chord and gap variations.

\subsection{Selection of Test Devices}

The devices selected include one under study by Northern Power Systems (NPS) and four additional configurations. These devices were selected based on their expected potential to create negative $C s$ and the presumed ease of attaching the complete configuration to a turbine blade.

The devices were built in the model shop at WSU. The wind-tunnel test was planned, coordinated, and supervised by Dr. L.S. Miller. The WSU wind-tunnel staff at the Beech Memorial wind-tunnel facility conducted the test the last quarter of 1993. The wind tunnel test took approximately 2 weeks to complete.

Wind-tunnel models were based on a modified NACA $64_{3}-618$ airfoil section supplied by NPS. The model full chord would be 18 inches. However, the airfoil was tested with a truncated trailing edge, so the actual model was 17.25 inches as can be seen in Figure 3-2. The forward 50\% of the airfoil was the same for all configurations. The aft $50 \%$ of the model was modified by the addition of various devices. The devices were tested through an AOA range of $-6^{\circ}$ to $90^{\circ}$ and aerodynamic forces and moments were measured. The force and moment data were then converted to coefficients that were plotted and tabulated for analysis. 


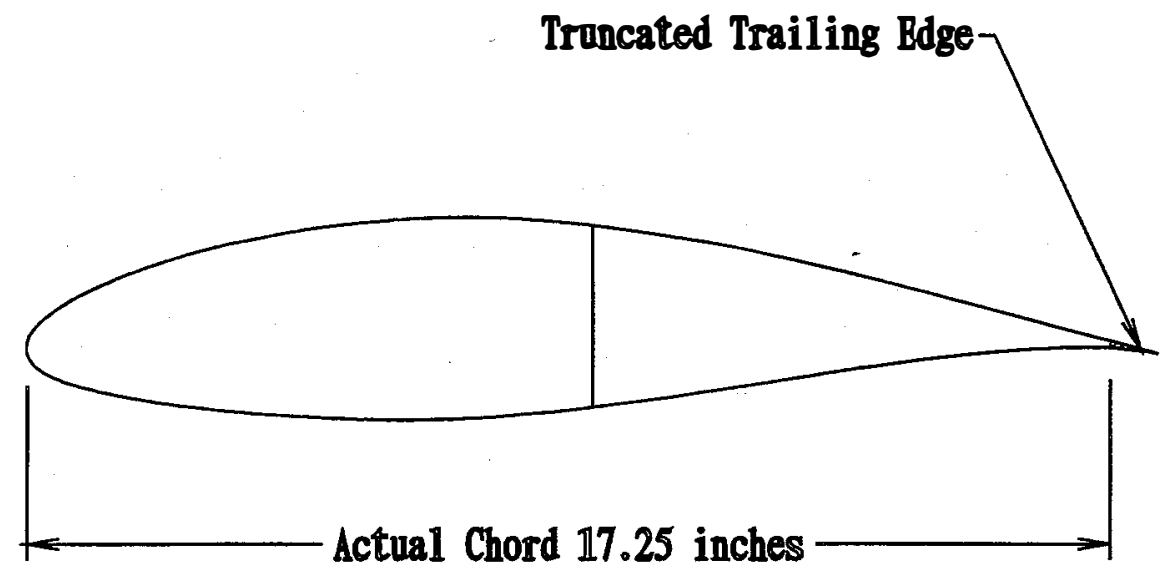

Figure 3-2. Basic airfoil section used for the wind-tunnel test.

The first step in the aerodynamic force analysis was selection of the device for preliminary design load measurement. The device with the best overall performance will be fitted with pressure belts to determine aerodynamic loads on the device. Both the Cs of the device and estimated actuating moments will be considered in the selection of a device for point design. Pressure loads were calculated using an integration procedure similar to Anderson (1984). This pressure testing was the final part of the Phase 1 wind-tunnel work. It was used to develop preliminary design loads for the actuating mechanism and the device support structure.

The model was a modified NACA 643-618 airfoil section supplied for testing by NPS. This two-dimensional 7-ft floor-to-ceiling-span wooden airfoil terminates at the $50 \%$ chord. The devices were attached to the rear of the airfoil section as shown below. In an effort to maximize the Re for all wind-tunnel tests, flow velocity was set as high as the model could tolerate without excessive vibration. The flap-wise bending instability would occur at relatively low flow velocities. The result is that much of the performance data were collected at Re far below the operating $R e$ for the HAWT that will likely employ the device.

The devices selected for testing are two NACA Double Split Flap configurations similar to those tested by Toll (1945). These are shown in Figures 3-3 and 3-4. The tested configurations could accommodate only chord and gap modifications due to the fixed nature of the supports. The supports constrained the flap-segment angle of deflection to those shown.

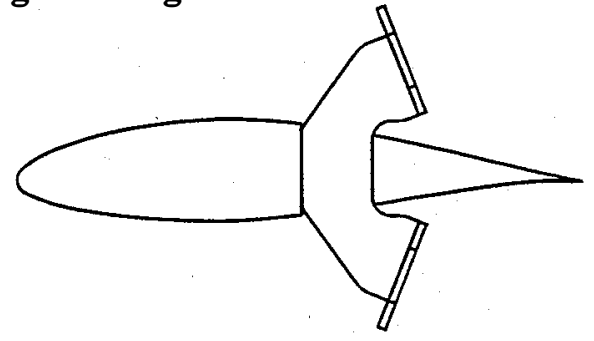

Figure 3-3. Double Split Flap 112 (Top 5/20, Bottom 5/20). 


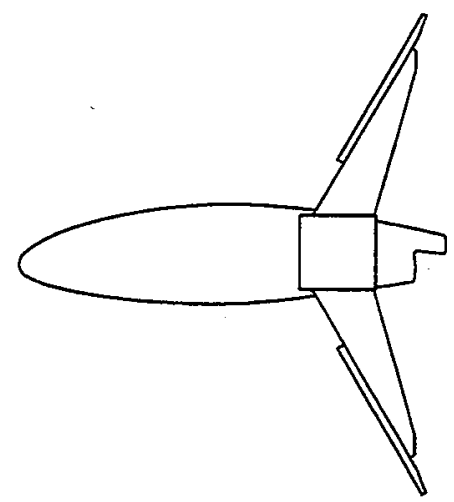

Figure 3-4. Double Split Flap 60 (Top 10/30, Bottom 10/30).

An aileron-type device was tested that has a chord of approximately $50 \%$ of the blade. The device has a smooth hinge on the high-pressure side of the fixed-blade segment, as seen in Figure 3-5. The device is capable of deflection from $0^{\circ}$ to $-90^{\circ}$. It was designed to test the possibility that flow will stay attached at a high AOA and moderated device deflection angles.

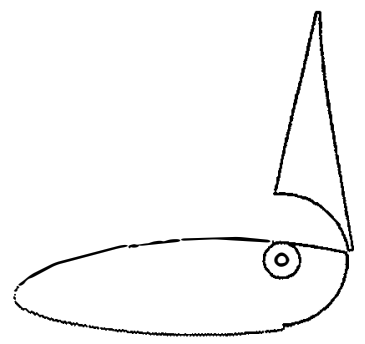

Figure 3-5. Smooth-hinge aileron device $\mathbf{5 0 \%}$ chord at delta $=\mathbf{- 9 0}$.

A simple device was conceived that would behave like the combination used by Rogallo (1941). This device is shown in Figure 3-6 and will be called a spoiler-flap. It was designed to work as a simplified Rogallo concept in that one device could accomplish both the spoiling and flap effects. This device incorporates both the novelty of the aerodynamics and the potential simplicity of an actuation system. The device is capable of deflection from $0^{\circ}$ to $90^{\circ}$.
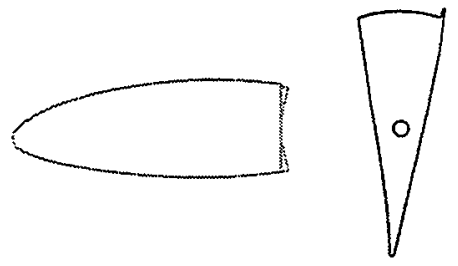

Figure 3-6. Spoiler-Flap 50\% chord at delta $=90^{\circ}$.

A negative camber-type device that is capable of deflection from $0^{\circ}$ to $-90^{\circ}$ also was tested. The device is the intellectual property of NPS. Its shape and aerodynamic data will not be published here. 


\subsection{Wind Tunnel Testing}

\subsection{Preparation, Facility, and Procedures}

The testing was done at Walter H. Beech Memorial wind tunnel at WSU. A comprehensive test report of all device wind-tunnel testing was prepared by L.S. Miller (1995)

\subsubsection{Wind Tunnel Layout}

The Walter H. Beech Memorial low-speed wind tunnel at WSU was used for wind-tunnel testing of the five devices. This is a closed-throat tunnel with a test section 7 -ft high by 10 -ft wide. The tunnel can provide flow velocity from 0 to $160 \mathrm{mph}$. Aerodynamic forces and moments are measured using two external balances located above and below the test section. The power plant is an electric motor fitted with a four-blade variable pitch propeller.

\subsubsection{Parameter Selection}

The primary variables to be studied are aerodynamic forces and moments. All five configurations will be tested through a full AOA sweep from $-6^{\circ}$ to $90^{\circ}$. The two NACA Double Split Flap configurations will be tested at various flap chords and flap-gap configurations. The other three devices have the ability to deflect from $0^{\circ}$ to $\pm 90^{\circ}$, depending on the device. The time required for each AOA sweep resulted in a compromise on the number of device deflections that were tested. Data for the three deflectable devices were collected for only four device deflection angles. The devices were deflected to $10^{\circ}, 30^{\circ}, 60^{\circ}$, and $90^{\circ}$ and an $\mathrm{AOA}$ sweep was run for each device deflection. The data presented in this report are for the four aerodynamic control and braking configurations tested.

Pressure data will be collected on the device that shows the most potential as a control and braking device. Device aerodynamics and overall system potential will be considered. The pressure data will be used to calculate device loads for the preliminary design.

\subsubsection{Wind Tunnel Model Fabrication}

The devices were fabricated for testing by the WSU model shop using both wood and aluminum. The airfoil section is a modified NACA 643-618, as shown in Figure 3-2. The devices were all placed aft of the $50 \%$ chord plane. The forward $50 \%$ of the model is wooden and is the same for all tested configurations. Operating dynamic pressures were as high as the model could tolerate 
without large vibrations. Device deflection angles required dynamic pressure variation from 3 psf to $15 \mathrm{psf}$, usually inversely related to the deflection angle.

\subsection{Data Collection and Reduction}

Wind-tunnel data were collected using various sensors, and all data were gathered and reduced using an HP-9000 workstation operated by WSU wind-tunnel personnel. Standard twodimensional wind-tunnel corrections were made to the data using the techniques of W. Rae (1984). The data were corrected for blockage, buoyancy, wake blocking, and streamline curvature effects. Data for each of the configurations are tabulated in Appendix A.

The aerodynamic suction coefficient for the devices, along with PROP93 braking performance data for the best braking performers, will be presented in charts. The presentation is limited because the Cs so thoroughly predict braking performance. Other aerodynamic coefficients for the tested configurations are presented in the Appendix $A$ data tables. The other coefficients are necessary for further design and will be evaluated for the device selected for the point design. The goal for this device is a tip-speed ratio of 1 for all wind conditions up to $60 \mathrm{mps}$; therefore the range of AOA that will be examined is from $0^{\circ}$ to $45^{\circ}$. For all of the Cs charts, a clean airfoil (No Device) configuration will be included to aid in device evaluation.

\subsubsection{Wind Tunnel Test Data for Two NACA Double Split Flaps (Configurations 1 and 6)}

The Double Split Flap was tested in two basic configurations: the $112^{\circ}$ flap deflection angle (Configuration 1) and the $60^{\circ}$ flap deflection angle (Configuration 6). Force and moment data for the two configurations are shown in Appendix A, Table 1A and Tables 2.1A through 2.3A, respectively. The data are separated into the configurations of specific gap and chord variations. The data are valuable in demonstrating the parametric importance of the upper and lower surface projections.

Configuration 1 was tested in four variations. All variations used a 5\% chord gap between the flap segments and the aft fixed-blade segment. Also, all DSF-112 devices tested had a $15 \%$ chord gap between the forward and aft fixed-airfoil segments. The four variations are:

1. $15 \%$ chord flap segment on the upper and lower surfaces (Top 5/15, Bottom $5 / 15$ ).

2. $20 \%$ chord flap segment on the upper and lower surfaces (Top 5/20, Bottom 5/20). 
3. $20 \%$ chord upper flap and a $15 \%$ chord lower flap (Top 5/20, Bottom 5/15).

4. $15 \%$ chord upper flap and a $20 \%$ chord lower flap (Top 5/15, Bottom 5/20).

The coefficient of suction data for Configuration 1 is presented in Figure 4-1.

In Configuration 1, Variation 1, the two $15 \%$ chord flap segments performed well as a braking device per unit area of control. The highest value of $\mathrm{Cs}$ for the AOA range between $0^{\circ}$ and $45^{\circ}$ is at $45^{\circ}$. The lowest value of $\mathrm{Cs}$ for the AOA range $0^{\circ}$ and $45^{\circ}$ occurs at $0^{\circ}$, and this was the worst of any of the Configuration 1 variations. However, this combination also had the smallest projected area for any of the Configuration 1 devices. In Variation 2, the two 20\% chord flap segments had the best braking performance of the variations. The highest value of $\mathrm{Cs}$ for the AOA range between $0^{\circ}$ and $45^{\circ}$ is at $45^{\circ}$. The lowest value of $C$ s for the $\mathrm{AOA}$ range between $0^{\circ}$ and $45^{\circ}$ occurs at $0^{\circ}$ and this was the best configuration 1 variation. In Variation 3, the $20 \%$ chord upper flap and a $\mathbf{1 5 \%}$ chord lower flap were middle performers. The highest value of $\mathrm{Cs}$ for the AOA range between $0^{\circ}$ and $45^{\circ}$ is at $45^{\circ}$. The lowest value of $\mathrm{Cs}$ for the $\mathrm{AOA}$ range between $0^{\circ}$ and $45^{\circ}$ is at $3^{\circ}$, and this was the worst of the asymmetric variations of Configuration 1. In Variation 4, the $15 \%$ chord upper flap and a $20 \%$ chord lower flap were also middle performers. The highest value of $\mathrm{Cs}$ for the $\mathrm{AOA}$ range $0^{\circ}$ to $45^{\circ}$ is at $21^{\circ}$. The lowest value of $\mathrm{Cs}$ for the range of $0^{\circ}$ to $45^{\circ}$ is at $3^{\circ}$. This was the best asymmetric variation of Configuration 1. The difference in Cs is small in the mixed variations, but notable beyond $21^{\circ}$.

The data indicate that the $20 \%$ chord segment is most effective on the lower surface. It is clear this configuration causes greater flow around the leading edge, resulting in increased lift and drag, as can be seen in the tabular data in Table $1 \mathrm{~A}$. The $20 \%$ chord segment on the lower surface results in greater drag for the AOA range of $0^{\circ}$ to $45^{\circ}$, and greater lift through the range of $0^{\circ}$ to $30^{\circ}$. However, the increased lift is not a problem because the absolute lift is still very low. 


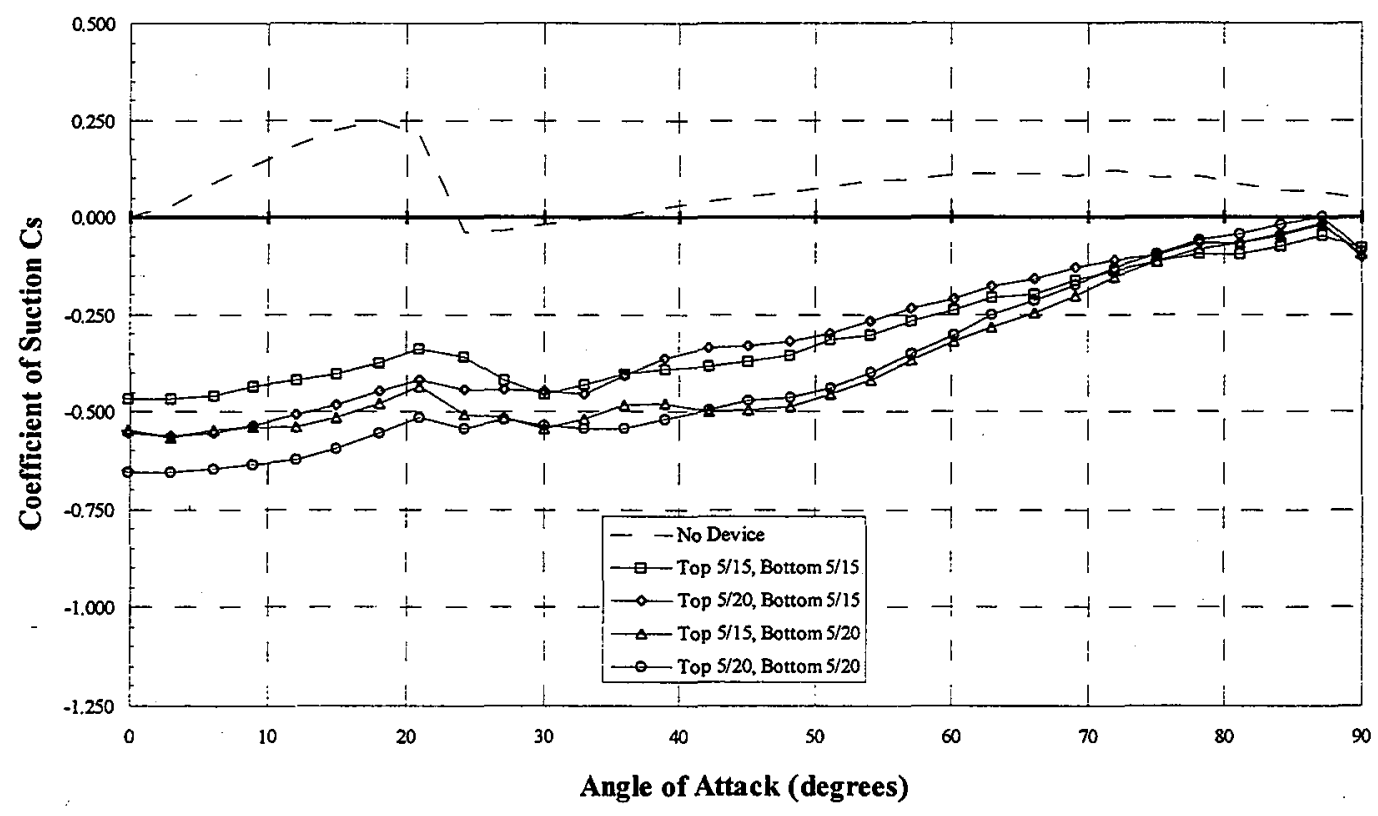

Figure 4-1. Suction coefficient for all NACA DSF 112 tested variations.

Configuration 6 was tested in ten variations. The gaps and chords were varied along with the position of fixed chord segments. The first four variations are:

1. $40 \%$ chord, $0 \%$ gap (Top 0/40, Bottom $0 / 40$ ).

2. $35 \%$ chord, $5 \%$ gap (Top 5/35, Bottom 5/35).

3. $30 \%$ chord, $10 \%$ gap (Top $10 / 30$, Bottom $10 / 30$ ).

4. $20 \%$ chord, $20 \%$ gap (Top 20/20, Bottom 20/20).

The last six variations are gap and chordwise position variations with a $20 \%$ chord flap on the upper and lower surface. The last six variations are:

5. $4 \%$ chord gap upper and $4 \%$ chord gap lower (Top $4 / 20$, Bottom $4 / 20$ ).

6. $4 \%$ chord gap upper and $9 \%$ chord gap lower (Top 4/20, Bottom 9/20).

7. $4 \%$ chord gap upper gap and $14 \%$ chord lower ((Top $4 / 20$, Bottom $14 / 20$ ).

8. $0 \%$ chord gap upper and $14 \%$ chord gap lower (Top 0/20, Bottom 14/20). 
9. $9 \%$ chord gap upper and $14 \%$ chord gap lower (Top 9/20, Bottom 14/20).

10. $14 \%$ chord gap upper and $14 \%$ chord gap lower (Top 14/20, Bottom 14/20).

The chordwise position is constrained by the support configuration, so the chordwise position is determined approximately by multiplying gap by $\tan 60^{\circ}$.

The study was broken into two parts. In the first, both chord and gap were varied symmetrically on the upper and lower surface of the model. The data for the Configuration 6 chord and gap study are presented in Figure 4-2. The second part was purely a gap study where two $20 \%$ chord flap segments were positioned on the upper and lower surface with various gaps in an effort to identify the optimum gap configuration. This resulted in a small range of differences in the aerodynamics based on gap alone. The data for the Configuration 6 gap study is presented in Figure 4-3.

In Configuration 6, Variation 1, two $40 \%$ chord flaps performed well as a braking device over only a limited $A O A$ range from $0^{\circ}$ to $15^{\circ}$. Beyond that point, the $\mathrm{Cs}$ were increased rapidly to a maximum value at $24^{\circ}$. The least negative value of $\mathrm{Cs}$ for the range of $\mathrm{AOA}$ from $0^{\circ}$ to $45^{\circ}$ is at $24^{\circ}$. The most negative value of $\mathrm{Cs}$ in the $0^{\circ}$ to $45^{\circ}$ range is at $3^{\circ}$, and this was the best of any of the variations of Configuration 6. However, this combination also had the largest projected area. This configuration is affected most by the peak in $\mathrm{C}_{\mathrm{l}}$, which is generated by the large flap segment on the lower surface.

In Configuration 6, Variation 2, two 35\% chord flap segments represented the second best overall braking performance of the variations. The least negative value of $\mathrm{Cs}$ for the range of AOA from $0^{\circ}$ to $45^{\circ}$ is at $21^{\circ}$, and the most negative value of $\mathrm{Cs}$ is at $0^{\circ}$. Overall, the $35 \%$ chord flap segments provide good aerodynamic braking, with a limited peak in the least negative Cs.

In Configuration 6, Variation 3, two 30\% chord flap segments represented the best overall braking performance of the variations. The least negative value of $\mathrm{Cs}$ for the range of $\mathrm{AOA}$ between $0^{\circ}$ and $45^{\circ}$ is at $24^{\circ}$; the most negative value of $\mathrm{Cs}$ is at $0^{\circ}$. Overall, the $30 \%$ chord flap segments are good aerodynamic braking devices, with the smallest peak in the least negative Cs.

In Configuration 6, Variation 4, two $20 \%$ chord flap segments represented the worst overall braking performance of the variations. This device also had the least projected area. The least negative value of $\mathrm{Cs}$ for the range of $\mathrm{AOA}$ from $0^{\circ}$ to $45^{\circ}$ is at $21^{\circ}$. The most negative value of $\mathrm{Cs}$ is 
at $0^{\circ}$. The $20 \%$ chord flap segments are marginal aerodynamic braking device, with a large peak in the least negative Cs.

For Configuration 6, Variation 5 through 10, the differences were small variations and can be evaluated in detail using Tables 2.1A-2.3A in Appendix A. The two variations shown envelope the Cs for a $20 \%$ chord flap segment. The least negative value of the Cs for the range of $\mathrm{AOA}$ from $0^{\circ}$ to $45^{\circ}$ is from $21^{\circ}-27^{\circ}$, and the most negative value of $\mathrm{Cs}$ is at $0^{\circ}$. Overall, the $20 \%$ chord flap segment device with any gap configuration is a marginal aerodynamic braking device due to a large peak in the least negative Cs. The data for the Configuration 6 gap study is presented in Figure 4-3.

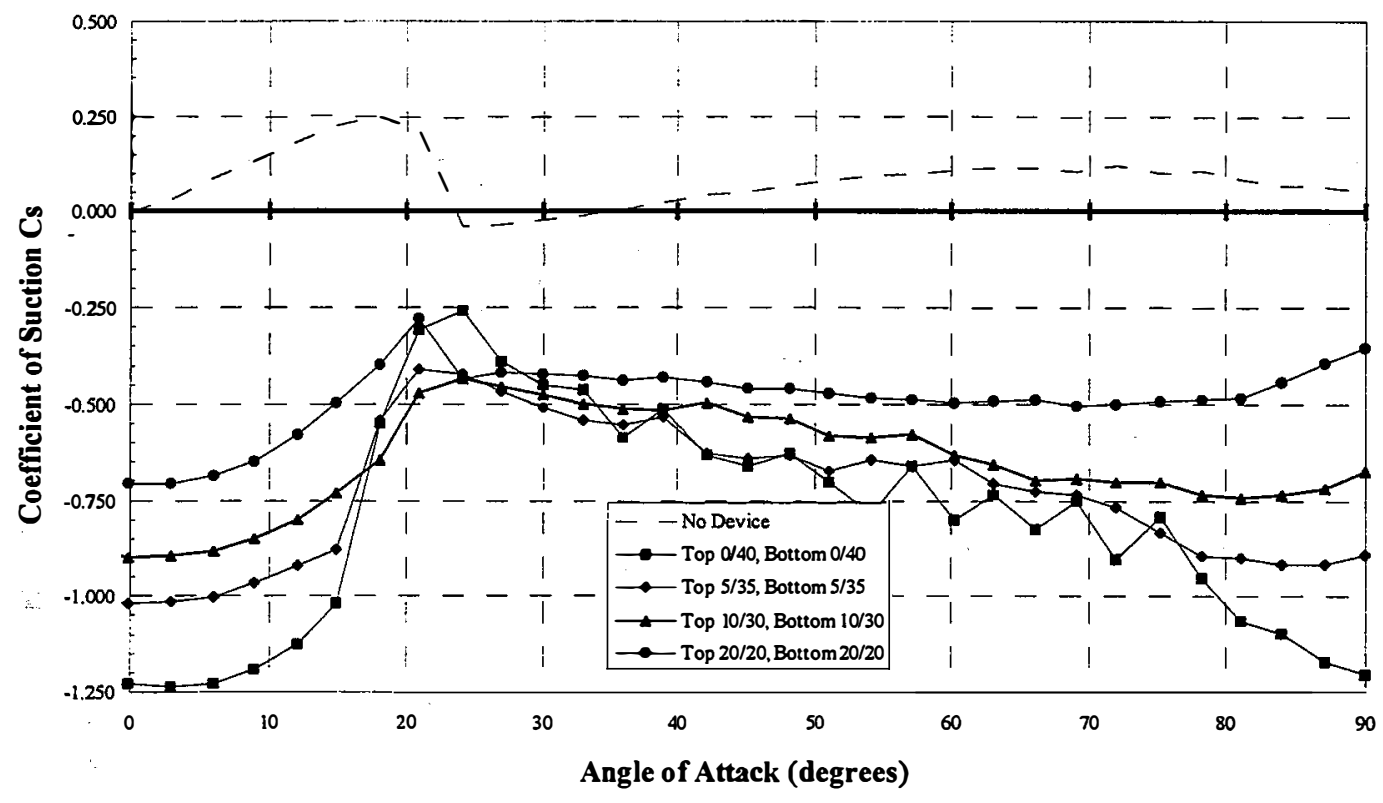

Figure 4-2. Suction coefficient for the first four symmetric NACA DSF 60 tested chord and gap variations. 


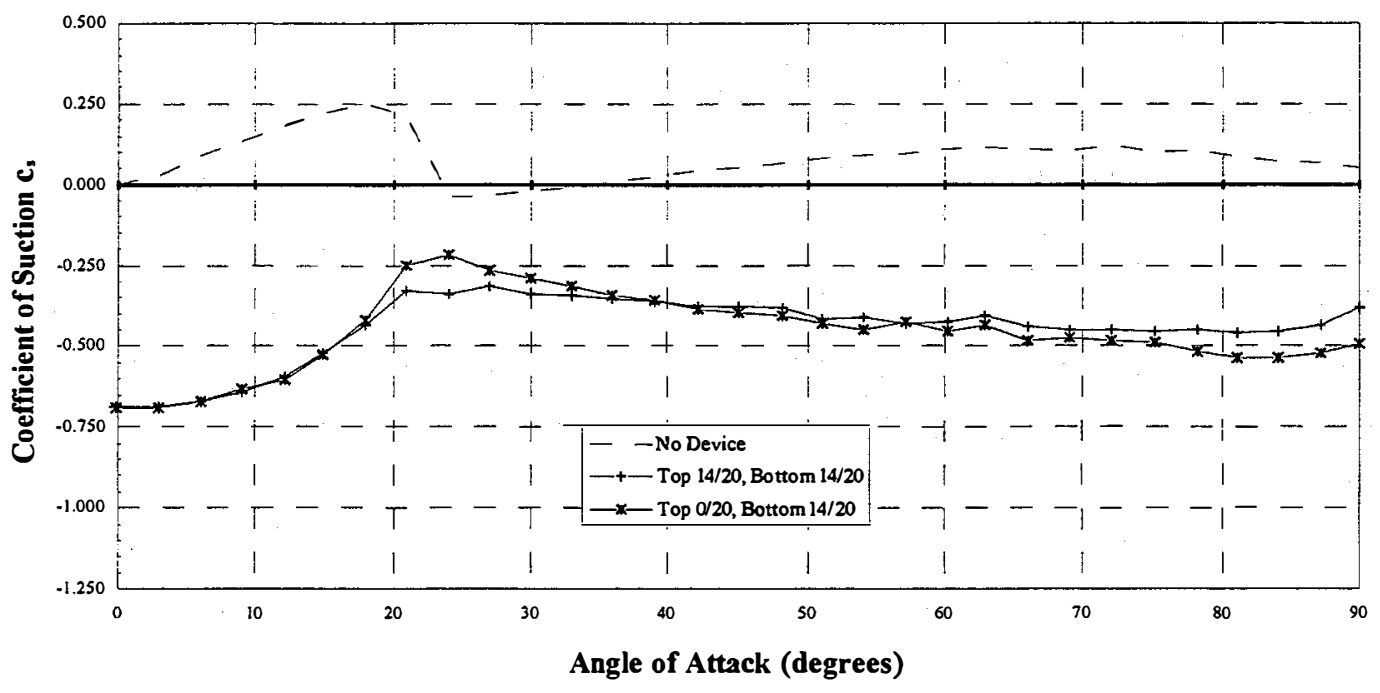

Figure 4-3. Suction coefficient for the typical $20 \%$ chord NACA DSF 60 tested gap variations.

\subsubsection{Wind Tunnel Test Data for the Aileron with Smooth Hinge (Configuration 4)}

Configuration 4 was tested at five deflections: $0^{\circ},-10^{\circ},-30^{\circ},-60^{\circ}$, and $-90^{\circ}$. In position 1 , the deflection angle delta is $0^{\circ}$. The device is stowed completely to form a clean airfoil section. The device deflections delta $-10^{\circ}$ and $-30^{\circ}$ are likely to be used for power control. The device deflections delta $-60^{\circ}$ and $-90^{\circ}$ are likely to be used for aerodynamic braking (overspeed control). The data for the Configuration 4 deflection study are presented in Figure 4-4.

The delta $=-10^{\circ}$ deflection case shows a control device that would be effective for a limited AOA range, from $3^{\circ}$ to $12^{\circ}$. The delta $=-30^{\circ}$ deflection case shows a control device that would be effective for two AOA ranges: from $0^{\circ}$ to $21^{\circ}$ and from $30^{\circ}$ to $48^{\circ}$. The delta $=-60^{\circ}$ deflection case shows a braking device that would be effective for AOA ranges $0^{\circ}$ to $27^{\circ}$ and $36^{\circ}$ to $78^{\circ}$. The delta $=-90^{\circ}$ deflection case shows a braking device that would be effective for $\mathrm{AOA}$ ranges $0^{\circ}$ to $33^{\circ}$ and $51^{\circ}$ to $75^{\circ}$. In all cases, the device would reduce the Cs generated by the section of the blade with the device installed. Data beyond $75^{\circ}$ were not taken due to severe model vibration. The data indicate that the smooth hinge device is an effective brake over a limited range of AOA. 


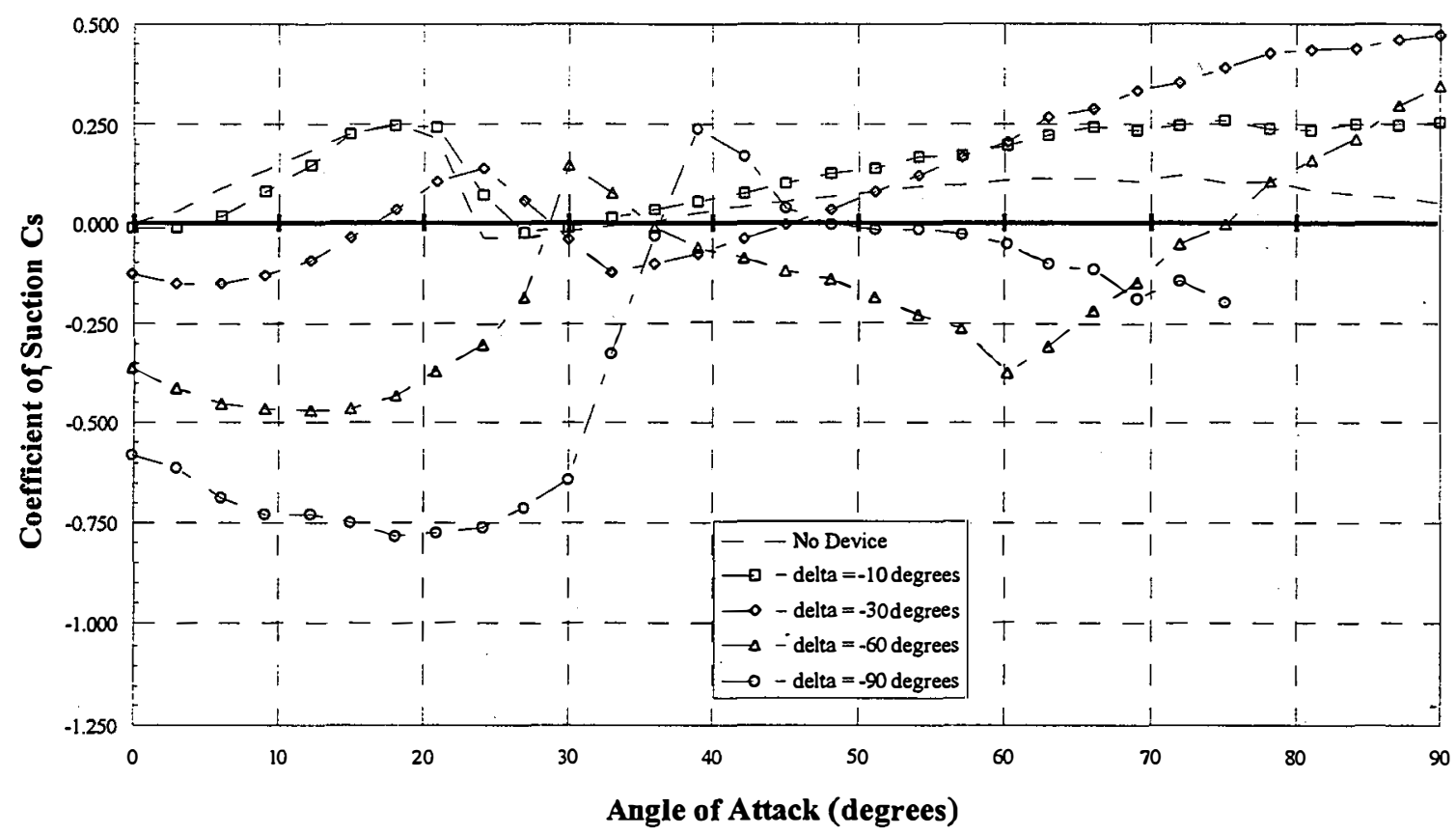

Figure 4-4. Suction coefficients for the $50 \%$ chord aileron with smooth hinge.

\subsubsection{Wind Tunnel Test Data for the Spoiler-Flap (Configuration 2)}

Configuration 2 was tested at five deflections: $0^{\circ}, 10^{\circ}, 30^{\circ}, 60^{\circ}$, and $90^{\circ}$. In position 1 , the deflection angle delta is $0^{\circ}$. The device is stowed completely to form a clean airfoil. The device deflections delta $10^{\circ}$ and $30^{\circ}$ are likely to be used for power control. The device deflections delta $60^{\circ}$ and $90^{\circ}$ are likely to be used for aerodynamic braking (overspeed control): The data for the Configuration 2 deflection study are presented in Figure 4-5.

The delta $=10^{\circ}$ and delta $=30^{\circ}$ deflection cases show two control device configurations that would be effective for an unlimited AOA range. The device would reduce the Cs generated by the section of the blade with the device installed for the range of $\mathrm{AOA}$ from $0^{\circ}$ to $90^{\circ}$. The delta $=60^{\circ}$ case has the least negative value of $\mathrm{Cs}$ for the $\mathrm{AOA}$ range $0^{\circ}$ to $45^{\circ}$ at $12^{\circ}$ and $45^{\circ}$. The most negative value of $\mathrm{Cs}$ for this $\mathrm{AOA}$ range occurs at $0^{\circ}$. The delta $=90^{\circ}$ deflection case shows a braking device that would be effective for an unlimited $\mathrm{AOA}$ range. The delta $=90^{\circ}$ case has the least negative value of Cs for the range of $\mathrm{AOA}$ from $0^{\circ}$ to $45^{\circ}$ at $45^{\circ}$. The most negative value of $\mathrm{Cs}$ for this $\mathrm{AOA}$ range occurs at $3^{\circ}$, and this was the best braking deflection angle for Configuration 2 . The Spoiler-Flap device would reduce the $\mathrm{Cs}$ generated by the section for all device deflection angles tested for all AOA, between $0^{\circ}$ and $90^{\circ}$. 


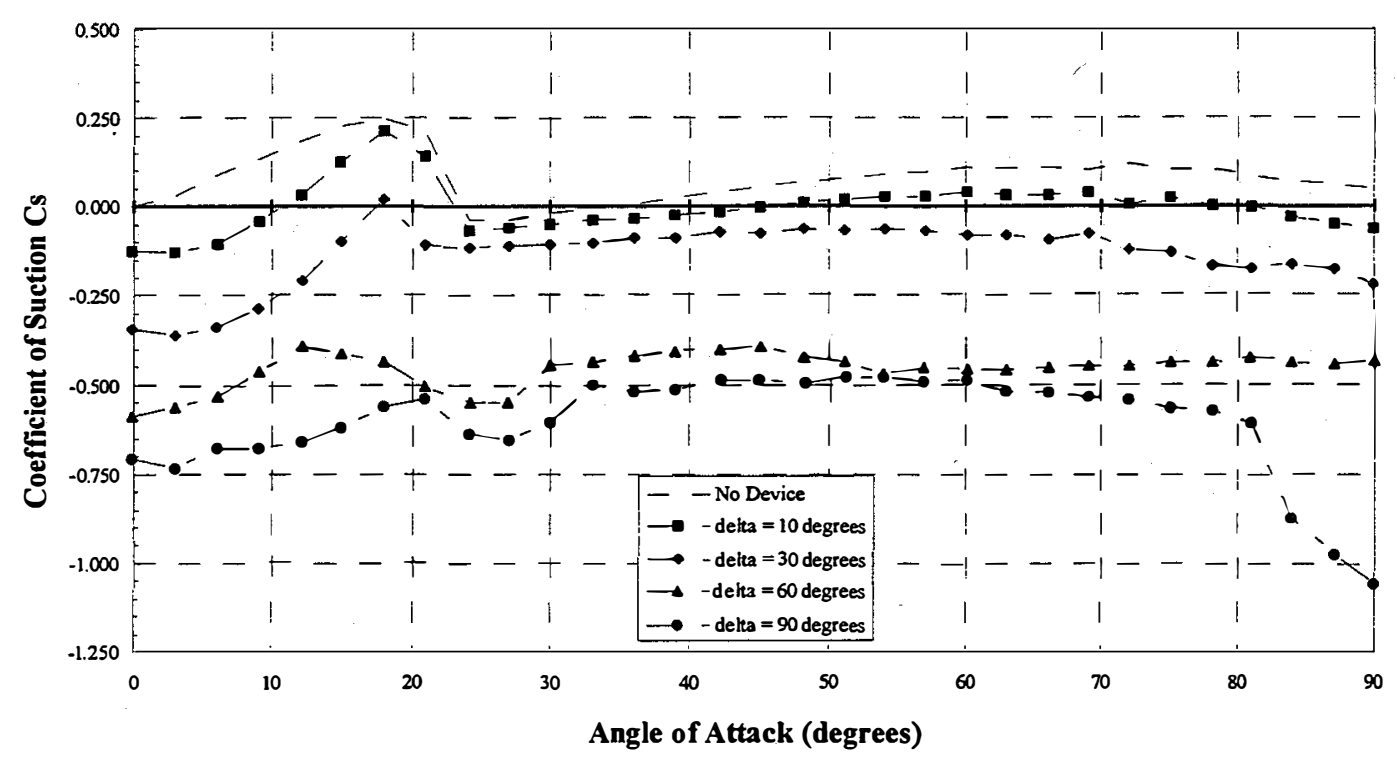

Figure 4-5. Suction coefficients for the $50 \%$ chord spoiler-flap.

\subsection{Data Summary and Performance Analysis}

The data presented for each of the tested configurations show that many of the devices will be effective aerodynamic brakes for wind turbine blades. The data also indicate that the devices have significantly different effective AOA ranges. This is an important characteristic of an aerodynamic braking device, as will be shown in the following comparative rotor analysis. The devices are not limited so much by where they are effective but by where they are not effective.

A comparative analysis of the devices highlights the need for an aerodynamic braking device that maintains negative suction coefficient to an AOA of $45^{\circ}$. This is the AOA of the rotor blade at 60 RPM and $80 \%$ of span if the design wind speed is $60 \mathrm{~m} / \mathrm{sec}$. Wind turbines produce torque about the rotor axis proportional to the Cs produced by a given blade segment. As the braking device section of the rotor blade $\mathrm{Cs}$ becomes less negative, the torque generated by the entire rotor increases. If the turbine is near or beyond the peak power position on the turbine's power curve, then the AOA that produces the minimum Cs for a device also will produce the greatest rotor torque during braking. This is a potential rotor design limitation.

The braking performance analysis of the devices is being performed using a 26-m-diameter stallcontrolled rotor at $60 \mathrm{RPM}$. The device is modeled as spanning from $65 \%$ to $95 \%$ span on each of the rotor's two blades. First, to demonstrate the dependence of the device performance on AOA, the entire rotor torque is output against AOA. Second, the same torque data is presented versus 


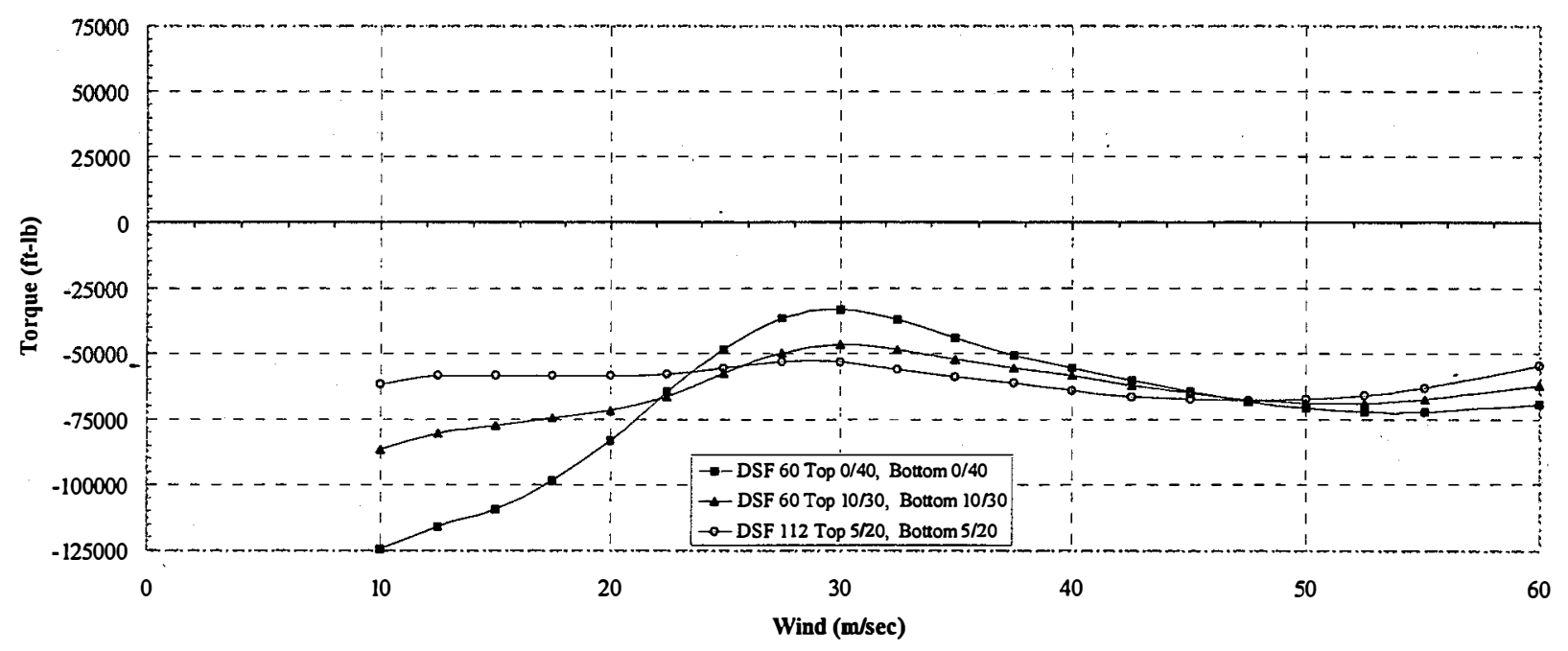

Figure 4-7. Typical NACA DSF rotor aerodynamic brake torque profiles.

\subsubsection{PROP93 Rotor Torque Data for the Aileron with a Smooth Hinge.}

The data presented in Figure 4-8 are rotor torques for the test turbine modeled with a smoothhinge aileron aerodynamic braking device at two deflection angles. It should be noted that the loss of braking torque nearly aligns with the angle at which the Cs crosses from negative to positive for both deflection cases. The delta $=60^{\circ}$ case is an effective aerodynamic braking device for AOAs up to $25^{\circ}$. However, the rotor begins to overspeed at AOAs beyond $28^{\circ}$. The delta $=90^{\circ}$ case is a capable braking device out to $35^{\circ}$, but begins to overspeed at $36^{\circ}$. The AOA dependence of the delta $=90^{\circ}$ case is greater than the delta $=60^{\circ}$ case near overspeed. The torque data for the aileron with a smooth hinge are plotted against wind speed in Figure 4-9 to clarify the need for consistent braking behavior.

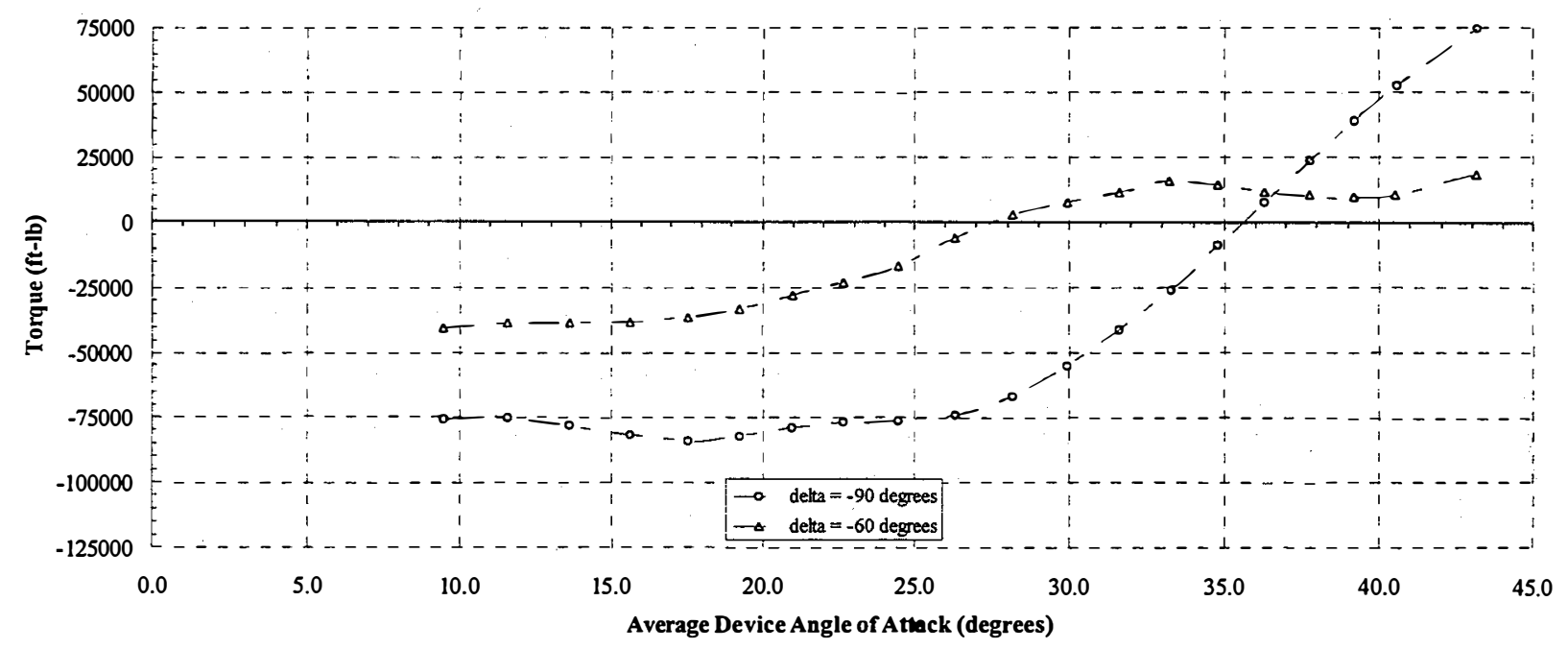

Figure 4-8. Smooth-hinge aileron rotor aerodynamic brake torque profiles. 


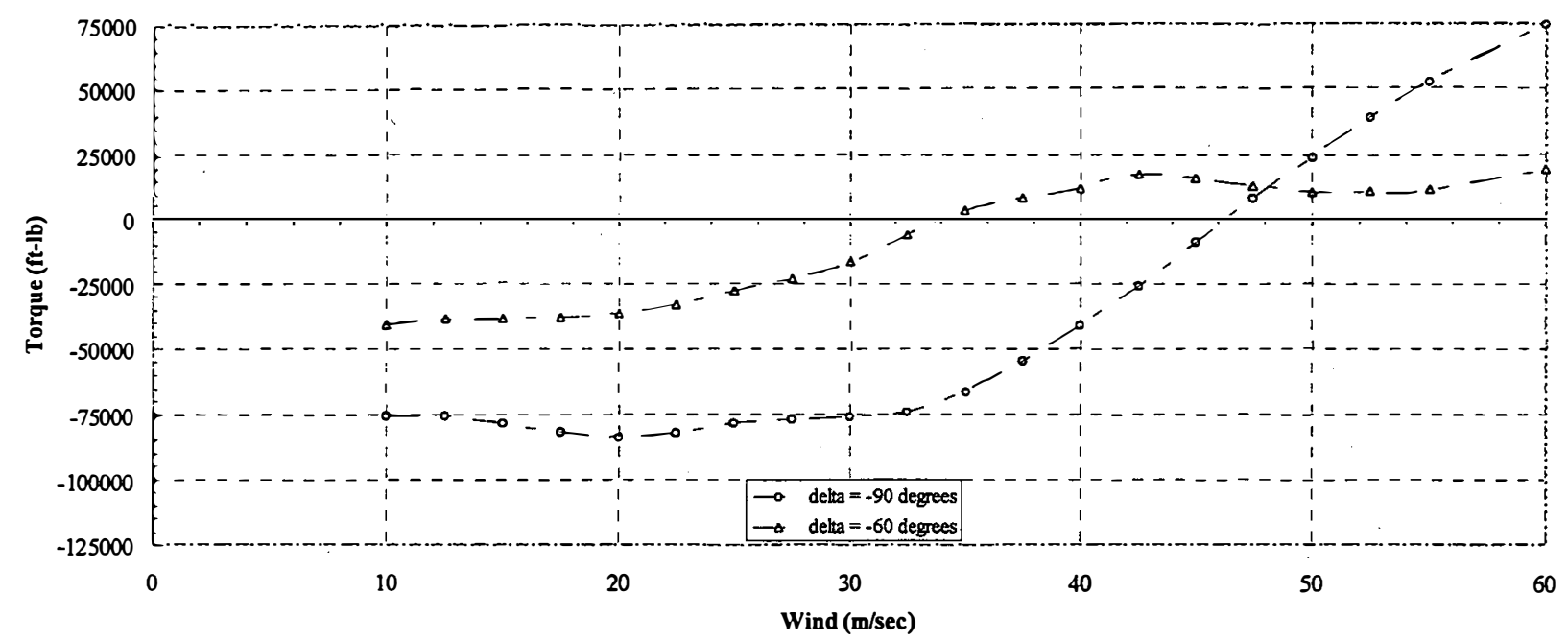

Figure 4-9. Smooth-hinge aileron rotor aerodynamic brake torque profiles.

\subsubsection{PROP93 Rotor Torque Data for the Spoiler-Flap}

The data presented in Figure 4-10 are rotor torques for the test turbine modeled with a SpoilerFlap aerodynamic braking device at two deflection angles. It should be noted that the minimum braking torque aligns with the least negative value of $\mathrm{Cs}$ for both of the deflected cases. The delta $=60^{\circ}$ case is an effective aerodynamic braking device for all AOAs. The least effective AOA is $12^{\circ}$. The delta $=90^{\circ}$ case also is an effective aerodynamic braking device for all AOAs and is generally less AOA dependent than the delta $=60^{\circ}$ case. The torque data for the Spoiler-Flap rotors are plotted in Figure 4-11 against wind speed to clarify the need for consistent braking behavior.

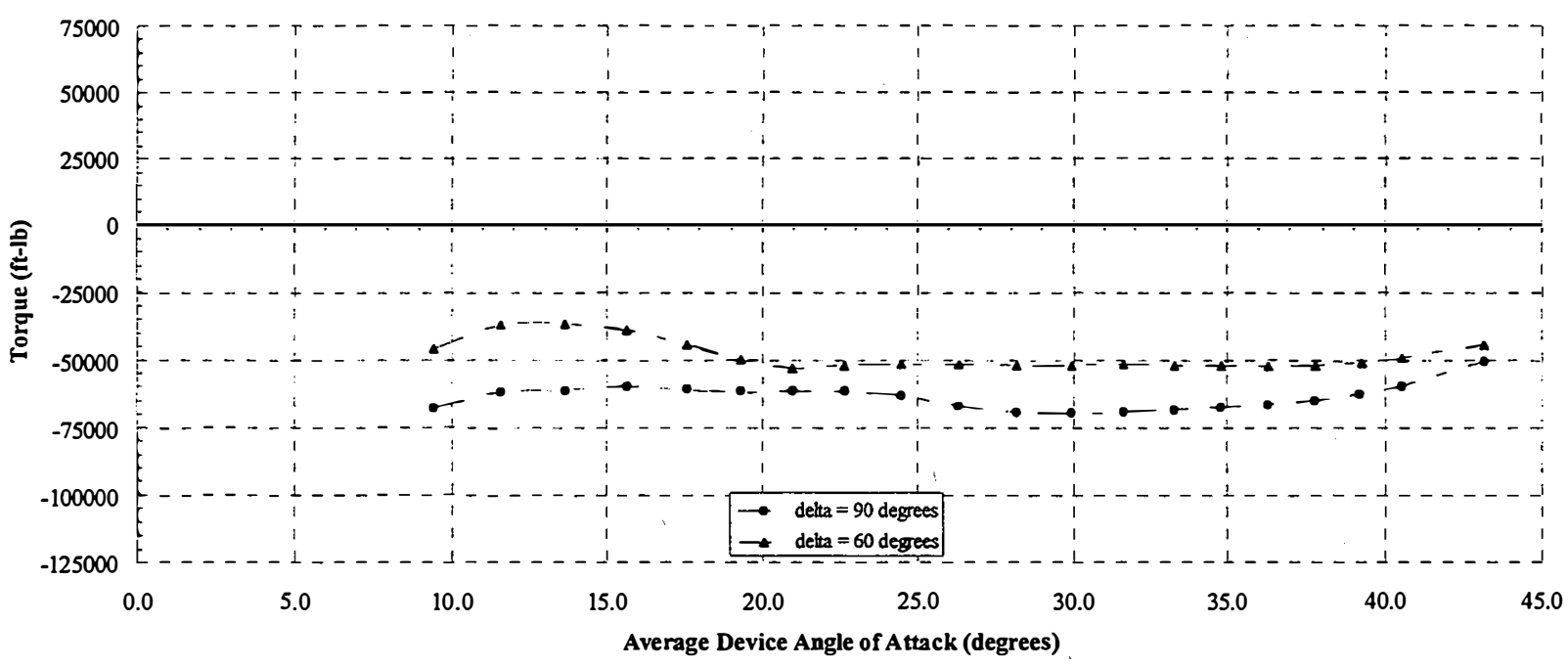

Figure 4-10. Spoiler-Flap rotor aerodynamic brake torque profiles. 


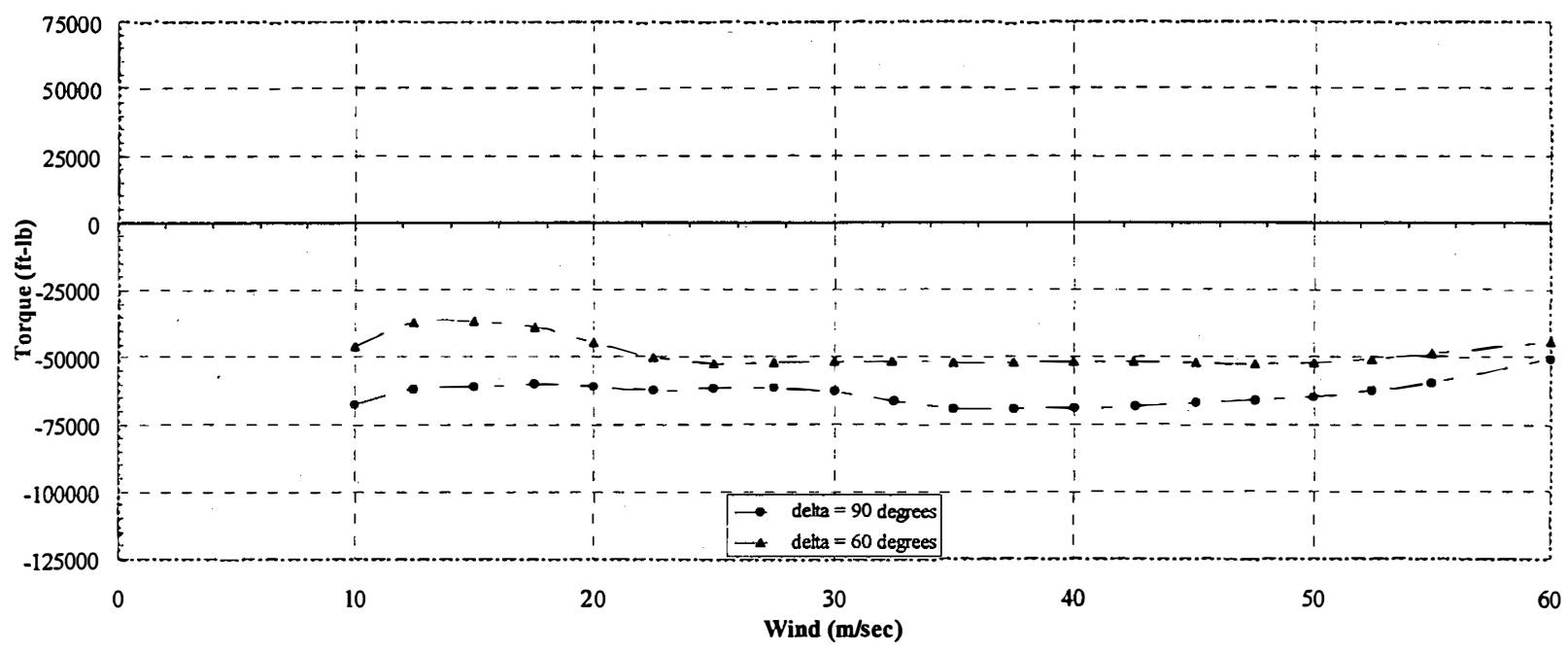

Figure 4-11. Śpoiler-Flap rotor aerodynamic brake torque profiles.

\subsubsection{Comparative Charts of PROP93 Rotor Torque Data for the Spoiler-Flap, NACA DSF 60 and DSF 112 Aileron with Smooth Hinge.}

The next step is to compare the best configurations of the four basic devices tested. First, we identified the configuration with the most negative braking torque at the worst AOA. Second, we identified the configuration that has the largest AOA range where the device is most effective. The devices that meet these two criteria are the Spoiler-Flap at delta $=90^{\circ}$ and the DSF 112 (Top 5/20, Bottom 5/20). Both of these devices are very similar aerodynamically, as can be seen in Figure 4-12. It should be noted that the Spoiler-Flap delta $=90^{\circ}$ is a better aerodynamic brake out to $35^{\circ}$, while the DSF 112 (Top 5/20, Bottom 5/20) is just slightly better than the Spoiler-Flap at AOAs beyond $35^{\circ}$. Also, the Spoiler-Flap delta $=90^{\circ}$ at $43^{\circ}$ has a slightly less negative torque than the DSF 112 (Top 5/20, Bottom 5/20) at 22.5 . The other best devices will be compared to the Spoiler-Flap because of its overall simplicity. 


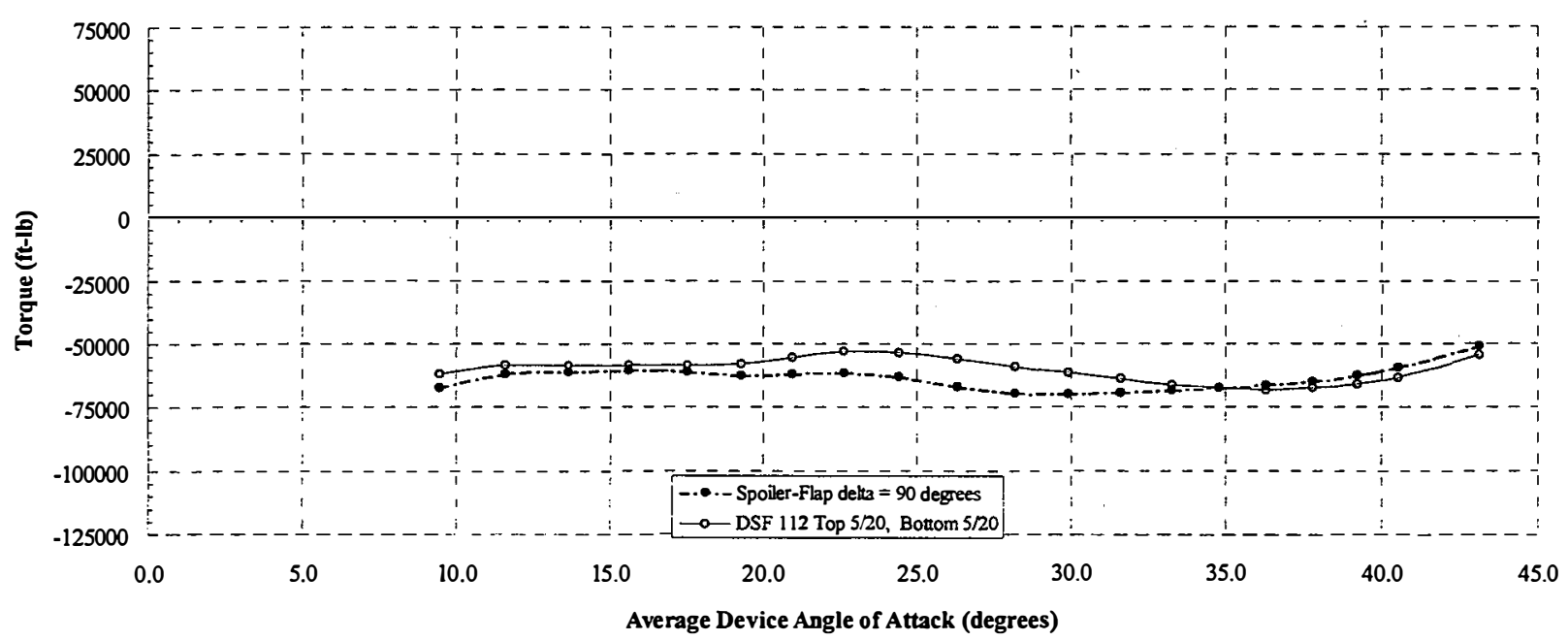

Figure 4-12. Spoiler-Flap and DSF 112 (Top 5/20, Bottom 5/20) comparison of aerodynamic brake torque profiles.

With respect to the braking criteria, the best DSF 60 configuration is the DSF 60 (Top 10/30, Bottom 10/30). This device is compared in Figure 4-13 with the Spoiler-Flap at delta $=90^{\circ}$. The Spoiler-Flap at delta $=90^{\circ}$ has a more negative torque than the DSF 60 (Top 10/30, Bottom 10/30) in the AOA range from $20^{\circ}$ to $35^{\circ}$. The DSF 60 (Top 10/30, Bottom 10/30) is a better aerodynamic braking device outside this range.

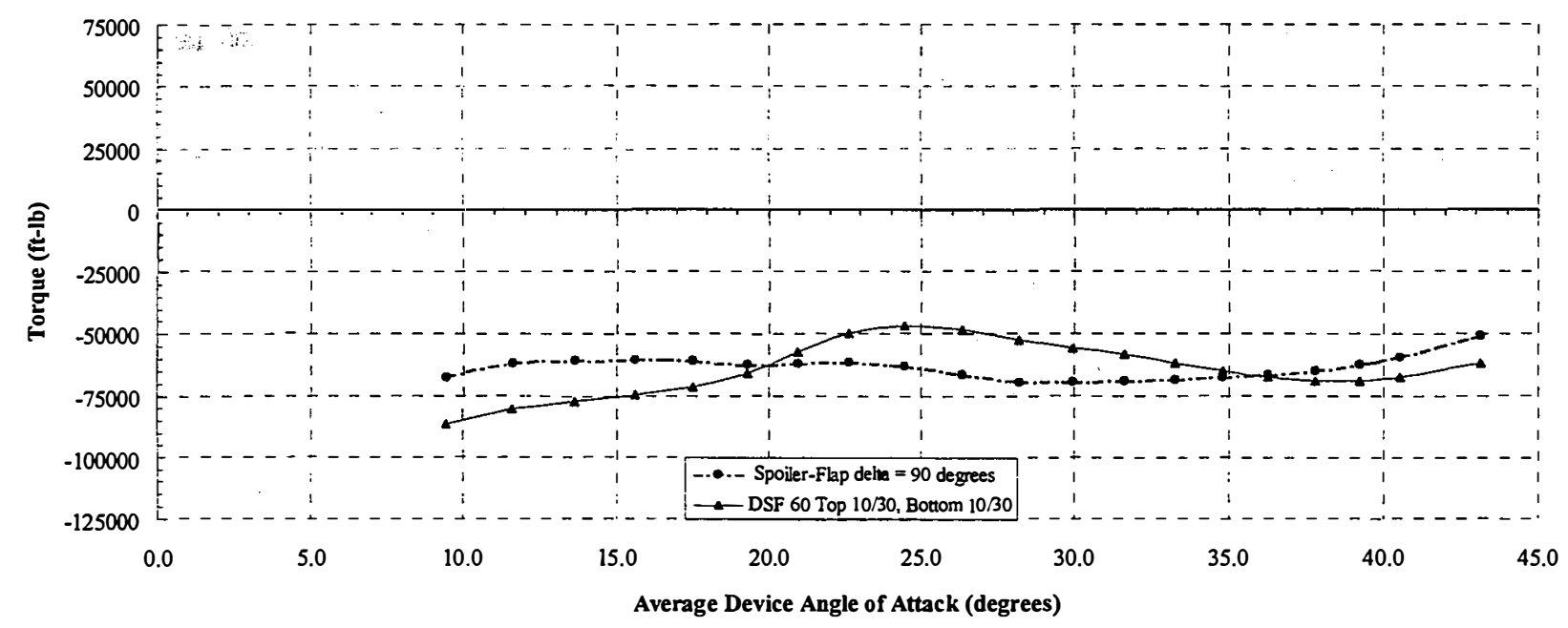

Figure 4-13. Spoiler-Flap and DSF 60 (Top 10/30, Bottom 10/30) comparison of aerodynamic brake torque profiles.

The best smooth-hinge aileron with respect to the braking criteria is the delta $=90^{\circ}$ case. This device is compared in Figure 4-14 with the Spoiler-Flap at delta $=90^{\circ}$. The Spoiler-Flap at delta $=$ $90^{\circ}$ has a more negative torque than the smooth-hinge aileron at delta $=90^{\circ}$ beyond an $\mathrm{AOA}$ of 
$27^{\circ}$. The smooth-hinge aileron at delta $=90^{\circ}$ is a better aerodynamic braking device below an AOA of $27^{\circ}$.

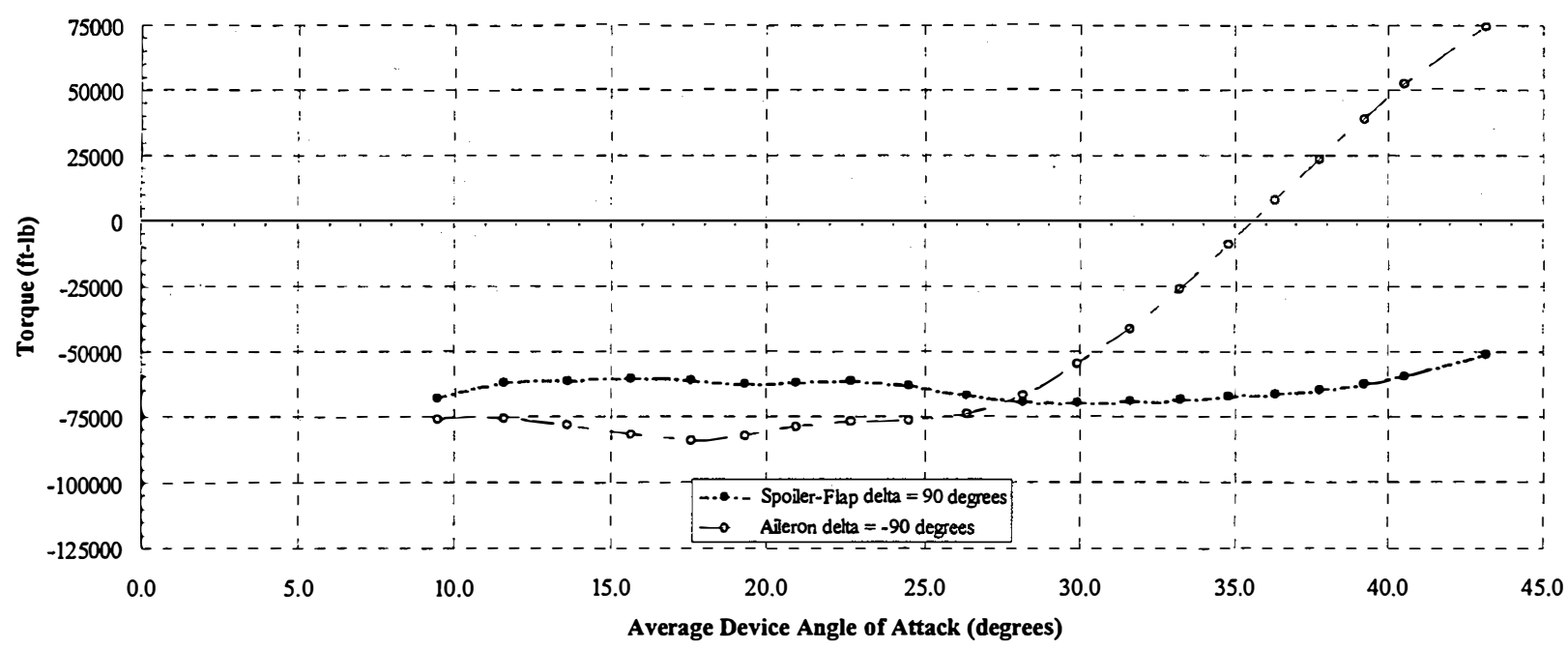

Figure 4-14. Comparison of Spoiler-Flap and smooth-hinge aileron aerodynamic brake torque profiles.

\subsubsection{Comparative Analysis of Rotor Torque Data for the Spoiler-Flap, NACA DSF 60 and DSF 112, and the Aileron with Smooth Hinge.}

The rotor torque data presented for each of the tested configurations show that all four of the devices will be effective aerodynamic brakes. All the devices will maintain rotor operating RPM at the tested device size up to a wind speed of $45 \mathrm{~m} / \mathrm{sec}$. The smooth-hinge aileron becomes ineffective as an aerodynamic braking device beyond a wind speed of $45 \mathrm{~m} / \mathrm{sec}$. The Spoiler-Flap, DSF 112 (Top 5/20, Bottom 5/20), and DSF 60 (Top 10/30, Bottom 10/30) configurations are effective aerodynamic braking devices up to a wind speed of $60 \mathrm{~m} / \mathrm{sec}$. These three configurations would be able to provide adequate braking torque at device spans smaller than $30 \%$. The amount that a device can be sized down to make it lighter and simpler is determined by engineering judgment and ECN, IEC, or NREL requirements. The DSF 60 (Top 10/30, Bottom 10/30) is the overall best of the 60 Double Split Flap configurations. The limiting wind speed for the device is $30 \mathrm{~m} / \mathrm{sec}$. The DSF 112 (Top 5/20, Bottom 5/20) is the best of the 112 Double Split Flaps with a limiting wind speed of $28 \mathrm{~m} / \mathrm{sec}$. The best tested braking configuration of the Spoiler-Flap is at delta $=90^{\circ}$. The limiting wind speed for the device is $60 \mathrm{~m} / \mathrm{sec}$.

The Spoiler-Flap is the only single-element device chosen for further consideration. The SpoilerFlap is capable of controlling the opening hinge moments by selectively locating the hinge line. Its limiting wind speed is in a very low-probability wind regime. The limiting torques for all three of 
the remaining devices are essentially equal. The Spoiler-Flap was chosen as the candidate for the point design.

\subsection{Pressure Data Measured on the Spoiler-Flap}

The pressure distribution on the device was measured by installing pressure tube belts. Holes were placed in the tube in a chordwise fashion so pressures could be measured at each hole location, yielding nearly continuous chordwise pressure distribution. These pressure data were then reduced to coefficient data.

The measured pressure data will be used to produce aerodynamic force and moment coefficients for the device. The device load coefficients will be used to generate device, device support, and actuator mechanism loads.

Device pressure coef ficient data will be scaled based on the local blade-segment velocity and AOA. The support structure aerodynamic loads will be calculated using integrated blade segment loads.

The data presented in Figure 4-15 are the device coefficients of pressures (Cp) for the upper and lower surfaces of the Spoiler-Flap aerodynamic braking device. The device is shown at AOA $18^{\circ}$ and device deflection angle of delta $=60^{\circ}$. The data presented in Figure 4-16 are for airfoil AOA $30^{\circ}$ and a device deflection angle of delta $=60^{\circ}$. These data show that although the overall blade and device aerodynamic coefficients are relatively independent of $\mathrm{AOA}$, the device moments and shears do vary considerably.

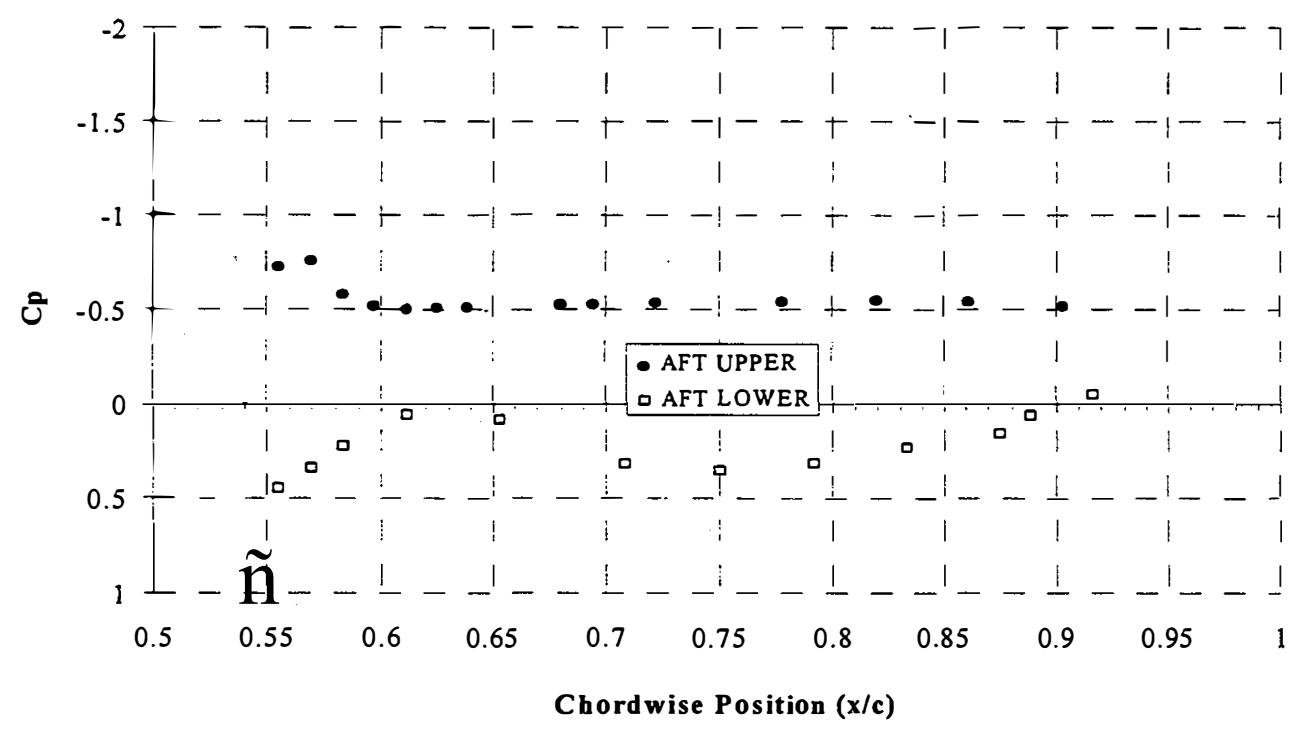

Figure 4-15. Typical Spoiler-Flap pressure distribution for $\mathrm{AOA} 18^{\circ}$ and delta $=60^{\circ}$. 


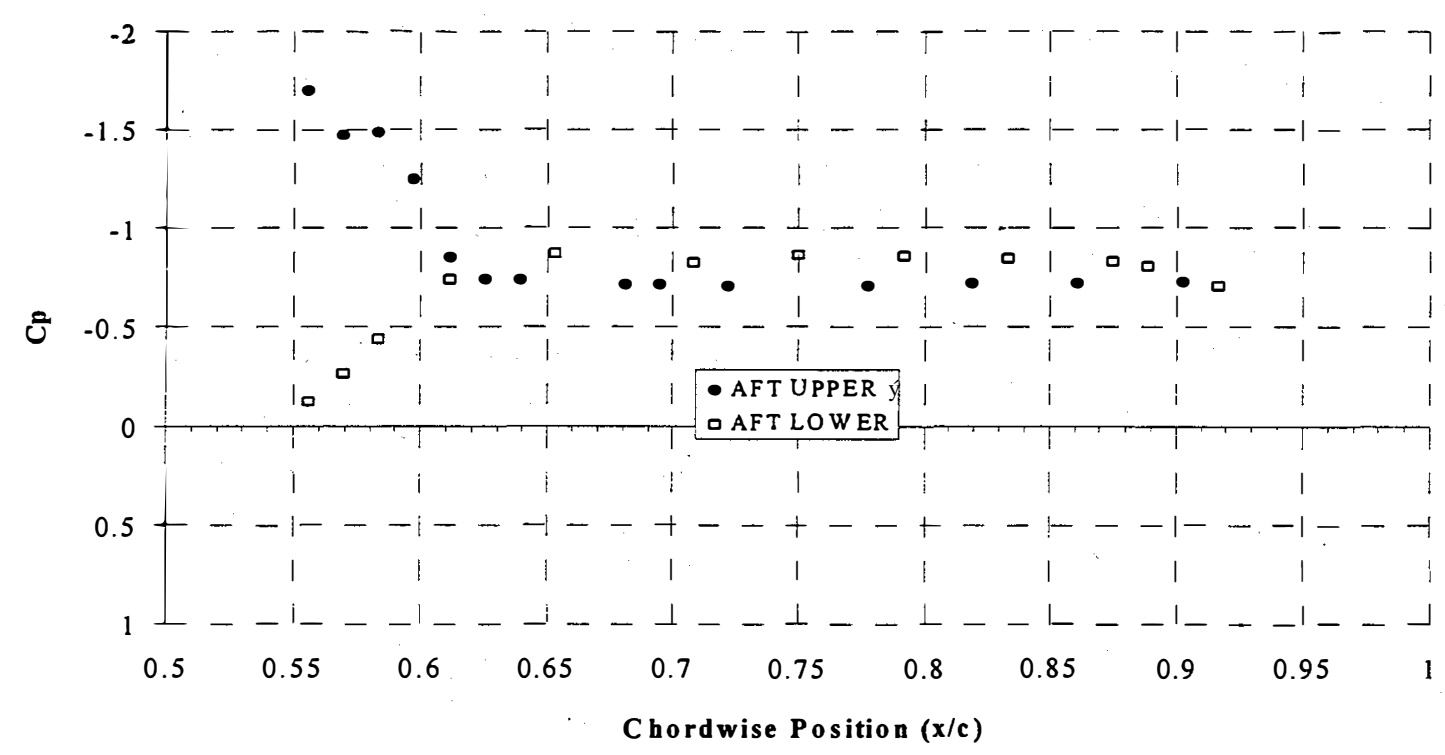

Figure 4-16. Typical Spoiler-Flap pressure distribution for $\mathrm{AOA} 30^{\circ}$ and delta $=60^{\circ}$. 


\subsection{Device Design}

The comparative analysis performed on the four devices tested at WSU resulted in the selection of the Spoiler-Flap as the point design for this report. The overall simplicity of the configuration and the device's consistent aerodynamic effectiveness led to this decision. The braking performance analysis was done using a 26-m diameter stall-controlled rotor at 60 RPM. The wind turbine that will be used for the actual point design is a MICON 65/13 turbine with NREL advanced windturbine blades. The MICON $65 / 13$ is a three-bladed upwind turbine that currently uses rotating tip aerodynamic braking. This turbine has been studied in great detail and is well documented in the literature.

\subsection{Aerodynamic Braking Requirements}

The two-dimensional aerodynamic testing performed at WSU resulted in the aerodynamic coefficients that will be used to modify the aerodynamic data for NREL advanced wind-turbine blades. The device span will be sized based on the ability of the device to produce braking torque at the design rotor RPM. An effort will be made to account for the three-dimensional reduction in effectiveness of the aerodynamic brake. Previous work Tangler and Ostowari (1984) with the 44XX family of airfoils indicates that the aspect ratio (AR) will produce a reduction in the predicted aerodynamic drag, just as in flat plates. The data collected at WSU resulted in an apparent $A R$ of 12 . This $A R$ is based on the maximum drag coefficient $\left(C_{d m a x}\right)$ of an entire clean blade at $90^{\circ} \mathrm{C}_{\mathrm{dmax}}$ of 1.7 . Because the device works mainly as a drag brake, the induced drag effects $\left(C_{d i}\right)$ will be neglected.

The ultimate and fatigue load requirements will meet or exceed IEC requirements and are based on operating and trigger RPM. The fatigue loads for the device will be calculated using the operating RPM inertial loads and pressure coefficients, based on the best wind-tunnel or blade atmospheric testing data available for the design. Ultimate loads are based on the trigger RPM for the braking device and the most severe 50 -year wind. The 50-year winds will be converted to aerodynamic loads using the best pressure coefficients available.

\subsection{Design Objectives}

\subsubsection{Aerodynamic Braking Requirements}

Deployment at 64 RPM is the current design point for the rotating tip. Therefore, the braking device also will deploy at 64 RPM. 
The wind-tunnel data collected at WSU have been used to modify MICON wind turbine rotor data files. The files contain 12 aerodynamic braking device variations. These data will be used to size the span of the device and to define the spanwise location of the device on the blade. The data are presented in the following set of braking performance charts.

\subsubsection{Aerodynamic Braking Performance for Phoenix 7.9-m Blade with Spoiler- Flap}

Device data at three spans are presented in each of the following sets of plots. The spans are of fset from the blade tip by a percent of span, as noted. The plots demonstrate the effect of spanwise location and the span required to meet braking requirements.

The data presented in Figures 5-1a through 5-1d are for tip of sets $0 \%, 5 \%, 10 \%, 15 \%$ respectively. The wind turbine is rotating at $60 \mathrm{RPM}$ for all four of the charts.

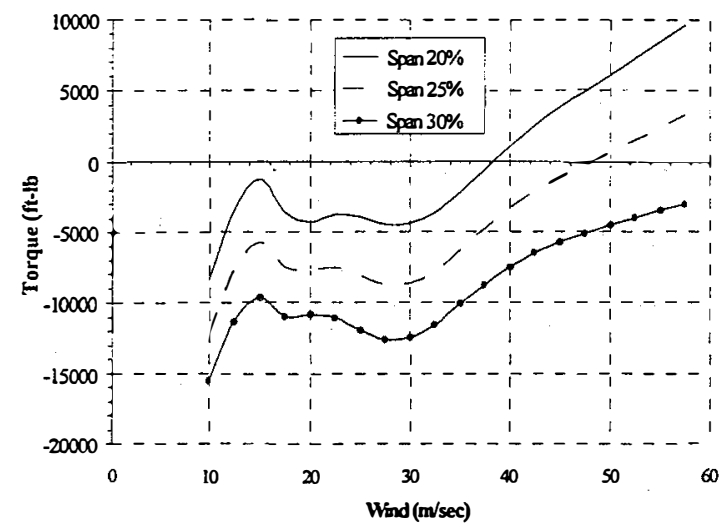

Figure 5-1a. Tip offset 0\%, RPM 60.

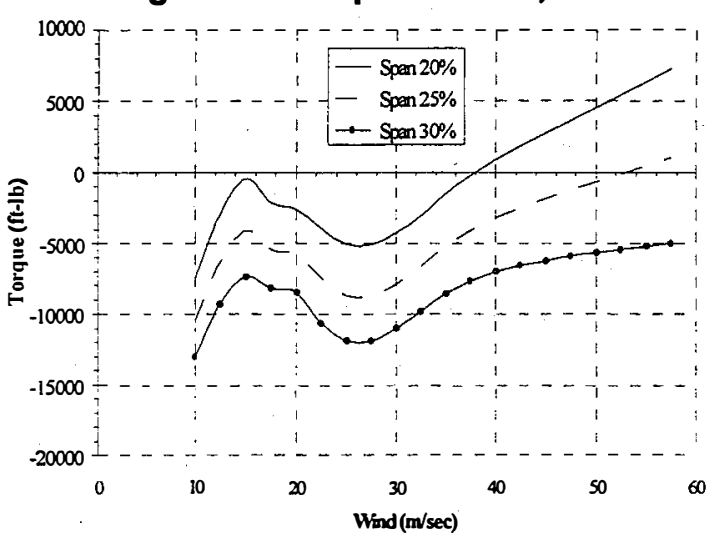

Figure 5-1c. Tip offset 10\%, RPM 60.

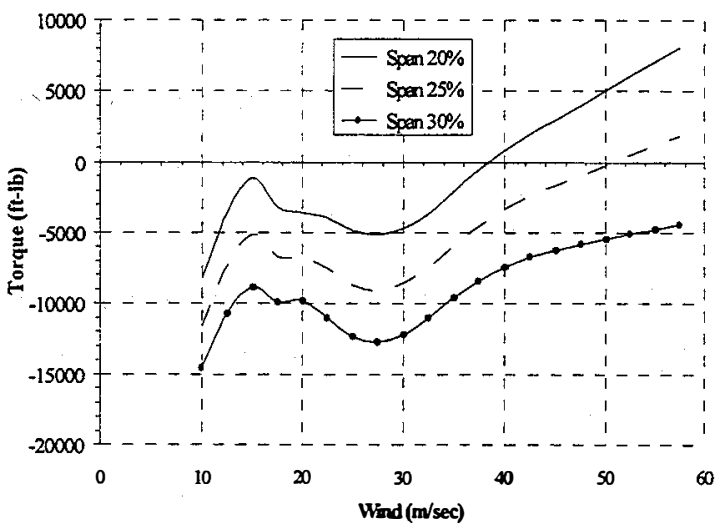

Figure 5-1b. Tip offset 5\%, RPM 60.

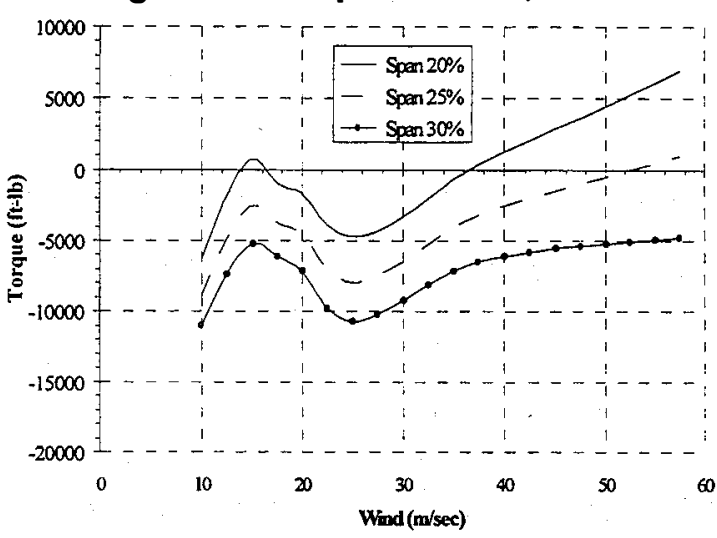

Figure 5-1d. Tip offset 15\%, RPM 60. 
The data presented in Figures 5-2a through 5-2d are for tip offsets $0 \%, 5 \%, 10 \%, 15 \%$, respectively. The wind turbine is rotating at $65 \mathrm{RPM}$ for all four of the charts.

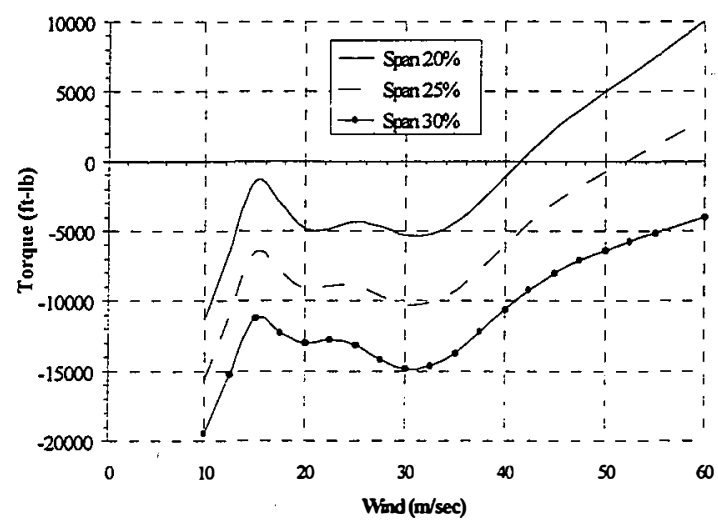

Figure 5-2a. Tip offset 0\%, RPM 65.

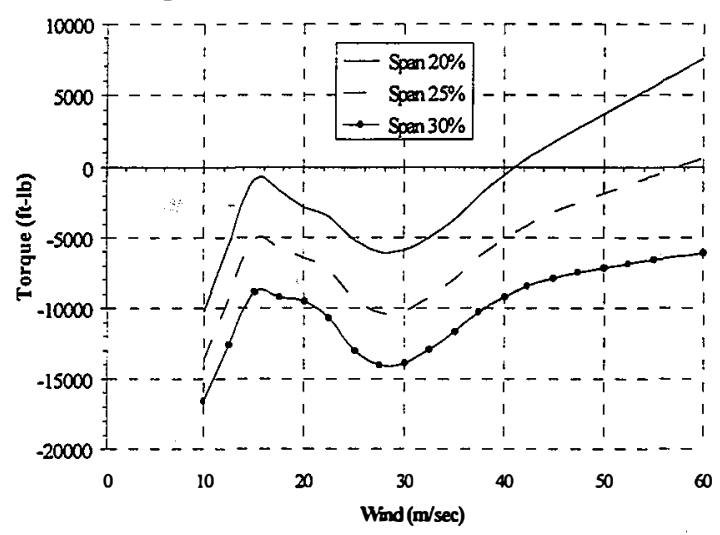

Figure 5-2c. Tip offset 10\%, RPM 65.

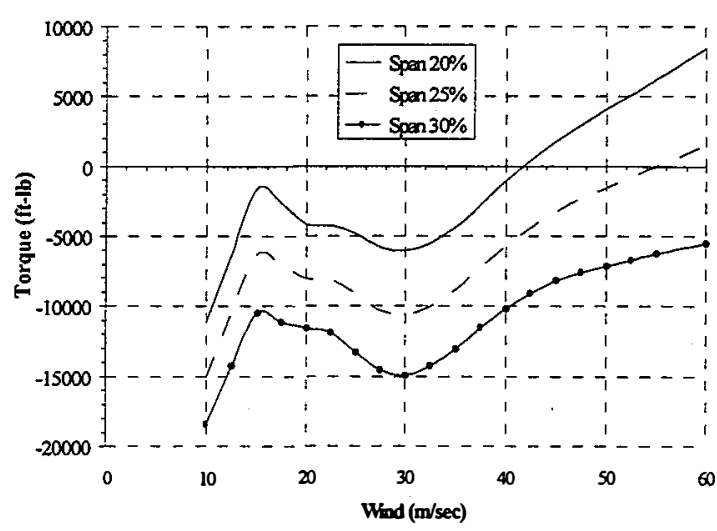

Figure 5-2b. Tip offset 5\%, RPM 65 .

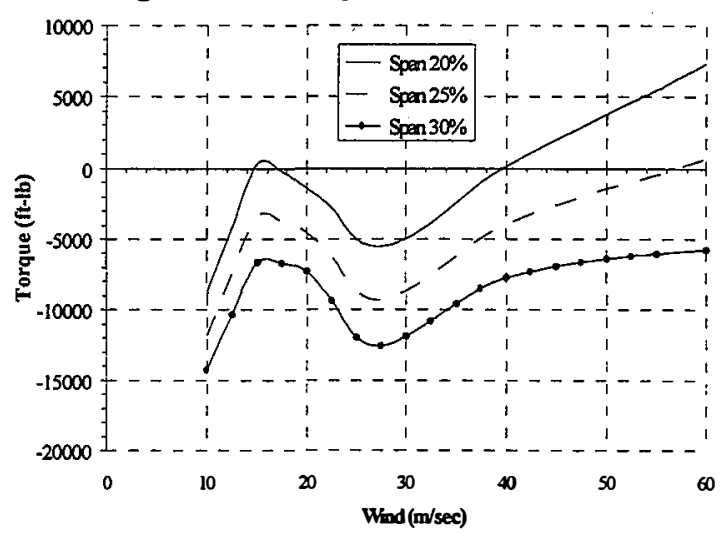

Figure 5-2d. Tip offset 15\%, RPM 65

The data presented in Figures 5-3a through 5-3d are for tip offsets $0 \%, 5 \%, 10 \%, 15 \%$, respectively. The wind turbine is rotating at 70 RPM for all four charts.

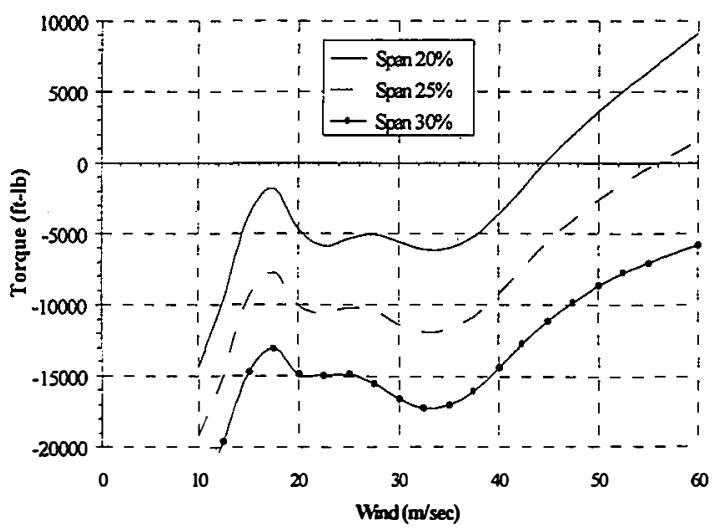

Figure 5-3a. Tip offset 0\%, RPM 70.

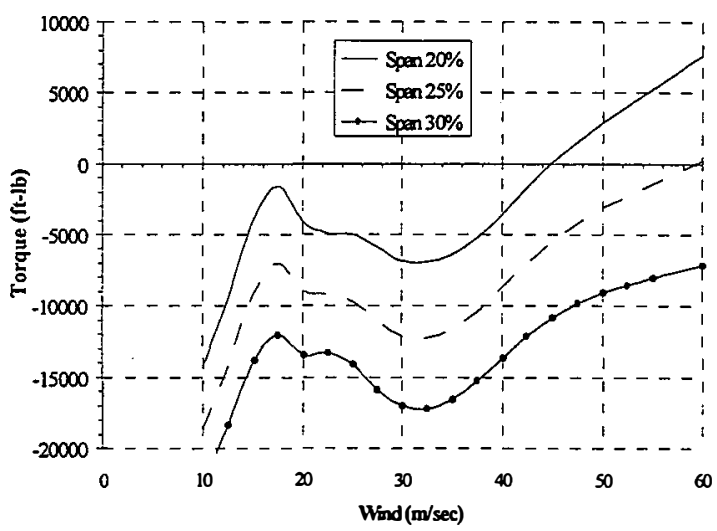

Figure 5-3b. Tip offset 5\%, RPM 70. 


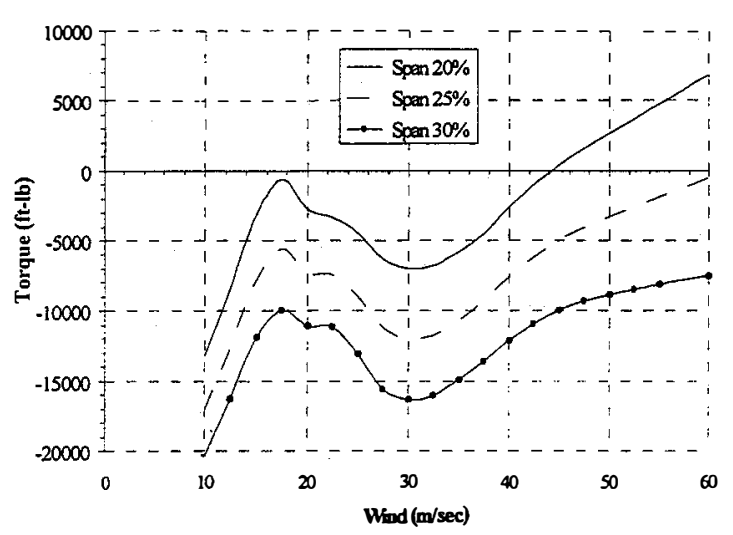

Figure 5-3c. Tip offset 10\%, RPM 70.

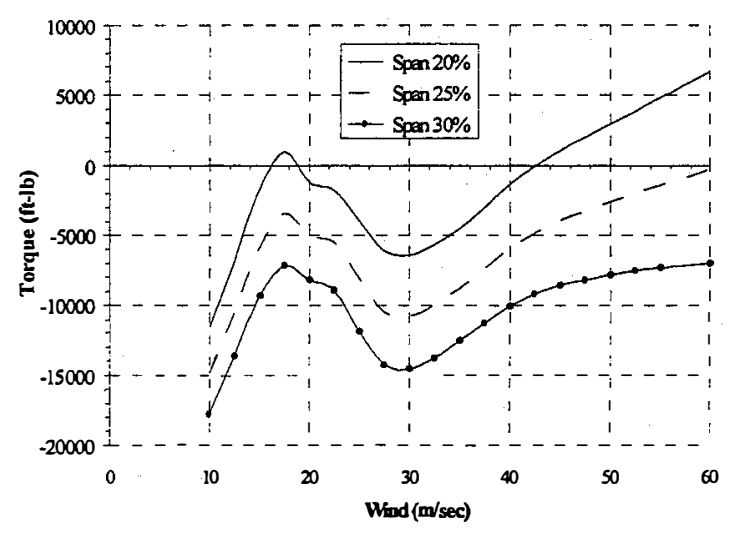

Figure 5-3d. Tip offset 15\%, RPM 70.

\subsubsection{Aerodynamic Braking Performance Analysis}

This analysis is being performed based on modifications to the MICON rotor data files using windtunnel data collected from a 643-618 airfoil. It should be noted that the Phoenix blades are made up of airfoils that are designed for HAWTs. The airfoils are designed with low $\mathrm{Cl}_{\max }$ in the area of the device. This presents a potential for error in the predicted braking performance. The accuracy of the turbine torque data in the low-wind-speed or operating range for the turbine is likely to be in better agreement than in the high-wind regime; therefore, the low-wind regime constrains the design. The post-stall area at high winds is more difficult to predict for all airfoils. The power generated and the braking torque required at the extreme $60 \mathrm{~m} / \mathrm{sec}$ wind speed is difficult to predict. The comparative study of the various spans shows that the $20 \%$ span device would be adequate in low winds. This is effectively a $25 \%$ span device with a $20 \%$ or greater reduction in capability. In effect, this estimates the downgraded performance of a device with three-dimensional effects.

The freewheeling RPM requirement is defined by the turbine structural design. The structural loads (fatigue and ultimate) for the device will meet or exceed the load cases in the IEC wind turbine generating system (WTGS) standards for the most severe wind-turbine class.

The data are clear for the following braking characteristics:

1. Increasing the device span increases the braking torque for all wind speeds.

2. Increasing tip of fset from $0 \%$ through $10 \%$ increases high-wind-speed performance.

3. Increasing tip of fset from $0 \%$ through $15 \%$ decreases low-wind-speed performance. 
4. A $20 \%$ span device is inadequate for high winds for all of fsets.

5. A $25 \%$ span device is the smallest that will work in all winds.

6. A $25 \%$ span device could freewheel below 65 RPM in all winds.

\subsubsection{Aerodynamic Braking Performance Analysis for 26-m HAWT}

The span of the device required is a function of the blade aerodynamics, length, and spanwise position of the device. The significant $\mathrm{Cs}$ that is generated by the device at its local blade position reduces the span required as the blade gets longer. The behavior can be gleaned from the expression for incremental torque, as shown in Equation (1). The same span requirement analysis done for the MICON 65/13 can be performed on the stall-controlled HAWT used for initial device selection. The analysis results in a much different percent of blade span required to ensure consistently negative torque values. The span ranges from $10 \%$ to $20 \%$ of the blade for the analysis shown in Figures 5-4a through 5-4d. The data are presented for the 60-RPM case only. These data show the same trends as the MICON 65/13 with a device installed. However, the device span required for consistently negative torque is $15 \%$ instead of $25 \%$ of the blade. This is a predictable and beneficial outcome of applying effective devices to larger turbines.

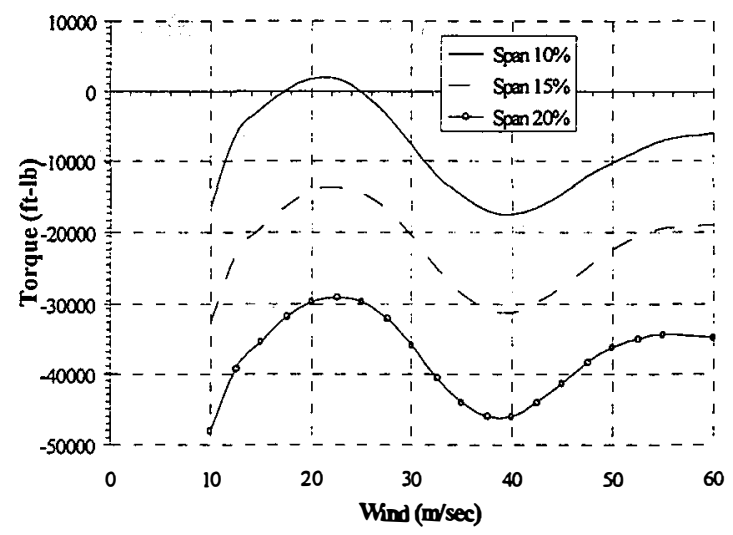

Figure 5-4a. Tip offset $0 \%$, RPM 60.

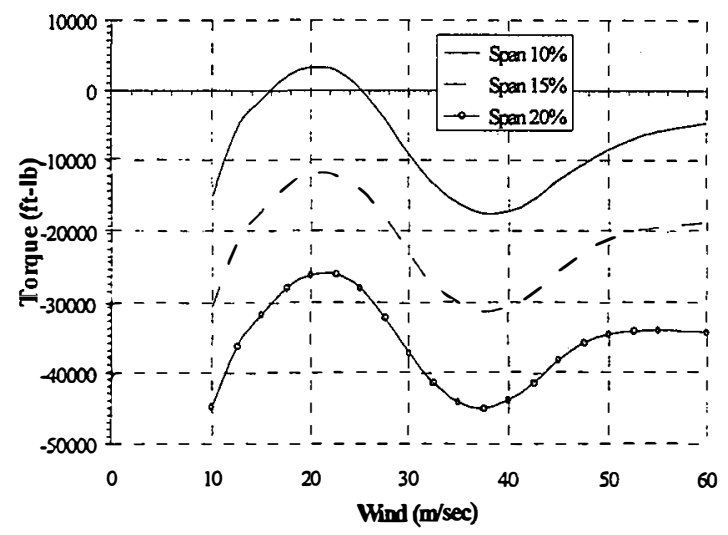

Figure 5-4b. Tip offset 5\%, RPM 60. 


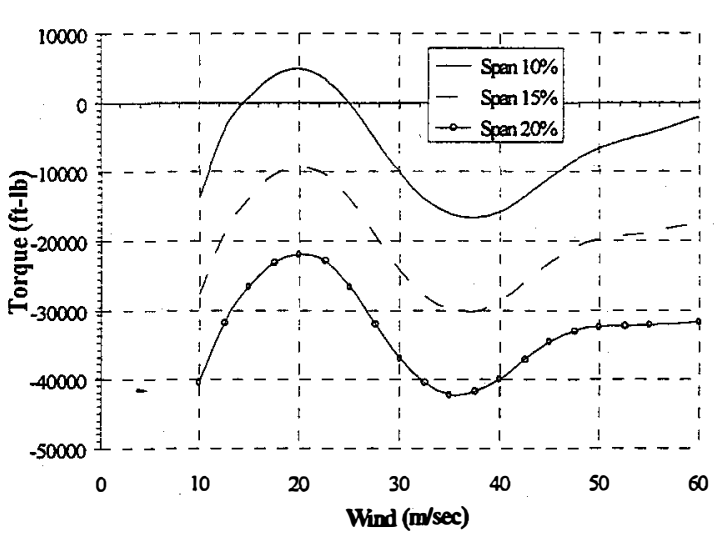

Figure 5-4c. Tip offset 10\%, RPM 60.

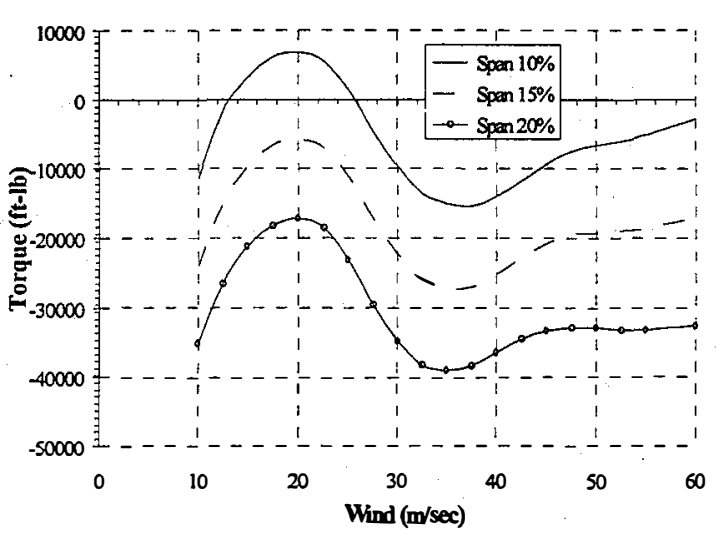

Figure 5-4d. Tip offset 15\%, RPM 60.

\subsection{Preliminary Design of the Device for the Phoenix 7.9-m Blade}

The basic design of the device is shown in Figure 5-5. The device tip will be located 18.35 inches inboard of the blade tip. This is approximately $5 \%$ of blade span inboard of the tip; the device will span 83.5 inches inboard, approximately $25 \%$ of blade span. The main components are identified in the figure. The device will be constructed of composite materials similar to the blade. It must have a shear web forward of the hinge-line to enable transfer of shear to the support structure. The device will require inboard and outboard main support ribs. At the inboard and outboard ends of the device, hinges are located at approximately $50 \%$ of the device chord. The ribs will form the hinge-line for the device and support the inboard and outboard magnet attachments. The section forward of the spar will house the three aerodynamic moment carrying magnets and the mechanism that holds the device in the deployed condition. Magnet fittings are shown at three spanwise locations. The rotating translating bearing is the interface between the main blade and the actuating and return mechanism.

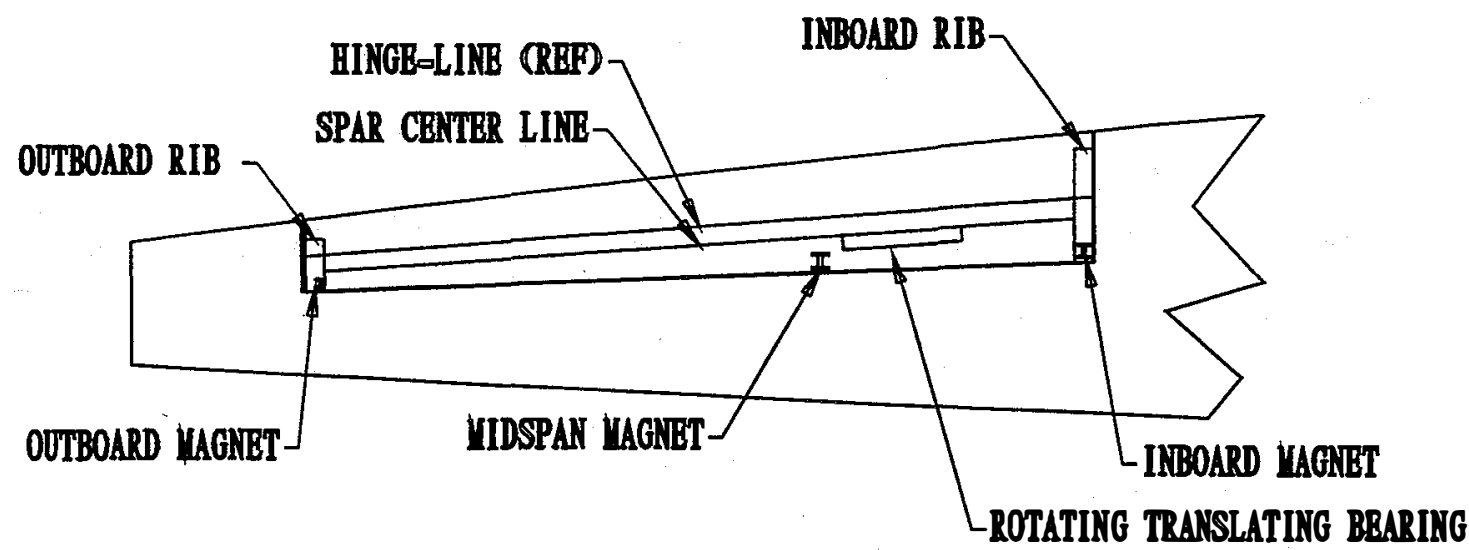

Figure 5-5. Plan view of a 25\% span Spoiler-Flap device for the Phoenix 7.9-m blade. 
The outboard hinge area is shown in more detail in Figure 5-6. The location of the hinge in the blade coordinate system "inches from the blade-hub interface" is called the blade station (BS), BS 294. On the outboard end of the device, the hinge rib is attached to the hinge link at joint $\mathbf{H} 294$. This joint is a clamped spherical joint and the amount of angular motion required is less than 10 ; therefore, standard bearings can be used. The joint is free to move spanwise because of pivot joint P294. Joint P294 is a revolute joint with its axis of rotation normal to the local chord plane. The hinge link is attached to the blade end rib at joint P294. These two joints form a floating hinge on the outboard end of the device. This configuration allows relative motion between the blade and the device, enabling the device to be actuated by a relative translation of the device to the blade with little loss in stiffness with respect to vertical motion at the hinge. The gap between the device and the blade is nearly closed when the device is deployed. For normal overspeed deployment, the pivot rotates approximately $5^{\circ}$ to enable a .25 -inch spanwise translation of the device. The device then begins to rotate on the ball of the spherical joint H294. As soon as the blade RPM begins to slow, the pivot rotates back and the device remains deployed with the pivot in its original position. The translation is guided by the translating revolving joint $\mathrm{H} 210$ at the inboard end of the device.

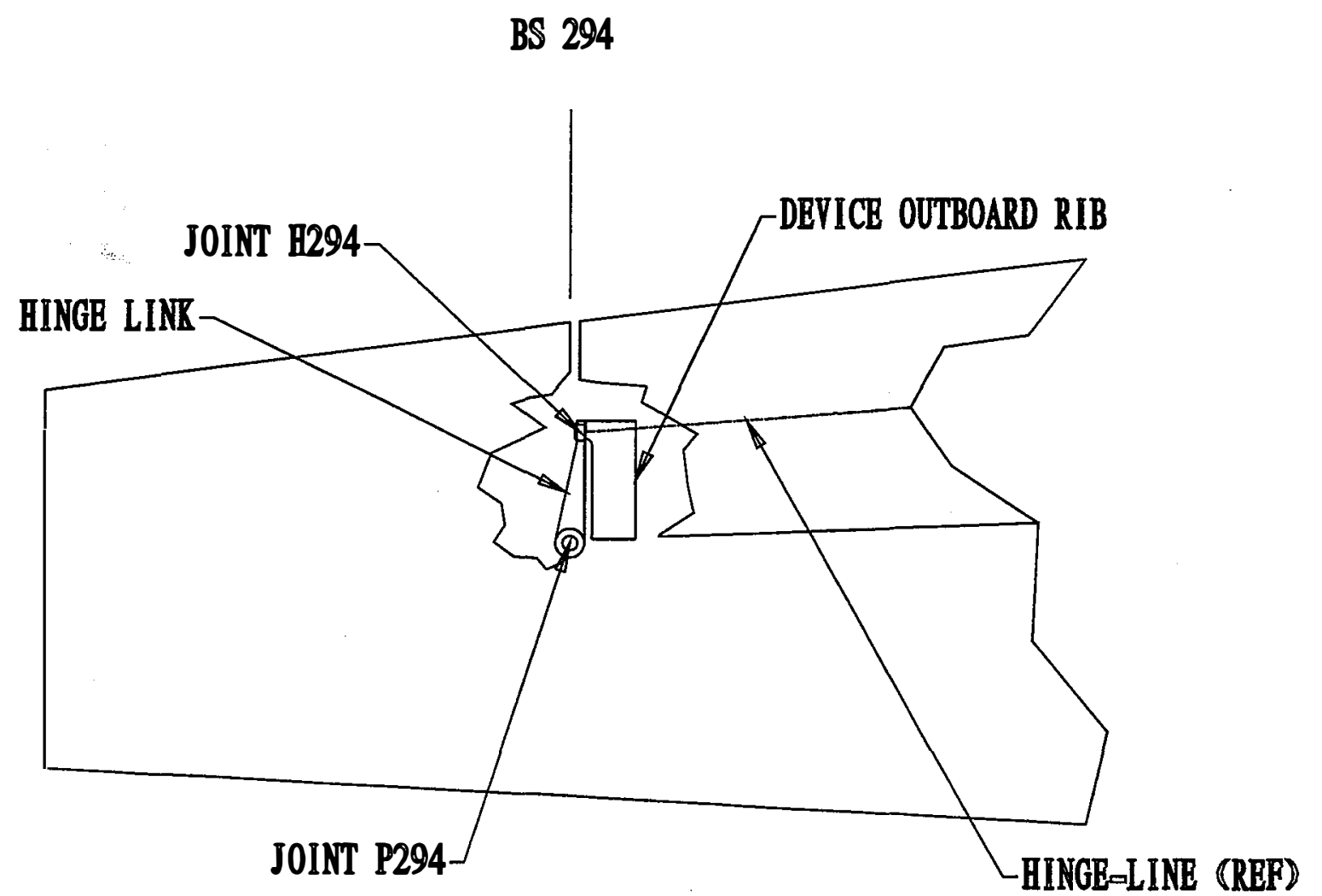

Figure 5-6. Outboard Spoiler-Flap floating hinge and rib fittings.

The inboard hinge installation is shown in more detail in Figure 5-7. The inboard hinge fitting serves three purposes. It carries both spanwise and transverse loads, and it acts to support the inboard magnet attachment. Joint $\mathrm{H} 210$ is a preloaded translating revolute joint. The inboard 
device rib is entrapped by thrust bearings that allow rotation but carry the spanwise loads to the inboard hinge fitting through the bolt. The preloaded spring is a heavy-duty compression spring with a 1.5-inch diameter and a free length of 6 inches. The spring rate is $750 \mathrm{lbs} / \mathrm{inch}$, and the required preload is approximately 900 lbs. The revolute joint will be made of fittings with replaceable bushings and 0.75 -inch-diameter bolt. The hinge fitting will be attached to the mid spar at its forward face. The inboard face of the fitting will be fastened to the aft spar via tension clips.

The magnet installation is shown in Figure 5-8. There are three magnet and attach fitting joints: M210, M240, and M294. They are located at approximately BS 210, BS 240, and BS 294, respectively. Magnets are designed to carry only aerodynamic moment by a transverse kick load. They will be designed to disengage at a spanwise displacement of 0.25 inches.

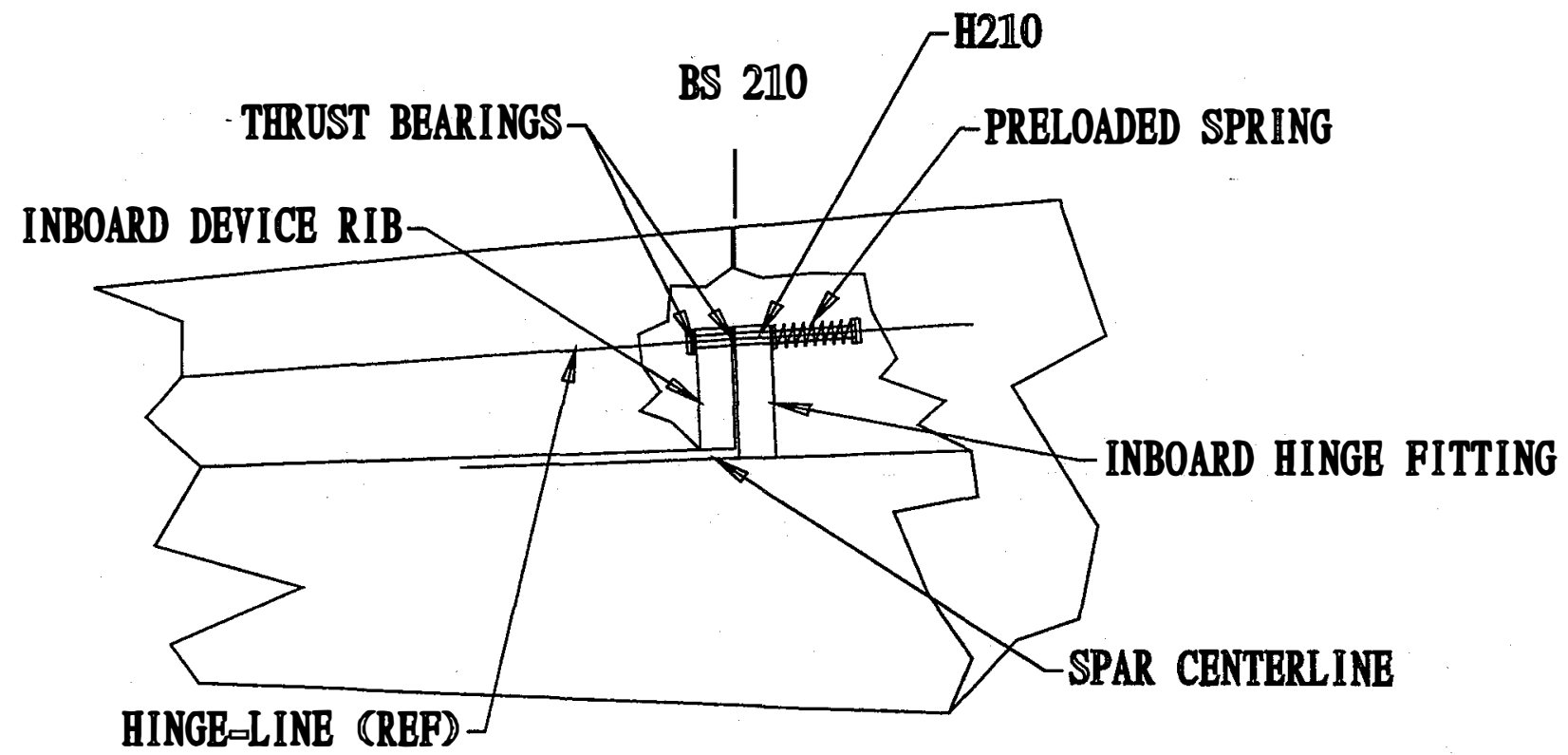

Figure 5-7. Inboard Spoiler-Flap translating revolute hinge and rib fittings.

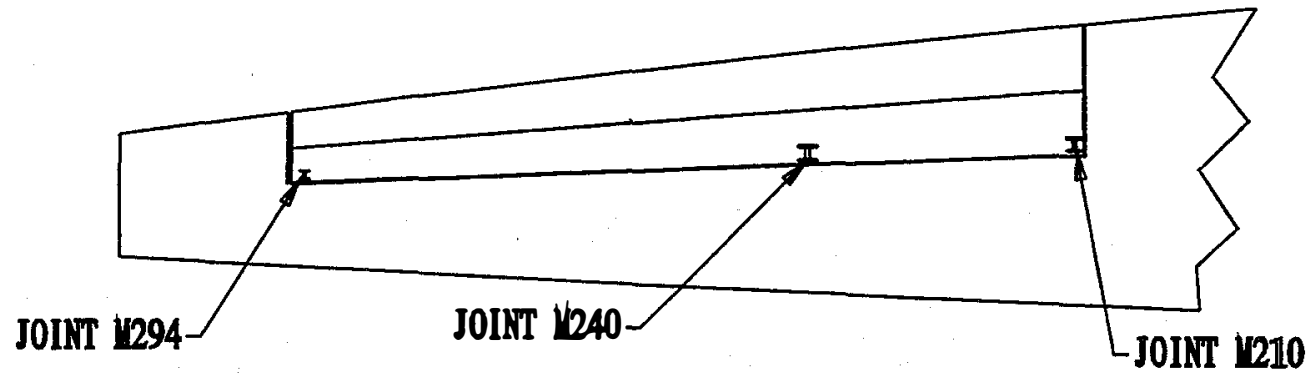

Figure 5-8. Magnet fittings laid out on the blade.

The device as modeled for the span sizing in the PROP93 code was segmented into blade stations. The $25 \%$ span, $5 \%$ offset device is located on the blade from Station 15 through Station 19, as 
shown in Figure 5-9. These stations will be used only for loads analysis. The position of the device in terms of the blade coordinates also is shown in Figure 5-9. At either end of the device, the hinge ribs are located by their blade stations, BS 210 for the inboard rib and BS 294 for the outboard rib.

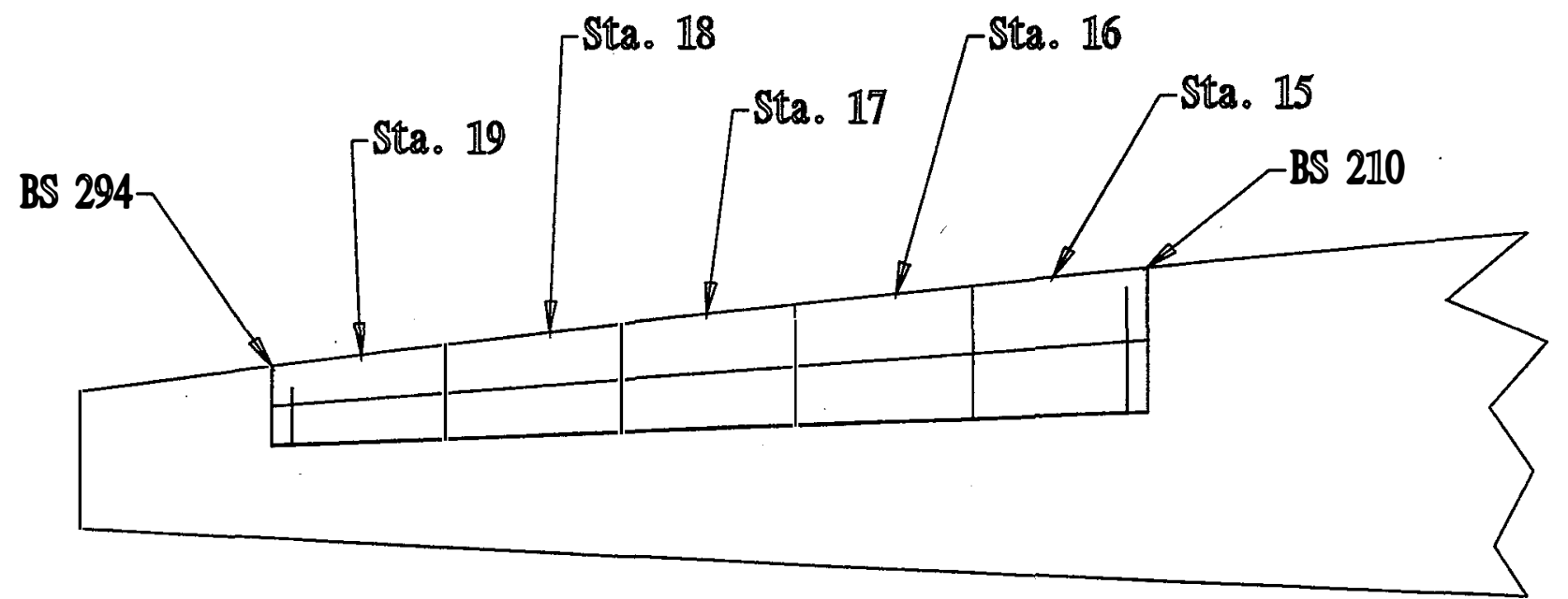

Figure 5-9. Plan view of Phoenix 7.9-m blade with a 25\% span Spoiler-Flap device showing load analysis segments.

There are many possible designs for the actuating mechanism. The exact nature of the mechanism is not of great importance. The device has positive opening moments for all but the greatest device deflection angles. The actuating mechanism need only slow deployment through the first $60^{\circ}$ of device deflection.

The free-body diagram for the device with air loads is shown in Figure 5-10. The airloads are applied at the center of each of the five stations. Airloads are then summed over the device and distributed to the support structure. The device is modeled as a simply supported beam for vertical shear. This is conservative for the hinge at zero device deflection because the magnet would share some load. The simple beam model is quite reasonable and less conservative for the more important cases of device deflection. The moment reactions are indeterminate and will be over-designed by taking $50 \%$ of the total moment at M240, 30\% of the total moment at M294, and $40 \%$ of the total moment at M210 for analysis. This analysis is not elegant, but with blade and device torsion and bending deflections, the loads estimates are a good start. Further testing will refine the numbers. 


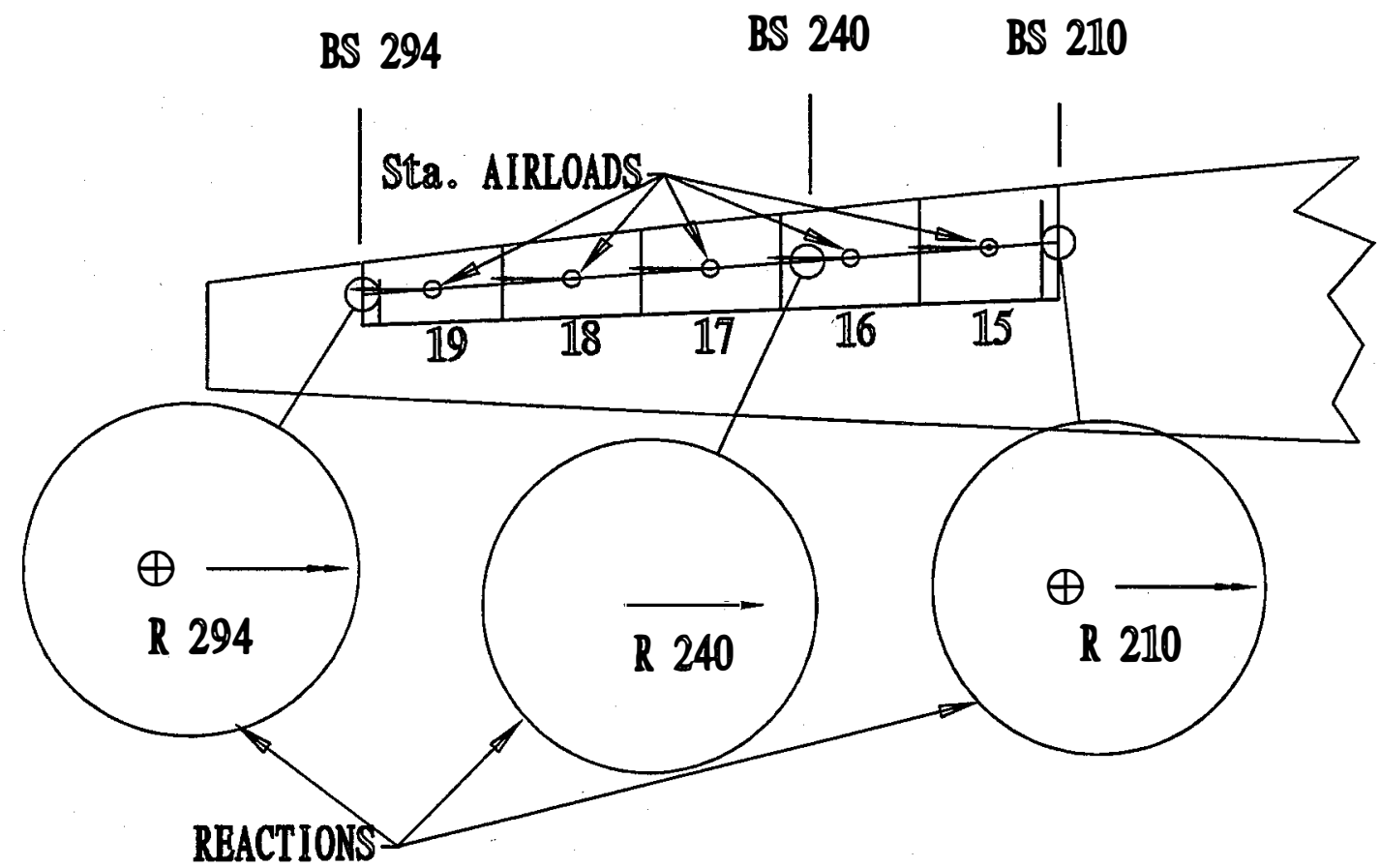

Figure 5-10. Plan view of a 25\% span Spoiler-Flap device showing segments, airloads, and reactions.

The free-body diagram for centrifugal loads is shown in Figure 5-11. The inboard ribs on the blade and on the device will take all the centrifugal force. The moment generated by holding the device at the inboard rib is reacted by the inboard and outboard hinge fittings in a couple. These centrifugal loads will be vectorally summed with an airload case and applied appropriately.

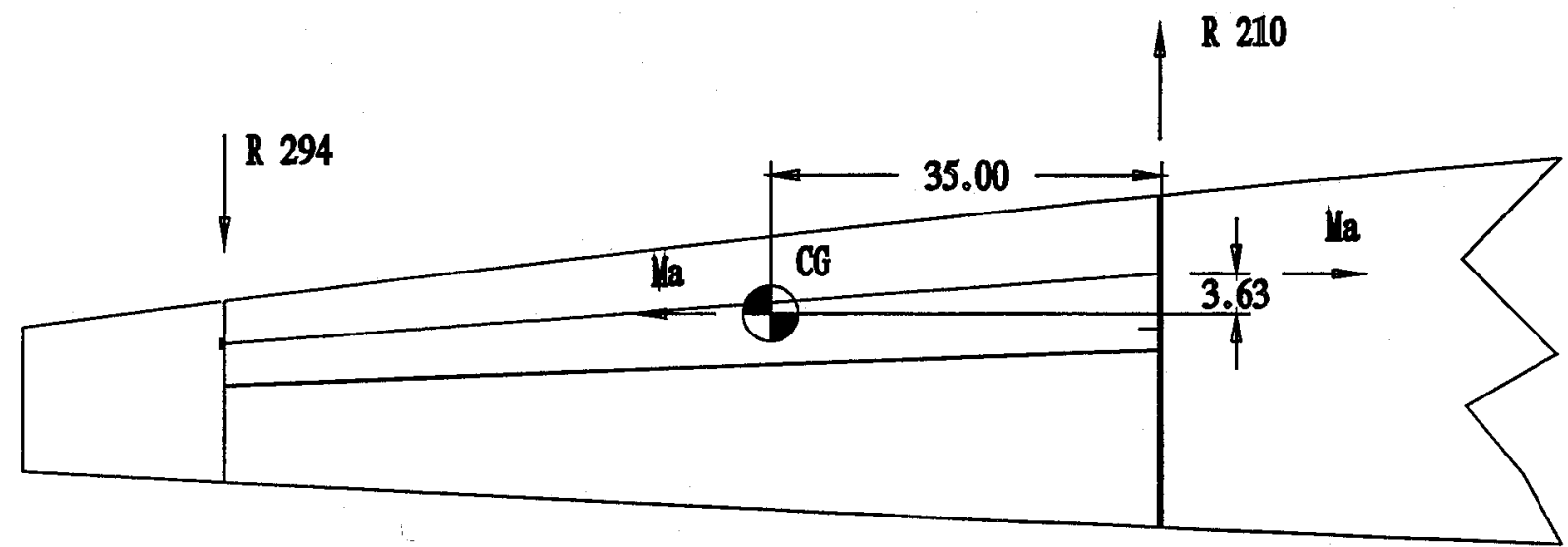

Figure 5-11.Plan view of a 25\% span Spoiler-Flap device showing device inertial loads and reactions.

The aerodynamic and centrifugal loading data are presented in Appendix $B$ in the form of load sheets. These load sheets are intended to adequately define critical loads for the device. The load cases were limited to four device deflection angles because both vertical shear and hinge moment data were needed. The four deflection cases presented will likely envelop the design loads. Other 
deflection cases should be tested as soon as possible. The load sheets are for wind speeds from $\mathbf{1 0}$ to $60 \mathrm{~m} / \mathrm{sec}$, four device deflection angles, and four rotor RPMs.

The device will be fatigue designed for operating loads at 47.7 .RPM. The fatigue analysis will identify operating stresses in the support structure, and the device design will be below the endurance limit for the structural components. In this way, the design life will exceed 20 years. If the endurance limit is not exceeded for wind speed in the operating range, the device will surpass IEC requirements.

Analysis should show that the structure does not yield at ultimate loads. This will be a conservative analysis for the most critical load cases because the real aerodynamic loads are not known for these airfoils with a Spoiler-Flap device. Only the factored wind-tunnel data are available at this point.

The aerodynamic overspeed control device has been sized for the Phoenix 7.9-m blade based on the aerodynamic data obtained in a two-dimensional wind-tunnel test. A conceptual design has been presented, and design loads have been calculated. These loads are based on the best estimates of airloads and device weights. This design is preliminary and requires maturation before implementation. The nature of operating loads and the load path indicate that the design should be competitive with the rotating tip device on a weight and cost basis. The load path for the rotating tip is a single steel shaft at the $\mathbf{4 0 \%}$ chord of the blade. This shaft must carry operating loads as well. The stowed configuration is better than the tip vane with respect to drag if the device is well sealed and deflections are limited. A detailed analysis of weight and cost benefits will be done if further development of this concept is undertaken.

\subsection{Future Work}

A detailed design of the device for production should be undertaken incrementally in the following steps:

1. Conduct rotating frame aerodynamic testing to verify the device performance.

2. Obtain more complete aerodynamic data for target airfoils with the device installed and deflected.

3. Perform rotor control experiments because the device shows potential as a power modulator. 
4. Make and test mock ups to ensure form, fit, and function of the key components.

5. Test the preliminary design to develop better loads estimates and ensure practicality.

6. Assess long term $O$ and $M$ requirements through proof of concept testing. 


\subsection{Summary}

The comparative analysis performed on the braking devices tested in the WSU wind tunnel resulted in the selection of the Spoiler-Flap as the device for the point design for MICON 65/13 braking device. The overall simplicity of the configuration and the device's consistent aerodynamic effectiveness led to its selection. The Spoiler-Flap met all of the following criteria:

1. The device is fully effective from a blade AOA range from $0^{\circ}$ to $45^{\circ}$. The Spoiler-Flap is in fact effective from $0^{\circ}$ to $90^{\circ}$ blade $\mathrm{AOA}$.

2. The device is stowed inside the blade profile prior to deployment.

3. The device is capable of sufficiently controlling the local blade aerodynamics to balance the positive aerodynamic torque still being produced by the rest of the rotor blade.

4. The device hinge is located chordwise to minimize hinge moments, thus lowering actuator load requirements and cost. For a wide range of positions, there is no loss in aerodynamic effectiveness.

5. The device appears to have potential as a power modulator for an active rotor control system. This assessment is based on the Cs data at device deflections from $0^{\circ}$ to $30^{\circ}$.

The point design was targeted to the Phoenix 7.9-m blade for convenience and cost. The device required a span of $25 \%$ of blade to ensure the blade would meet ICE TIC 88 requirements for aerodynamic braking. The device was offset from the tip of the blade by $0.46 \mathrm{~m}$.

It should be noted that a 26-m-diameter turbine could meet the ICE TC-88 requirements for aerodynamic braking with only a $15 \%$ span device with a $0.46-\mathrm{m}$ tip offset. This is due to the large negative $\mathrm{Cs}$ of the device and the greater length of the blade. 


\section{REFERENCES}

Abbott, I.H.; Von Donenhoff, A.E. (1958). Theory of Wing Sections. Canada: Dover Publications.

Anderson, John D. Jr. (1984). Fundamentals of Aerodynamics. New York: McGraw-Hill, Inc.

Cao, H.V.: Wentz,W.H. (July 1987). Performance and Aerodynamic Braking of a Horizontal-Axis Wind Turbine from Small-Scale Wind Tunnel Tests. NASA CR-180812. Work Performed for the U.S. Department of Energy, Conservation and Renewable Energy Wind/Ocean Technology Division, Washington, D.C.

Corrigan, R.D.; Ensworth, C.B.; Miller, D.R. (October 1987). Performance and Power Regulation Characteristics of Two Aileron-Controlled Rotors and a Pitchable Tip-Controlled Rotor on the Mod-0 Wind Turbine. NASA TM-100136. Work Performed for the U.S. Department of Energy, Conservation and Renewable Energy Wind/Ocean Technology Division, Washington, D.C.

Eggleston, D.M.; Stoddard, F.S. (1987). Wind Turbine Engineering Design. New York, New York: Van Nostrand Reinhold Company, Inc.

Gregorek, G.M. (May 1984). "Comparative Wind Tunnel Tests at High Reynolds Numbers of NACA 64621 Airfoils with Two Aileron Configurations." Prepared for the Horizontal-Axis Wind Turbine Technology Workshop, Cleveland, Ohio.

Gregorek, G.M.; Kuniega, R.J.; Nyland T.W. (April 1988). Comparison of Pressure Distributions on Model and Full-Scale NACA 64-621 Airfoils With Ailerons for Wind Turbine Application. NASA TM-100802. Work Performed for the U.S. Department Of Energy, Conservation and Renewable Energy Wind/Ocean Technology Division, Washington, D.C.

Hoerner, S.F. (1958). Fluid-Dynamic Drag. Midland Park, New Jersey: Hoerner.

Jamieson, P.; Agius, P. (1990). "A Comparison of Aerodynamic Devices for Control and Overspeed Protection of HAWTs." Prepared for the 12th British Wind Energy Association Conference, London. pp. 205-213.

Jamieson, P.; Bowles, A.; Derrick, A.; Leithead, W.; Rogers, M. (1992) "Innovative Concepts for Aerodynamic Control of Wind Turbine Rotors." Journal of Wind Engineering and Industrial Aerodynamics, (39); pp.395-404. 
Miller, D.R.; Putoff, R.L. (August 1984). "Aileron Controls for Wind Turbine Applications." Prepared for the Intersociety Energy Conversion Engineering Conference, San Francisco, California, NASA TM-86867.

McCarty, J. (June 1993). “Prop 93 Version 1.0.” Prepared for Alternative Energy Institute, West Texas A\&M University, Canyon, Texas.

Miller, D.R. (February 1986). "Summary of NASA/DOE Aileron Control Development Program for Wind Turbines." Prepared for the Energy-Sources Technology Conference and Exhibition, New Orleans, Louisiana. NASA TM-86811.

Miller, L.S. (1995). "Experimental Investigation of Aerodynamic Devices for Wind Turbine Rotational Speed Control." Prepared for the National Renewable Energy Laboratory, Golden, Colorado. NREL /TP441-6913.

Purser, P.E. (June 1942). A Study of the Application of Data on Various Types of Flap to the Design of Fighter Brakes. Prepared for the National Advisory Committee For Aeronautics ACR (WR L-414).

Rae, W.H.; Pope, A. (1984). Low-Speed Wind Tunnel Testing 2nd Edition, New York, John Wiley \& Sons.

Rogallo, F.M. (1941). Aerodynamic Characteristics of a Slot-Lip Aileron and Slotted Flap for Dive Brakes. NACA ACR No. L-337. Prepared for the National Advisory Committee for Aeronautics.

Satran, D.; Snyder, M.H. (January 1977). Wind Energy Report No. 1: Two-Dimensional Test of GA(W)-1 and GA(W)-2 Airfoils at Angles of Attack From 0 to 360 Degrees. Release Date January 1979. Work Performed by the Wind Energy Laboratory, Wichita State University, Wichita, Kansas.

Savino, J.M.; Nyland, T.W.; Birchenough A.G. (August 1985). Reflection Plane Tests of a Wind Turbine Blade Tip Section With Ailerons. NASA TM-87018. Work Performed for the U.S. Department of Energy, Conservation and Renewable Energy Wind Energy Technology Division, Washington, D.C. 
Shimizu, Y.; Van Bussel, G.J.W.; Matsumura, S.; Bruining A. (1992) "New Technology of Power Augmentation on Horizontal Axis Wind Turbines using Mie Vanes." Journal of Wind Engineering and Industrial Aerodynamics, (39); pp.119-127.

Shimizu, Y.; Van Bussel, G.J.W.; Matsumura, S.; Bruining A. (September 1990) "Studies on Horizontal Axis Wind Turbines With Tip Attachments." Prepared for the European Community Wind Energy Conference, Madrid, Spain.

Stephenson, J.D. (1949). The Effects of Aerodynamic Brakes Upon the Speed Characteristics of Airplanes. NACA TN 1939. Prepared for the National Advisory Committee for Aeronautics.

Tangler, J.L.; Ostowari, C. (May 1984). "Horizontal Axis Wind Turbine Post Stall Airfoil Characteristics Synthesization." Prepared for the Horizontal-Axis Wind Turbine Technology Workshop, Cleveland, Ohi.

Tangler, J.L. (January 1987). “HAWT Performance Prediction Code for Personal Computers." Solar Energy Research Institute.

Toll, T.A.; Ivey, M.F. (1945). Wind Tunnel Investigation of a Rectangular NACA 2212 Airfoil with Semispan Ailerons and with Nonperforated, Balanced Split Flaps For Use as Aerodynamic Brakes. NACA ARR No. L5B17. Prepared for the National Advisory Committee for Aeronautics.

Wentz, W.H.; Snyder, M.H. (May 1980). NASA CR-159856 WER-10: Feasibility Study of Aileron and Spoiler Control Systems For Large Horizontal Axis Wind Turbines. Work Performed by Wichita State University. Prepared for the U.S. Department Of Energy, Energy Technology Division, Washington, D.C.

Wentz, W.H.; Snyder, M.H.; Ahmed A. (October 1984). Wind Energy Report No. 23 (Revised): Reflection Plane Test of Control Devices on a Thick Airfoil at High Angle of Attack. Release date October 1986. Work performed by the Wind Energy Laboratory, Wichita State University, Wichita, Kansas. Work Performed for NASA Grant No. NSG 3277.

Wentz, W.H. (May 1993). "Aerodynamic Characteristics of Truncated Airfoils at High Angles of Attack." Prepared for SAE General, Corporate, \& Regional Aviation Meeting \& Exposition. Paper No. 931227. 
Appendix A

Wind Tunnel Aerodynamic Data 
Table 1A: NACA Double Split Flap 112 Degrees 2-D Wind Tunnel Data (\% Chord Device) / (\% Chord Gap)

\begin{tabular}{|c|c|c|c|c|c|c|c|c|c|c|c|c|c|c|c|c|c|c|c|}
\hline \multirow{2}{*}{$\begin{array}{l}\text { AOA } \\
\text { Dogreos }\end{array}$} & \multicolumn{4}{|c|}{ Top 15/5, Bottom 15/5 } & \multirow{2}{*}{$\begin{array}{l}\mathrm{AOA} \\
\text { Degrees }\end{array}$} & \multicolumn{4}{|c|}{ Top 20/5, Bottom 20/5 } & \multirow{2}{*}{$\begin{array}{l}\mathrm{AOA} \\
\text { Degrees }\end{array}$} & \multicolumn{4}{|c|}{ Top 20/5, Bottom 15/5 } & \multirow{2}{*}{$\mid \begin{array}{l}\mathrm{AOA} \\
\text { Degrees }\end{array}$} & \multicolumn{4}{|c|}{ Top 15/5, Bottom 20/5 } \\
\hline & cl & $C_{d}$ & $c_{s}$ & $\mathrm{C}_{\mathrm{m}(1 / 4)}$ & & $c_{1}$ & $C_{d}$ & $c_{s}$ & $C_{n n(1 / 4)}$ & & cl & $C_{d}$ & $c_{s}$ & $C_{m(1 / 4)}$ & & cl & $C_{d}$ & cs & $C_{n(1 / 4)}$ \\
\hline-6 & -0.033 & 0.445 & -0.439 & -0.148 & -6.1 & -0.209 & 0.604 & -0.578 & -0.198 & -6 & -0.343 & 0.522 & -0.483 & -0.171 & -6.1 & 0.086 & 0.526 & 0.532 & $\overline{0.171}$ \\
\hline-3 & -0.181 & 0.461 & -0.451 & -0.151 & -3 & -0.158 & 0.627 & -0.617 & -0.204 & -2.7 & -0.263 & 0.540 & -0.527 & -0.175 & -3 & 0.115 & 0.546 & -0.552 & -0.178 \\
\hline 0.1 & -0.141 & 0.465 & -0.465 & -0.151 & 0.1 & -0.130 & 0.655 & -0.655 & -0.211 & 0.2 & -0.206 & 0.556 & -0.557 & -0.181 & 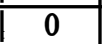 & 0.176 & 0.546 & -0.546 & -0.176 \\
\hline 3.1 & -0.066 & 466 & -0.469 & -0.151 & 3 & -0.103 & 0.652 & -0.657 & -0.212 & 3.1 & -0.152 & & -0.564 & & 3.1 & 012 & 565 & & 0.181 \\
\hline 6.1 & 0.010 & .462 & -0.458 & -0.149 & 6 & -0.059 & 0.644 & -0.646 & -0.208 & 6 & -0.093 & 0.549 & -0.556 & -0.178 & 6 & 0.045 & 0.556 & 0.548 & -0.179 \\
\hline 9.1 & 0.066 & 450 & -0.434 & -0.145 & 9 & -0.015 & 0.640 & -0.635 & -0.206 & 9.1 & 0.054 & 0.532 & -0.534 & -0.172 & 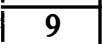 & 0.087 & 0.559 & -0.539 & -0.180 \\
\hline 12.1 & 0118 & & -0.418 & -0.1 & 11.9 & 0.015 & 0.640 & -0.6 & -0.206 & 12.1 & -0.003 & & -0.508 & 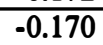 & 12 & 0.115 & 0.574 & & \\
\hline 15 & 0.156 & .457 & -0.401 & -0.147 & 14.9 & 0.054 & 0.630 & -0.595 & -0.202 & 15.2 & 0.051 & 0.516 & -0.485 & -0.169 & 15 & 0.151 & 0.572 & 0.513 & -0.182 \\
\hline 18 & 0.191 & 456 & -0.375 & -0.148 & 18 & 0.106 & 0.618 & -0.555 & -0.198 & 18.2 & 0.090 & 0.502 & -0.449 & & 18.1 & 0.190 & 0.566 & .479 & -0.179 \\
\hline 21.1 & 0.227 & & -0.340 & -0.145 & 21 & 0.136 & 0.6 & & -0.194 & 21 & 0.13 & 499 & -0.419 & -0.161 & 21 & 0.230 & 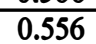 & & -0.177 \\
\hline 24.1 & 0.230 & 0.496 & -0.358 & -0.160 & 24 & 0.154 & 0.662 & -0.542 & -0.209 & 24.2 & 0.137 & 0.547 & -0.443 & -0.177 & 24.1 & 0.191 & 0.638 & .505 & -0.205 \\
\hline 27.1 & 0.165 & 0.554 & -0.4 & -0.1 & 27 & $\overline{0.17}$ & 0.6 & -0 . & -0.215 & 27.1 & 0.1 & 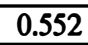 & -0.442 & -0.178 & 26.9 & 0.171 & 666 & & -0.214 \\
\hline 30.1 & 0.183 & 0.633 & -0.456 & -0.203 & 30 & 0.128 & 0.689 & -0 & -0.223 & 30 & 0.123 & 588 & -0.447 & -0.191 & 30.1 & 0.148 & 712 & .542 & -0.225 \\
\hline 33 & 0.193 & 630 & -0.431 & -0.204 & 33 & 115 & 20 & & -0.233 & 33.1 & & 677 & -0.455 & & 33 & 0.172 & .732 & & -0.234 \\
\hline 36.1 & 0.215 & 57 & -0.404 & -0.2 & 36 & 0.090 & 0.7 & & -0.239 & 36.1 & 0.247 & 686 & -0.409 & -0.225 & 35.9 & 0.183 & 31 & & -0.242 \\
\hline 39.1 & 0.221 & & -0.392 & -0.223 & 39 & 0.114 & 0.7 & -0. & -0.251 & 39.1 & 0.274 & & -0.362 & & 39 & 0.156 & 41 & & -0.241 \\
\hline 42.1 & 0.252 & & -0. & -0.241 & 42 & & & & -0.255 & 42 & 03 & & & & 42 & 0.117 & 774 & & -0.255 \\
\hline 45.2 & 0.275 & 0.800 & -0.369 & -0.261 & 45 & 0.134 & 0.799 & -0.471 & -0.265 & 45.1 & 0.308 & 0.775 & -0.329 & -0.253 & 45 & 0.087 & 0.787 & 495 & -0.258 \\
\hline 48 & 0.280 & & -0353 & -0.276 & 48.1 & & & & & 48 & & & & & 47.9 & & & & -0.269 \\
\hline 51 & 0.319 & 895 & -0.315 & -0.295 & 51 & .128 & 0.857 & -0. & -0.282 & 51.2 & .338 & 0.899 & -0.300 & -0.297 & 51 & 0.108 & 0.859 & 57 & -0.283 \\
\hline 54 & 0.309 & 0.942 & -0.304 & -0.309 & 53.9 & 0.151 & 0.883 & -0.3 & -0.295 & 54.2 & 0.351 & 0.940 & -0.265 & -0.311 & 53.9 & 0.130 & 0.891 & & -0.292 \\
\hline 57.1 & & & 00267 & -0.3 & 57 & 0182 & 6 & & -0.308 & 57 & & 0.984 & -0.235 & -0.328 & 57 & 0.153 & 009 & 66 & -0.301 \\
\hline 60 & 0.320 & 031 & -0.238 & -0.343 & 59.9 & 0.216 & 0.973 & -0.302 & -0.324 & 60.1 & 0.343 & 1.023 & -0.213 & -0.343 & 59.9 & 0.195 & 0.973 & 319 & -0.323 \\
\hline 63 & 0.312 & 12 & -0.209 & -0.3 & 63.1 & 0.241 & 1.028 & -0.2 & -0.3 & 63 & 0.339 & 1.064 & -0.181 & -0.357 & 62.9 & 0.208 & 1.024 & 282 & -0.342 \\
\hline 66.1 & & & 10 & -03 & 65.9 & & & & -0.3 & 66 & & & & & 65.9 & 0.210 & 1.077 & 48 & -0.357 \\
\hline 69.3 & 0.263 & 1.154 & -0.162 & -0.387 & 69 & 0.240 & 1.115 & -0.176 & -0.376 & 69.1 & 0.297 & 1.144 & -0.131 & -0.384 & 68.9 & 0.217 & 1.124 & 0.202 & -0.378 \\
\hline 72 & 0.236 & 1.175 & -0.139 & -0.398 & 72 & 0.239 & 1.157 & -0.131 & -0.397 & 72.1 & 0.263 & 1.174 & -0.111 & -0.400 & 71.8 & 0.214 & 1.152 & .157 & -0.387 \\
\hline 75 & & & & 0.11 & 75 & & & & & 75 & & & & & 74.9 & 0.200 & 179 & & -0.397 \\
\hline 78.3 & 0.152 & 1.214 & -0.097 & -0.411 & 78 & 0.198 & 1.212 & -0.058 & -0.416 & 78.1 & 0.185 & 1.214 & -0.069 & -0.413 & 78 & 0.172 & 1.203 & 82 & -0.408 \\
\hline 81 & 0.095 & 1.211 & -0.096 & -0.410 & 81.1 & 0.147 & 1.225 & -0.045 & -0.420 & 81.2 & 0.120 & 1.208 & -0.066 & -0.413 & 80.9 & 0.127 & 1.220 & 667. & -0.413 \\
\hline 84.1 & & & & & 84 & & & & & 84 & & & & & 83.9 & & 1.223 & & -0.415 \\
\hline 87 & 0.014 & 1.201 & -0.049 & -0.404 & 87 & 0.066 & 1.216 & 0.0 & -0.417 & 87 & 0.049 & 1.206 & -0.014 & -0.415 & 87 & 0.044 & 1.221 & -0.020 & -0.415 \\
\hline 90 & -0.081 & 1.201 & -0.081 & -0.401 & 89.9 & -0.086 & 1.214 & -0.088 & -0.415 & 89.9 & -0.103 & 1.206 & -0.105 & -0.413 & 89.9 & -0.093 & 1.216 & -0.096 & -0.415 \\
\hline
\end{tabular}




\begin{tabular}{|c|c|c|c|c|c|c|c|c|c|c|c|c|c|c|c|c|c|c|c|}
\hline \multicolumn{20}{|c|}{$\begin{array}{c}\text { Table 2.1A: NACA Double Split Flap } 60 \text { Degrees 2-D Wind Tunnel Data } \\
\text { (\% Chord Device)/( } \% \text { Chord Gap) }\end{array}$} \\
\hline $\mathrm{AOA}$ & \multicolumn{4}{|c|}{ Top 4010, Bottom 4010 } & \multirow{2}{*}{\begin{tabular}{|l}
$\mathrm{AOA}$ \\
Degrecs
\end{tabular}} & \multicolumn{4}{|c|}{ Top 3515, Bottom 331/5 } & \multirow{2}{*}{$\begin{array}{l}\text { AOA } \\
\text { Degrecs }\end{array}$} & \multicolumn{4}{|c|}{ Top 30/10, Boftom 30/10 } & \multirow{2}{*}{\begin{tabular}{l|l} 
AOA \\
Dogreos
\end{tabular}} & \multicolumn{4}{|c|}{ Top 20120, Bottom 20/20 } \\
\hline Degres & c & $c_{d}$ & $\overline{c_{3}}$ & $C_{m(1 / 4)}$ & & $c_{1}$ & $\overline{c d}$ & $c_{s}$ & $\mathrm{c}_{\mathrm{m}(1 / 4)}$ & & C1 & $\mathrm{cdd}_{\mathrm{d}}$ & $c_{8}$ & $\mathbf{c}_{\mathrm{m}(1 / 4)}$ & & a & $c_{d}$ & $\overline{c_{3}}$ & $\mathrm{C}_{(\mathrm{m})}(1 / 4)$ \\
\hline-6.1 & -0.158 & 1.243 & -1.219 & -0.424 & -6.1 & -0.233 & 0.999 & -0.969 & -0.336 & \begin{tabular}{|l|}
-5.9 \\
\end{tabular} & -0.301 & 0.878 & -0.842 & -0.293 & .6 & -0.153 & $\begin{array}{c}.702 \\
\end{array}$ & $\begin{array}{c}-0.682 \\
\end{array}$ & -0.232 \\
\hline-3 & -0.082 & 1.248 & -1.242 & -0.426 & -3 & -0.153 & 1.013 & -1.003 & -0.339 & \begin{tabular}{|c|}
-3.1 \\
\end{tabular} & -0.209 & 0.888 & -0.876 & -0.296 & .2 .9 & -0.066 & 0.705 & -0.701 & -0.232 \\
\hline 0.1 & -0.027 & 1.228 & -1.228 & -0.410 & 0.1 & -0.077 & 1.021 & -1.021 & -0.343 & 0 & -0.121 & 0.901 & -0.901 & -0.300 & 0 & -0.074 & 0.706 & -0.706 & $\begin{array}{c}-0.232 \\
-0.232\end{array}$ \\
\hline 3.1 & 0.017 & 1.239 & -1.236 & -0.421 & 3 & -0.009 & 1.014 & -1.013 & -0.341 & 3 & -0.021 & 0.896 & -0.895 & -0.298 & 3.1 & 0.045 & 0.709 & -0.706 & -0.232 \\
\hline $\begin{array}{l}6.1 \\
\end{array}$ & 0.066 & 1.244 & -1.230 & -0.424 & $\frac{\pi}{6}$ & 0.058 & $\begin{array}{l}1.013 \\
\end{array}$ & -1.001 & -0.336 & $\frac{5}{6}$ & 0.071 & 0.0796 & -0.884 & $\begin{array}{l}-0.230 \\
-0.297\end{array}$ & $\frac{1.1}{6}$ & $\frac{0.045}{0.167}$ & 0.708 & -0.686 & $\frac{-0.232}{-0.232}$ \\
\hline 9.1 & 0.116 & 1.228 & -1.194 & -0.426 & 9 & 0.133 & 0.999 & -0.965 & -0.330 & 9 & 0.167 & 0.890 & -0.852 & -0.294 & 9.1 & 0.311 & 0.705 & -0.647 & -0.230 \\
\hline 12.2 & 0.110 & 1.197 & -1.125 & $\frac{-0.4214}{-0.41}$ & 12.1 & 0.203 & 0.983 & -0.919 & $\begin{array}{c}-0.3528 \\
-0.32\end{array}$ & 12 & $\begin{array}{l}0.262 \\
0.25\end{array}$ & \begin{tabular}{|l}
0.873 \\
\end{tabular} & -0.000 & $\begin{array}{l}-0.294 \\
-0.288\end{array}$ & $\frac{1.1}{12.1}$ & 0.04 & \begin{tabular}{|l}
0.693 \\
0.03
\end{tabular} & $\begin{array}{l}-0.041 \\
-0.580\end{array}$ & $\frac{-0.250}{-0.225}$ \\
\hline 15 & 0.340 & 1.145 & -1.018 & -0.390 & 15 & 0.274 & 0.983 & -0.878 & -0.328 & 15 & 0.363 & 0.854 & -0.731 & -0.280 & 15.1 & 0.612 & 0.680 & -0.497 & -0.220 \\
\hline 18 & 1.213 & 0.972 & -0.549 & -0.311 & 17.9 & 0.984 & 0.886 & -0.541 & $\begin{array}{r}-0.290 \\
\end{array}$ & 18 & 0.490 & 0.838 & -0.646 & $\begin{array}{l}-0.270 \\
-0.275\end{array}$ & \begin{tabular}{|l|l}
18.1 \\
\end{tabular} & 0.0759 & $\begin{array}{l}0.667 \\
\end{array}$ & $\begin{array}{l}-0.4717 \\
-0.398\end{array}$ & $\frac{0.220}{-0.216}$ \\
\hline 21 & 1.523 & 0.912 & -0.305 & -0.300 & 21 & 1.157 & 0.885 & -0.411 & -0.287 & \begin{tabular}{|l}
20.9 \\
\end{tabular} & 0.933 & 0.863 & -0.473 & -0.281 & 21 & 0.912 & 0.647 & -0.278 & -0.210 \\
\hline 24 & 1.432 & 0.921 & $\begin{array}{l}-0.259 \\
\end{array}$ & -0.300 & 23.9 & 1.101 & $\begin{array}{l}0.949 \\
\end{array}$ & -0.422 & $\frac{-0.311}{-0.31}$ & 24 & $\begin{array}{l}0.992 \\
\end{array}$ & $\begin{array}{l}0.919 \\
\end{array}$ & $\begin{array}{l}-0.4156 \\
-0.43\end{array}$ & -0.300 & 23.9 & 0.663 & $\begin{array}{l}0.0471 \\
\end{array}$ & $\begin{array}{l}-0.476 \\
-0.436\end{array}$ & $\frac{-0.251}{-0.251}$ \\
\hline 27 & 1.206 & 1.052 & -0.390 & -0.348 & 26.9 & 1.017 & 1.043 & -0.470 & -0.344 & 27.1 & 0.938 & 0.990 & -0.454 & -0.326 & 27 & 0.703 & 0.829 & -0.420 & -0.270 \\
\hline 30.1 & 1.126 & 1.173 & -0.450 & -0.395 & 29.9 & 0.944 & 1.131 & -0.510 & -0.379 & 30 & 0.897 & 1.066 & -0.475 & -0.354 & 29.9 & 0.693 & 0.884 & $\begin{array}{c}-0.420 \\
-0.421\end{array}$ & $\frac{-0.289}{-0.289}$ \\
\hline 33 & 1.072 & 1.248 & -0.463 & -0.424 & 32.9 & 0.882 & 1.216 & -0.542 & -0.413 & \begin{tabular}{|l|}
33.1 \\
\end{tabular} & 0.822 & 1.135 & -0.502 & -0.380 & 33.1 & 0.639 & 0.925 & -0.426 & -0.309 \\
\hline 36 & 0.878 & 1.363 & -0.586 & -0.469 & 35.9 & 0.846 & 1.295 & -0.553 & -0.444 & 36 & 0.785 & 1.203 & -0.512 & -0.407 & 36 & 0.595 & 0.977 & -0.440 & -0.328 \\
\hline 39.1 & 0.875 & 1.373 & $\begin{array}{r}-0.513 \\
\end{array}$ & $\begin{array}{l}-0.400 \\
-0.40\end{array}$ & 39 & 0.0795 & $\frac{1.230}{1.330}$ & -0.533 & $\begin{array}{c}-0.459 \\
\end{array}$ & 39 & 0.719 & 1.249 & -0.518 & -0.427 & 39.1 & 0.536 & 0.992 & -0.431 & -0.328 \\
\hline 42.1 & 0.678 & 1.462 & -0.631 & -0.510 & 42.1 & 0.599 & 1.386 & -0.627 & -0.478 & \begin{tabular}{|l|}
41.9 \\
\end{tabular} & 0.673 & 1.273 & -0.498 & -0.437 & 41.9 & 0.459 & 1.005 & $\begin{array}{l}-0.442 \\
-0.45\end{array}$ & $\frac{0.020}{-0.335}$ \\
\hline 45.1 & 0.540 & 1.479 & -0.661 & -0.521 & 44.9 & 0.522 & 1.424 & -0.640 & -0.499 & \begin{tabular}{|l}
44.9 \\
\end{tabular} & 0.550 & 1.302 & -0.534 & -0.443 & 45 & 0.401 & 1.050 & -0.459 & -0.347 \\
\hline$\frac{4.1}{48}$ & 0.482 & 1.475 & $\begin{array}{c}-0.629 \\
\end{array}$ & -0.518 & 477.8 & $\begin{array}{l}0.428 \\
0\end{array}$ & $\frac{1.727}{1.416}$ & -0.634 & $\frac{-0.493}{-0.493}$ & $\frac{44 .}{48}$ & $\begin{array}{l}0.458 \\
\end{array}$ & $\begin{array}{l}1.309 \\
\end{array}$ & $\begin{array}{l}-0.536 \\
-0.53\end{array}$ & $\begin{array}{l}-0.445 \\
-0.453\end{array}$ & $\frac{75}{48}$ & 0.4019 & $\frac{1.050}{1.084}$ & $\begin{array}{l}-0.4559 \\
-0.459\end{array}$ & $\frac{-0.041}{-0.365}$ \\
\hline 51.1 & 0.322 & 1.518 & -0.703 & -0.537 & 50.9 & 0.289 & 1.423 & -0.674 & -0.494 & \begin{tabular}{|l}
50.9 \\
\end{tabular} & 0.337 & 1.340 & -0.584 & -0.469 & 51.1 & 0.284 & 1.101 & -0.470 & -0.370 \\
\hline 54 & 0.143 & 1.531 & -0.784 & -0.547 & 53.8 & 0.245 & $\frac{1.424}{1.42}$ & -0.643 & -0.494 & \begin{tabular}{|l|}
53.9 \\
\end{tabular} & 0.255 & $\frac{1.345}{1.345}$ & -0.587 & -0.466 & 54 & 0.225 & $\frac{1.136}{1.13}$ & $\begin{array}{l}-0.485 \\
\end{array}$ & $\frac{-0.0783}{-0.383}$ \\
\hline 56.9 & 0.211 & 1.531 & -0.659 & -0.549 & 57 & 0.139 & 1.426 & -0.660 & -0.497 & \begin{tabular}{|c|}
56.9 \\
\end{tabular} & 0.175 & 1.326 & -0.578 & -0.457 & 57 & 0.173 & 1.159 & -0.486 & -0.390 \\
\hline 60.1 & -0.044 & 1.534 & $\begin{array}{l}0.802 \\
\end{array}$ & -0.551 & 59.8 & 0.085 & $\begin{array}{l}1.428 \\
\end{array}$ & -0.645 & -0.504 & 60 & 0.039 & 1.329 & -0.630 & -0.463 & 60 & 0.107 & 1.176 & -0.495 & -0.398 \\
\hline$\frac{0.1}{63}$ & $\frac{-0.044}{-0.051}$ & $\frac{1.034}{1.522}$ & $\begin{array}{c}0.002 \\
-0.736\end{array}$ & $\frac{0.050}{-0.540}$ & $\frac{67.0}{62.8}$ & $\begin{array}{c}0.000 \\
-0.067\end{array}$ & $\frac{1.420}{1.420}$ & $\begin{array}{l}-0.045 \\
-0.708\end{array}$ & $\frac{-0.004}{-0.496}$ & $\frac{00}{63}$ & $\begin{array}{l}.0 .065 \\
\end{array}$ & $\frac{1.029}{1.322}$ & $\begin{array}{c}-0.030 \\
-0.658\end{array}$ & $\begin{array}{l}-0.405 \\
-0.459\end{array}$ & 63.1 & \begin{tabular}{|l|l|l}
0.044 \\
\end{tabular} & $\frac{1.170}{1.171}$ & $\begin{array}{l}-0.490 \\
-0.491\end{array}$ & $\frac{-0.090}{-0.404}$ \\
\hline 66.1 & -0.257 & 1.463 & -0.827 & -0.507 & 65.9 & -0.160 & $\frac{1.420}{1.420}$ & -0.726 & -0.497 & 65.9 & -0.178 & 1.316 & -0.700 & -0.458 & 66 & -0.005 & 1186 & -0.487 & $\frac{0.0405}{-0.45}$ \\
\hline 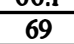 & -0.236 & 1.479 & $\begin{array}{c}-0.751 \\
\end{array}$ & -0.506 & 68.9 & -0.250 & 1.398 & -0.736 & -0.487 & 69 & -0.251 & 1.280 & -0.693 & $\begin{array}{l}-0.430 \\
\end{array}$ & 68.9 & -0.081 & 1.191 & $\begin{array}{l}-0.504 \\
\end{array}$ & $\begin{array}{l}-0.402 \\
-0.04\end{array}$ \\
\hline 72 & -0.467 & 1.491 & -0.905 & -0.530 & \begin{tabular}{|l|l|}
71.9 \\
\end{tabular} & -0.363 & 1.360 & -0.767 & $\begin{array}{l}-0.467 \\
\end{array}$ & \begin{tabular}{|l}
71.9 \\
\end{tabular} & $\begin{array}{c}-0.323 \\
\end{array}$ & 1.276 & $\begin{array}{l}-0.703 \\
\end{array}$ & -0.440 & 72 & -0.135 & 1.205 & $\begin{array}{c}-0.501 \\
\end{array}$ & -0.412 \\
\hline$\frac{12}{75}$ & $\frac{-0.401}{-0.424}$ & $\frac{1.441}{1.481}$ & $\begin{array}{l}-0.905 \\
-0.793\end{array}$ & $\frac{0.030}{-0.516}$ & \begin{tabular}{|l|l|}
74.9 \\
\end{tabular} & $\begin{array}{l}-0.000 \\
-0.507\end{array}$ & $\frac{1.000}{1.320}$ & $\frac{-0.101}{-0.833}$ & $\frac{-0.401}{-0.454}$ & \begin{tabular}{|l|}
74.9 \\
\end{tabular} & $\begin{array}{l}-0.394 \\
-0.394\end{array}$ & $\frac{1.270}{1.230}$ & $\begin{array}{l}-0.105 \\
-0.701\end{array}$ & $\frac{-0.440}{-0.423}$ & $\frac{12}{75}$ & $\frac{-0.1359}{-0.189}$ & $\begin{array}{l}1.205 \\
1.193\end{array}$ & $\begin{array}{c}-0.001 \\
-0.491\end{array}$ & $\frac{-0.412}{-0.414}$ \\
\hline 78 & -0.674 & 1.425 & -0.956 & -0.493 & 78 & -0.644 & 1.276 & -0.895 & -0.432 & 78 & -0.488 & 1.237 & -0.735 & -0.425 & 77.9 & -0.242 & 1.201 & -0.488 & -0.408 \\
\hline$\frac{70}{81}$ & $\begin{array}{l}-0.014 \\
-0.857\end{array}$ & $\begin{array}{l}.425 \\
1.397\end{array}$ & $\begin{array}{l}-0.900 \\
-1.065\end{array}$ & $\begin{array}{c}-0.4758 \\
-0.48\end{array}$ & 80 & $\begin{array}{l}-0.0413 \\
\end{array}$ & $\frac{1.280}{1.250}$ & $\begin{array}{l}-0.070 \\
-0.902\end{array}$ & $\frac{-0.452}{-0.430}$ & \begin{tabular}{|c|}
80.8 \\
\end{tabular} & $\begin{array}{l}-0.558 \\
-0.5\end{array}$ & $\frac{1.257}{1.197}$ & $\begin{array}{l}-0.1352 \\
-0.742\end{array}$ & $\begin{array}{l}-0.420 \\
-0.409\end{array}$ & 81 & $\begin{array}{l}-0.242 \\
-0.299\end{array}$ & $\frac{1.201}{1.206}$ & $\begin{array}{l}-0.400 \\
-0.484\end{array}$ & $\begin{array}{l}-0.408 \\
-0.408\end{array}$ \\
\hline 84.1 & -0.969 & 1.310 & -1.098 & -0.446 & $\begin{array}{l}83.8 \\
\end{array}$ & -0.790 & 1.204 & -0.915 & -0.404 & \begin{tabular}{|l|l|}
83.9 \\
\end{tabular} & -0.613 & 1.185 & -0.735 & -0.405 & 84 & -0.320 & 1.199 & -0.443 & -0.409 \\
\hline $\begin{array}{l}0.14 .1 \\
86.9\end{array}$ & -0.909 & $\frac{1.010}{1.225}$ & $\begin{array}{l}-1.070 \\
-1.173\end{array}$ & $\frac{-0.440}{-0.411}$ & $\begin{array}{l}86.0 \\
86.8\end{array}$ & -0.852 & $\frac{1.204}{1.195}$ & -0.917 & $\frac{-0.404}{-0.402}$ & \begin{tabular}{|l|}
80.9 \\
86.9
\end{tabular} & $\begin{array}{l}-0.056 \\
-0.65\end{array}$ & $\frac{1.105}{1.157}$ & $\begin{array}{l}-0.1317 \\
-0.717\end{array}$ & $\frac{-0.405}{-0.393}$ & 87.1 & $\frac{-0.320}{-0.331}$ & $\frac{1.197}{1.231}$ & $\begin{array}{l}-0.4453 \\
-0.393\end{array}$ & $\frac{-0.4075}{-0.415}$ \\
\hline 89.9 & -1.201 & 1.114 & -1.203 & -0.370 & 89.9 & -0.891 & 1.108 & -0.893 & -0.372 & 90 & -0.674 & 1.148 & -0.674 & -0.387 & 89.9 & -0.350 & 1.223 & -0.352 & -0.422 \\
\hline
\end{tabular}




\begin{tabular}{|c|c|c|c|c|c|c|c|c|c|c|c|c|c|c|c|c|c|c|c|}
\hline \multicolumn{20}{|c|}{$\begin{array}{l}\text { Table 2.2A: NACA Double Split Flap } 60 \text { Degrees 2-D Wind Tunnel Data } \\
\text { (\% Chord Device) } /(\% \text { Chord Gap) }\end{array}$} \\
\hline \multirow{2}{*}{$\begin{array}{l}\text { AOA } \\
\text { Degy rees }\end{array}$} & \multicolumn{4}{|c|}{ Top 20/4, Bottom 20/4 } & \multirow{2}{*}{$\begin{array}{l}\text { AOA } \\
\text { Degrees }\end{array}$} & \multicolumn{4}{|c|}{ Top 20/4, Bottom 2019 } & \multirow{2}{*}{\begin{tabular}{l|l|} 
AOA \\
Deggees
\end{tabular}} & \multicolumn{4}{|c|}{ Top 20/4, Bottom 20/14 } & \multirow{2}{*}{$\begin{array}{l}\text { AOA } \\
\text { Degreos }\end{array}$} & \multicolumn{4}{|c|}{ Top 20/0, Botfom 20/14 } \\
\hline & $\mathbf{c l}_{1}$ & $c_{d}$ & $c_{s}$ & $C_{m(1 / 4)}$ & & Cl & Cd & $c_{s}$ & $C_{m(1 / 4)}$ & & $\mathbf{C l}$ & $C_{d}$ & Cs & $C_{m(1 / 4)}$ & & a & $c_{d}$ & $C_{3}$ & $C_{m(1 / 4)}$ \\
\hline-6 & -0.180 & 0.639 & -0.617 & -0.211 & -6 & -0.225 & 0.631 & -0.604 & -0.208 & -6 & -0.283 & 0.638 & -0.605 & -0.208 & -6 & -0.406 & 0.687 & -0.641 & -0.227 \\
\hline-3 & -0.072 & 0.638 & -0.633 & -0.210 & -2.9 & -0.129 & 0.631 & -0.624 & -0.208 & -2.9 & -0.186 & 0.643 & -0.633 & -0.210 & -3 & -0.317 & 0.692 & -0.674 & -0.227 \\
\hline 0 & 0.019 & 0.630 & -0.630 & -0.208 & 0 & -0.034 & 0.632 & -0.632 & -0.207 & 0 & -0.078 & 0.643 & -0.643 & -0.209 & 0 & -0.215 & 0.692 & -0.692 & -0.228 \\
\hline 3 & 0.105 & 0.622 & -0.616 & -0.205 & 3 & 0.073 & 0.623 & -0.619 & -0.205 & 3 & 0.036 & 0.636 & -0.633 & -0.209 & 3 & -0.103 & 0.685 & -0.690 & -0.227 \\
\hline 6 & 0.203 & 0.606 & -0.582 & -0.200 & 6 & 0.173 & 0.620 & -0.598 & -0.204 & 6 & 0.147 & 0.629 & -0.610 & -0.207 & 6.1 & 0.008 & 0.675 & -0.671 & -0.223 \\
\hline 9.1 & 0.138 & 0.615 & -0.586 & -0.203 & 9 & 0.085 & 0.610 & -0.589 & -0.201 & 9 & 0.250 & 0.617 & -0.570 & -0.204 & 9.1 & 0.119 & 0.661 & -0.634 & -0.217 \\
\hline 12 & 0.227 & 0.618 & -0.557 & -0.202 & 12 & 0.189 & 0.610 & -0.558 & -0.203 & 12 & 0.105 & 0.636 & -0.600 & -0.210 & 12 & 0.062 & 0.630 & -0.604 & -0.207 \\
\hline 15.1 & 0.325 & 0.615 & -0.509 & -0.203 & 15 & 0.282 & 0.593 & -0.500 & -0.194 & 15 & 0.209 & 0.620 & -0.545 & -0.204 & 15.1 & 0.219 & 0.604 & -0.526 & -0.198 \\
\hline 18.1 & 0.495 & 0.599 & -0.416 & -0.197 & 18 & 0.450 & 0.564 & -0.397 & -0.186 & 18 & 0.374 & 0.595 & -0.450 & -0.196 & 18 & 0.404 & 0.572 & -0.419 & -0.187 \\
\hline 21 & 0.871 & 0.582 & -0.231 & -0.191 & 21 & 0.824 & 0.570 & -0.237 & -0.188 & 21.1 & 0.645 & 0.547 & -0.278 & -0.178 & 21.1 & 0.756 & 0.559 & -0.250 & -0.188 \\
\hline 24.1 & 0.900 & 0.682 & -0.255 & -0.221 & 24 & 0.843 & 0.669 & -0.268 & -0.220 & 24 & 0.792 & 0.664 & -0.284 & -0.218 & 24 & 0.884 & 0.630 & -0.216 & -0.206 \\
\hline & & & & & 27 & 0.818 & 0.760 & -0.306 & -0.249 & 27 & 0.744 & 0.731 & -0.313 & -0.241 & 27 & 0.795 & 0.703 & -0.265 & -0.232 \\
\hline 30.2 & 0.857 & 0.850 & -0.304 & -0.280 & 30 & 0.803 & 0.833 & -0.320 & -0.275 & 30 & 0.723 & 0.808 & -0.338 & -0.268 & 30 & 0.749 & 0.771 & -0.293 & -0.256 \\
\hline 33.1 & 0.847 & 0.923 & -0.311 & -0.309 & 33 & 0.782 & 0.914 & -0.341 & -0.304 & 33 & 0.699 & 0.866 & -0.345 & -0.289 & 32.9 & 0.727 & 0.847 & -0.316 & -0.283 \\
\hline 36.1 & 0.793 & 0.988 & -0.331 & -0.334 & 35.9 & 0.736 & 0.978 & -0.361 & -0.330 & 36 & 0.667 & 0.925 & -0.357 & -0.307 & 36.1 & 0.691 & 0.927 & -0.342 & -0.310 \\
\hline 39.1 & 0.753 & 1.048 & -0.338 & -0.351 & 39 & 0.686 & 1.029 & -0.368 & -0.343 & 39 & 0.605 & 0.975 & $\begin{array}{l}-0.377 \\
\end{array}$ & -0.325 & 39.1 & 0.661 & 0.997 & -0.357 & -0.337 \\
\hline 42 & 0.666 & 1.094 & -0.367 & -0.374 & 42 & 0.633 & 1.079 & -0.379 & -0.363 & 42 & 0.551 & 1.022 & -0.390 & -0.345 & 42 & 0.589 & 1.049 & -0.385 & -0.357 \\
\hline 45 & 0.624 & 1.126 & -0.355 & -0.384 & 44.9 & 0.570 & 1.109 & -0.384 & -0.378 & 45 & 0.510 & 1.061 & -0.390 & -0.356 & 45 & 0.533 & 1.091 & -0.395 & $\begin{array}{l}-0.368 \\
\end{array}$ \\
\hline 48 & 0.542 & 1.134 & -0.356 & -0.388 & 48 & 0.527 & 1.120 & -0.358 & -0.380 & 48 & 0.459 & 1.108 & -0.400 & -0.375 & 48 & 0.470 & 1.127 & -0.405 & -0.388 \\
\hline 51 & 0.426 & 1.161 & $\begin{array}{l}-0.399 \\
\end{array}$ & -0.383 & 50.9 & 0.412 & 1.143 & -0.401 & -0.388 & 51.1 & 0.377 & 1.119 & -0.409 & -0.381 & 51 & 0.376 & 1.146 & -0.429 & -0.392 \\
\hline 54 & 0.359 & 1.163 & -0.393 & -0.391 & 53.9 & 0.343 & 1.161 & -0.407 & -0.391 & 54 & 0.285 & 1.139 & -0.439 & -0.379 & 54 & 0.283 & 1.151 & -0.448 & $\begin{array}{r}-0.388 \\
\end{array}$ \\
\hline 57.1 & 0.303 & 1.163 & -0.377 & -0.397 & 56.9 & 0.266 & 1.172 & -0.417 & -0.399 & 57 & 0.242 & 1.163 & -0.431 & -0.393 & 57 & 0.254 & 1.169 & -0.424 & -0.402 \\
\hline 60.1 & 0.200 & 1.173 & -0.412 & -0.401 & 59.9 & 0.172 & 1.187 & -0.447 & -0.409 & 60 & 0.162 & 1.199 & -0.459 & -0.409 & 60 & 0.163 & 1.191 & -0.455 & -0.408 \\
\hline 63.1 & 0.120 & 1.201 & -0.436 & -0.409 & 62.9 & 0.103 & 1.201 & -0.456 & -0.414 & 63 & 0.088 & 1.189 & -0.461 & -0.406 & 63 & 0.121 & 1.194 & -0.434 & -0.407 \\
\hline 66.1 & 0.033 & 1.200 & -0.456 & -0.407 & 65.9 & 0.020 & 1.207 & -0.475 & -0.415 & 65.9 & 0.023 & 1.212 & $\begin{array}{l}-0.474 \\
\end{array}$ & -0.418 & 66 & 0.008 & 1.203 & $\begin{array}{l}-0.482 \\
\end{array}$ & -0.411 \\
\hline 69.1 & -0.049 & 1.184 & -0.468 & -0.406 & 68.9 & -0.081 & 1.191 & -0.504 & -0.408 & 68.9 & -0.029 & 1.208 & -0.462 & -0.412 & 69 & -0.046 & 1.198 & -0.473 & -0.410 \\
\hline 72.1 & -0.179 & 1.199 & -0.538 & -0.408 & 72.9 & -0.158 & 1.187 & -0.500 & -0.406 & 72 & -0.124 & 1.210 & -0.492 & -0.413 & 71.9 & -0.113 & 1.210 & -0.483 & -0.415 \\
\hline 75.1 & -0.246 & 1.185 & -0.542 & -0.397 & 74.9 & -0.209 & 1.178 & -0.509 & -0.399 & 75 & -0.179 & 1.188 & -0.481 & -0.400 & 75 & -0.184 & 1.192 & -0.487 & -0.404 \\
\hline 78 & -0.313 & 1.164 & -0.548 & -0.391 & 77.9 & -0.318 & 1.182 & -0.558 & -0.403 & 78 & -0.259 & 1.200 & -0.502 & -0.408 & 78 & -0.281 & 1.168 & -0.518 & -0.397 \\
\hline 81 & -0.364 & 1.147 & -0.539 & -0.371 & $\begin{array}{l}80.9 \\
\end{array}$ & -0.374 & 1.181 & -0.556 & -0.397 & 81 & -0.329 & 1.181 & -0.510 & -0.402 & 81 & $\begin{array}{l}-0.359 \\
\end{array}$ & 1.163 & -0.536 & -0.393 \\
\hline 84 & -0.460 & 1.148 & -0.577 & -0.387 & 83.9 & -0.421 & 1.177 & -0.543 & -0.394 & 84 & -0.364 & 1.172 & -0.484 & -0.397 & 84 & -0.420 & 1.144 & -0.537 & -0.387 \\
\hline 87 & -0.464 & 1.166 & -0.525 & -0.391 & 86.9 & -0.450 & 1.166 & -0.512 & -0.391 & 86.9 & -0.429 & 1.194 & -0.493 & -0.403 & 87 & -0.466 & 1.133 & -0.524 & $\begin{array}{l}-0.384 \\
\end{array}$ \\
\hline 90 & -0.498 & 1.168 & $\begin{array}{c}-0.498 \\
\end{array}$ & -0.389 & 89.9 & -0.489 & 1.177 & -0.491 & -0.394 & 89.9 & -0.450 & 1.167 & -0.452 & -0.391 & 90 & -0.496 & 1.134 & -0.496 & $\begin{array}{c}-0.381 \\
\end{array}$ \\
\hline
\end{tabular}


Table 2.3A: NACA Double Split Flap 60 Degrees 2-D Wind Tunnel Data (\% Chord Device) / (\% Chord Gap)

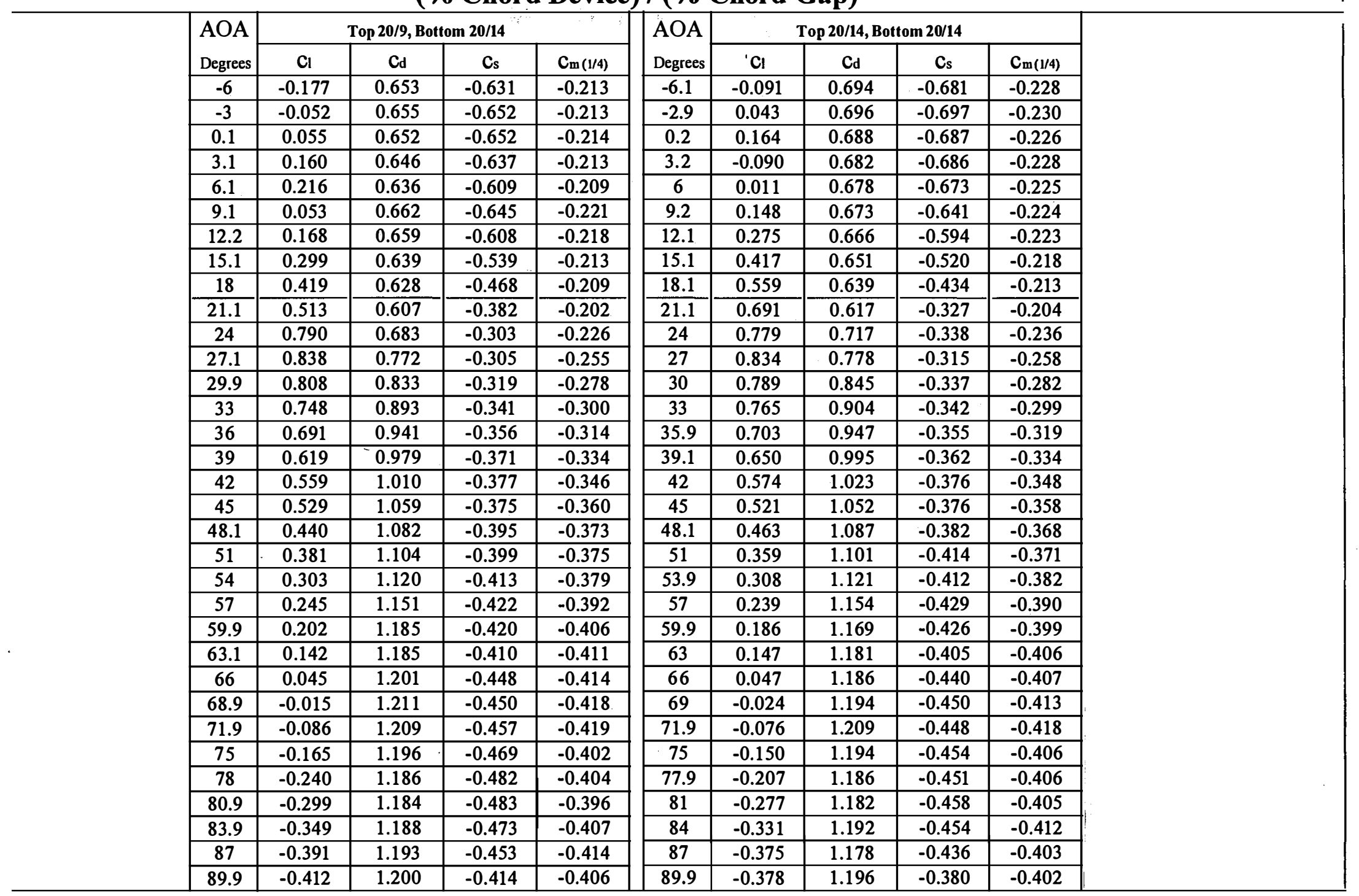




\section{Table 3.1A: Aileron with Smooth Hinge 2-D Wind Tunnel Data Stowed, 10, 30}

\begin{tabular}{|c|c|c|c|c|c|c|c|c|c|c|c|c|c|c|}
\hline \multirow{2}{*}{$\begin{array}{l}\mathrm{AOA} \\
\text { Degrees }\end{array}$} & \multicolumn{4}{|c|}{ Stowed } & \multirow{2}{*}{$\begin{array}{l}\mathrm{AOA} \\
\text { Degrees }\end{array}$} & \multicolumn{4}{|c|}{ Deflection 10} & \multirow{2}{*}{$\begin{array}{l}\text { AOA } \\
\text { Degrees }\end{array}$} & \multicolumn{4}{|c|}{ Deflection 30} \\
\hline & $\mathrm{Cl}_{\mathrm{I}}$ & $C_{d}$ & $c_{s}$ & $C_{m(1 / 4)}$ & & cl & $c_{d}$ & $C_{s}$ & $C_{m(1 / 4)}$ & & Cl & $c_{d}$ & $c_{s}$ & $C_{m(1 / 4)}$ \\
\hline-6 & -0.272 & 0.008 & 0.020 & -0.013 & -6 & -0.662 & 0.055 & 0.015 & -0.027 & -6 & -1.276 & 0.181 & -0.046 & -0.065 \\
\hline-3 & 0.024 & 0.002 & -0.003 & -0.010 & -3 & -0.485 & 0.036 & -0.011 & -0.021 & -3.1 & -1.115 & 0.155 & -0.094 & -0.057 \\
\hline 0.1 & 0.355 & 0.001 & 0.000 & -0.010 & 0.1 & -0.382 & 0.013 & -0.013 & -0.014 & 0.1 & -0.931 & 0.126 & -0.127 & -0.048 \\
\hline 3.1 & 0.671 & 0.004 & 0.033 & -0.010 & 3 & -0.089 & 0.007 & -0.012 & -0.012 & 3 & -0.845 & 0.108 & -0.152 & -0.042 \\
\hline 6.1 & 0.955 & 0.012 & 0.090 & -0.012 & 6.1 & 0.205 & 0.006 & 0.016 & -0.011 & 6 & -0.610 & 0.088 & -0.151 & -0.037 \\
\hline 9.1 & 1.005 & 0.028 & 0.132 & -0.017 & 9.3 & 0.514 & 0.005 & 0.078 & -0.011 & 9.1 & -0.364 & 0.075 & -0.131 & -0.032 \\
\hline 12 & 1.095 & 0.050 & 0.179 & -0.024 & 12 & 0.743 & 0.009 & 0.146 & -0.013 & 12.2 & -0.138 & 0.066 & -0.094 & -0.029 \\
\hline 15.2 & 1.162 & 0.079 & 0.228 & -0.032 & 15.1 & 0.951 & 0.025 & 0.224 & -0.016 & 15.1 & 0.082 & 0.061 & -0.037 & -0.026 \\
\hline 18.1 & 1.162 & 0.118 & 0.249 & -0.045 & 18.1 & 0.971 & 0.062 & 0.243 & -0.027 & 18.1 & 0.280 & 0.058 & 0.032 & -0.025 \\
\hline 21.2 & 1.087 & 0.196 & 0.210 & -0.066 & 21.1 & 0.934 & 0.104 & 0.239 & -0.039 & 21.1 & 0.432 & 0.057 & 0.102 & -0.024 \\
\hline 24.2 & 0.752 & 0.378 & -0.036 & -0.126 & 24.1 & 0.723 & 0.246 & 0.071 & -0.084 & 24.1 & $\begin{array}{l}0.488 \\
\end{array}$ & 0.067 & 0.138 & -0.028 \\
\hline 27.3 & 0.837 & 0.468 & -0.032 & -0.152 & 27.2 & 0.573 & 0.319 & -0.022 & -0.107 & 27.2 & 0.366 & 0.127 & 0.055 & -0.041 \\
\hline 30.1 & 0.970 & 0.584 & -0.018 & -0.190 & 30.1 & 0.659 & 0.396 & -0.012 & -0.130 & 30.1 & 0.243 & 0.186 & -0.039 & -0.067 \\
\hline 33.2 & 1.031 & 0.680 & -0.004 & -0.225 & 33 & 0.787 & 0.496 & 0.012 & -0.163 & 33.1 & 0.150 & 0.244 & -0.122 & -0.084 \\
\hline 36.1 & 1.087 & 0.783 & 0.007 & -0.258 & 36.2 & 0.871 & 0.595 & 0.034 & -0.196 & 36.4 & 0.227 & 0.296 & -0.104 & -0.101 \\
\hline 39.2 & 1.102 & 0.869 & 0.023 & -0.289 & 39 & 0.940 & 0.694 & 0.052 & -0.226 & 39.1 & 0.311 & 0.356 & -0.080 & -0.121 \\
\hline 42.1 & 1.115 & 0.961 & 0.035 & -0.322 & 42.2 & 0.970 & 0.780 & 0.074 & -0.262 & 42.1 & 0.428 & 0.437 & -0.037 & -0.144 \\
\hline 45.1 & 1.112 & 1.050 & 0.046 & -0.352 & 45.1 & 1.026 & 0.890 & 0.099 & -0.299 & 45.2 & 0.513 & 0.520 & -0.002 & -0.172 \\
\hline 48.1 & 1.115 & 1.159 & 0.055 & -0.410 & 48.1 & 1.031 & 0.962 & 0.125 & -0.324 & 48.2 & $\begin{array}{l}0.583 \\
\end{array}$ & 0.599 & 0.035 & -0.199 \\
\hline 51.1 & 1.089 & 1.238 & 0.070 & -0.433 & 51 & 1.034 & 1.058 & 0.138 & -0.353 & 51.1 & 0.652 & 0.684 & 0.078 & -0.227 \\
\hline 54.2 & 1.031 & 1.275 & 0.090 & -0.437 & 54 & 1.024 & 1.127 & 0.166 & -0.386 & 54.2 & 0.712 & 0.780 & 0.121 & -0.256 \\
\hline 57.2 & 0.946 & 1.312 & 0.085 & -0.474 & 57.1 & 0.992 & 1.217 & 0.172 & -0.425 & 57.2 & 0.755 & 0.866 & 0.166 & -0.294 \\
\hline 60.1 & 0.881 & 1.364 & 0.084 & -0.488 & 60 & 0.956 & 1.266 & 0.195 & -0.447 & 60 & 0.775 & 0.932 & 0.205 & -0.318 \\
\hline 63.2 & 0.850 & 1.466 & 0.098 & -0.520 & 63.1 & 0.930 & 1.352 & 0.217 & -0.479 & 63 & 0.829 & 1.042 & 0.266 & -0.360 \\
\hline 66.2 & 0.772 & 1.496 & 0.103 & -0.550 & 66.1 & 0.891 & 1.421 & 0.239 & -0.509 & 66.1 & 0.798 & 1.098 & 0.284 & -0.370 \\
\hline 69.2 & 0.693 & 1.547 & 0.099 & -0.582 & 69 & 0.811 & 1.466 & 0.231 & -0.534 & $\begin{array}{l}69.2 \\
\end{array}$ & 0.801 & 1.177 & 0.330 & -0.410 \\
\hline 72.1 & 0.611 & 1.604 & 0.088 & -0.590 & 72 & 0.735 & 1.478 & 0.243 & -0.544 & 72.1 & 0.763 & 1.222 & 0.350 & -0.427 \\
\hline 75.1 & 0.514 & 1.608 & 0.083 & -0.593 & 74.9 & 0.677 & 1.525 & 0.256 & -0.555 & 75.2 & 0.744 & 1.295 & 0.389 & -0.462 \\
\hline $\begin{array}{ll}78.1 \\
\end{array}$ & 0.408 & 1.616 & 0.066 & -0.598 & 78 & 0.565 & 1.536 & 0.234 & -0.567 & 78.2 & 0.720 & 1.363 & 0.426 & -0.493 \\
\hline 81.1 & 0.333 & 1.631 & 0.076 & -0.617 & 81.1 & 0.481 & 1.564 & 0.233 & -0.576 & 81.2 & 0.652 & 1.388 & 0.432 & -0.484 \\
\hline 84.2 & 0.222 & 1.663 & 0.053 & -0.624 & 84 & 0.421 & 1.635 & 0.248 & -0.593 & 84.1 & 0.583 & 1.401 & 0.436 & -0.500 \\
\hline 87.6 & 0.113 & 1.643 & 0.044 & -0.606 & 87 & 0.329 & 1.633 & 0.243 & -0.609 & 87 & 0.537 & 1.457 & 0.460 & -0.524 \\
\hline 90 & 0.041 & 1.647 & 0.041 & -0.616 & 89.9 & 0.255 & 1.656 & 0.252 & -0.619 & 89.9 & 0.475 & 1.485 & 0.473 & -0.540 \\
\hline
\end{tabular}




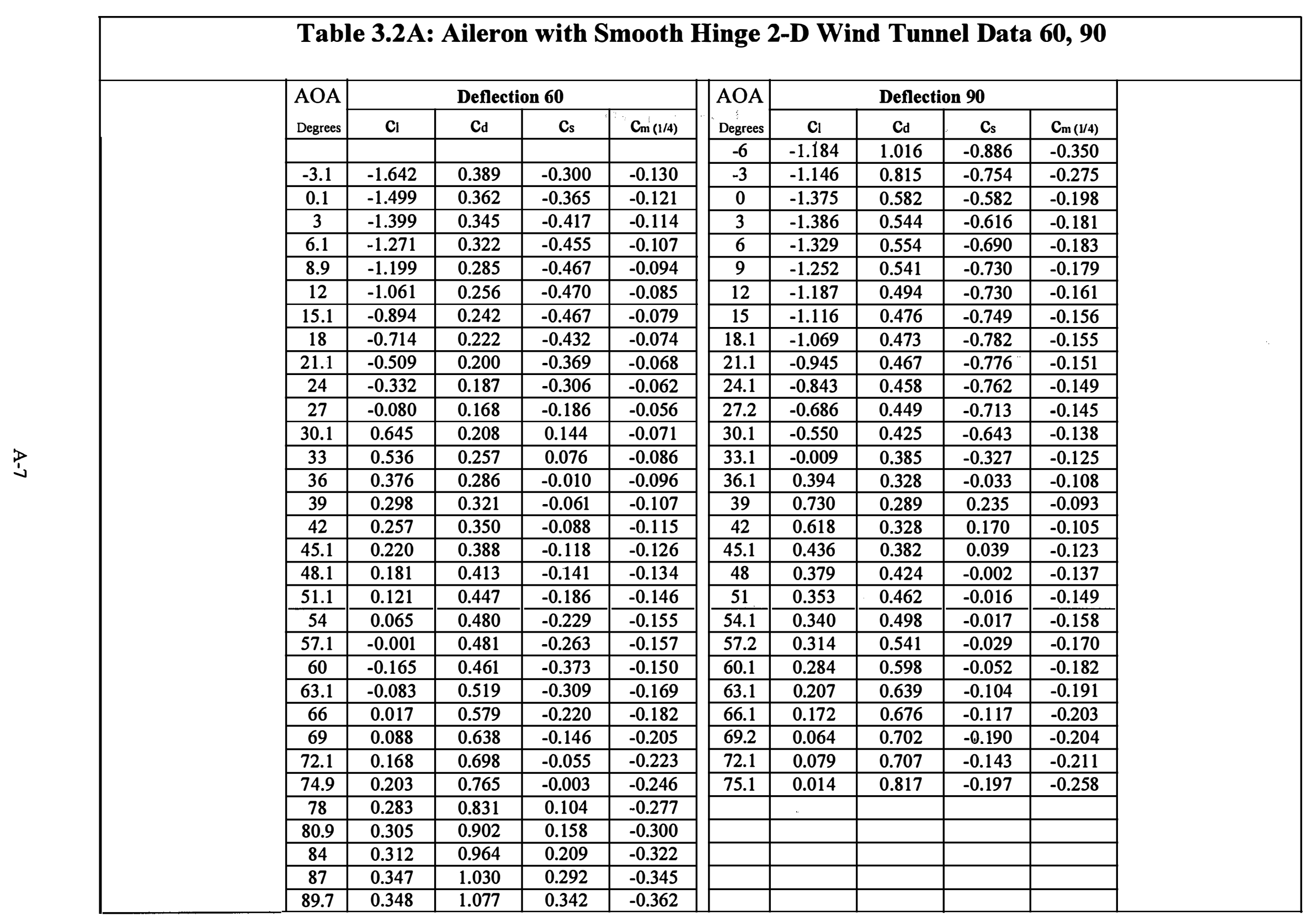


Table 4.1A: Spoiler-Flap 2-D Wind Tunnel Data Stowed, 10, 30

\begin{tabular}{|c|c|c|c|c|c|c|c|c|c|c|c|c|c|c|}
\hline \multirow{2}{*}{$\begin{array}{l}\mathrm{AOA} \\
\text { Degrees }\end{array}$} & \multicolumn{4}{|c|}{ Stowed } & \multirow{2}{*}{$\begin{array}{l}\text { AOA } \\
\text { Degrees }\end{array}$} & \multicolumn{4}{|c|}{ Deflection 10} & \multirow{2}{*}{$\begin{array}{l}\text { AOA } \\
\text { Degrees }\end{array}$} & \multicolumn{4}{|c|}{ Deflection 30} \\
\hline & $c_{1}$ & $C_{d}$ & $c_{s}$ & $C_{m(1 / 4)}$ & & cl & $C_{d}$ & $c_{s}$ & $C_{m(1 / 4)}$ & & cl & $c_{d}$ & Cs & $c_{m(1 / 4)}$ \\
\hline-6 & -0.274 & 0.004 & 0.025 & -0.011 & -6 & -0.617 & 0.113 & -0.048 & -0.041 & -6 & -0.451 & 0.305 & -0.256 & -0.101 \\
\hline-3.1 & 0.029 & 0.001 & -0.002 & -0.009 & -2.8 & -0.249 & 0.120 & -0.108 & -0.043 & -3.2 & -0.197 & 0.328 & -0.316 & -0.106 \\
\hline-0.1 & 0.356 & 0.000 & 0.000 & -0.009 & -0.1 & 0.015 & 0.126 & -0.126 & -0.046 & $\begin{array}{l}-0.1 \\
\end{array}$ & 0.069 & 0.343 & -0.343 & -0.115 \\
\hline 3 & 0.675 & 0.006 & 0.029 & -0.010 & 3 & 0.244 & 0.143 & -0.130 & -0.049 & 3.1 & 0.267 & 0.379 & -0.364 & -0.124 \\
\hline 6.1 & 0.974 & 0.016 & 0.088 & -0.013 & 6 & 0.460 & 0.159 & -0.110 & -0.052 & 6 & 0.452 & 0.388 & $\begin{array}{l}-0.338 \\
\end{array}$ & -0.126 \\
\hline 9 & 1.043 & 0.030 & 0.133 & -0.017 & 9 & 0.708 & 0.154 & -0.041 & -0.053 & 9 & 0.646 & 0.392 & -0.286 & -0.127 \\
\hline 12.1 & 1.131 & 0.055 & 0.184 & -0.024 & 12 & 0.952 & 0.169 & 0.032 & $\begin{array}{l}-0.058 \\
\end{array}$ & 12 & 0.911 & 0.407 & -0.208 & -0.131 \\
\hline 14.9 & 1.181 & 0.084 & 0.223 & -0.032 & 15 & 1.152 & 0.181 & 0.123 & -0.063 & 15 & 1.116 & 0.401 & -0.098 & -0.132 \\
\hline 18 & 1.184 & 0.123 & 0.248 & -0.045 & 18 & 1.318 & 0.208 & 0.209 & -0.070 & 17.9 & 1.322 & 0.408 & 0.018 & -0.133 \\
\hline 20.9 & 1.108 & 0.197 & 0.211 & -0.065 & 21 & 1.163 & 0.293 & 0.143 & -0.084 & 21 & 1.117 & 0.544 & -0.108 & -0.177 \\
\hline 24.1 & 0.768 & 0.386 & -0.038 & -0.126 & 24 & 0.951 & 0.498 & -0.068 & -0.161 & 23.9 & 1.193 & 0.655 & -0.115 & -0.213 \\
\hline 27 & 0.859 & 0.479 & -0.037 & -0.155 & 26.9 & 1.057 & 0.601 & -0.058 & -0.195 & 27 & 1.257 & 0.769 & -0.114 & -0.248 \\
\hline 30 & 0.966 & 0.582 & -0.021 & -0.187 & 30 & 1.122 & 0.708 & -0.052 & -0.230 & 29.9 & 1.292 & 0.866 & -0.107 & -0.288 \\
\hline 33 & 1.044 & 0.689 & -0.009 & -0.225 & 33.1 & 1.176 & 0.810 & -0.036 & -0.264 & 32.9 & 1.301 & 0.963 & -0.102 & -0.322 \\
\hline 36 & 1.085 & 0.781 & 0.006 & -0.257 & 36.1 & 1.191 & 0.908 & -0.032 & -0.299 & 36 & 1.283 & 1.045 & -0.092 & -0.352 \\
\hline 39 & 1.124 & 0.879 & 0.024 & -0.292 & 39.1 & 1.183 & 0.996 & -0.027 & -0.327 & 38.9 & 1.235 & 1.113 & $\begin{array}{l}-0.091 \\
\end{array}$ & -0.374 \\
\hline 42.2 & 1.144 & 0.982 & 0.041 & -0.326 & 42 & 1.173 & 1.079 & -0.017 & -0.359 & 42 & 1.224 & 1.201 & -0.074 & -0.415 \\
\hline 45.1 & 1.136 & 1.066 & 0.053 & -0.353 & 44.9 & 1.146 & 1.147 & -0.004 & -0.381 & 44.8 & $\begin{array}{l}1.178 \\
\end{array}$ & 1.281 & -0.078 & -0.448 \\
\hline 48.2 & 1.105 & 1.137 & 0.066 & $\begin{array}{c}-0.379 \\
\end{array}$ & 48 & 1.129 & 1.238 & 0.010 & -0.423 & 47.9 & 1.106 & 1.320 & -0.064 & -0.452 \\
\hline 51.11 & 1.083 & 1.217 & 0.078 & -0.424 & 51 & 1.074 & 1.295 & 0.020 & -0.449 & 51 & 1.050 & 1.403 & -0.067 & -0.487 \\
\hline 54.1 & 1.040 & 1.279 & 0.092 & -0.442 & 54 & 1.001 & 1.333 & 0.027 & -0.453 & 54 & 0.986 & 1.468 & -0.065 & -0.519 \\
\hline 57.1 & 0.990 & 1.353 & 0.096 & -0.466 & 57.1 & 0.937 & 1.401 & 0.026 & -0.493 & 57 & $\begin{array}{l}0.889 \\
\end{array}$ & 1.497 & -0.070 & -0.522 \\
\hline 60.2 & 0.931 & 1.407 & 0.109 & -0.485 & 60.1 & 0.882 & 1.453 & 0.040 & -0.513 & 60 & 0.787 & 1.525 & -0.081 & -0.547 \\
\hline 63 & 0.863 & 1.448 & 0.112 & -0.504 & 63 & 0.811 & 1.518 & 0.033 & -0.546 & 62.9 & 0.714 & 1.573 & -0.081 & -0.556 \\
\hline 66.1 & 0.798 & 1.525 & 0.112 & -0.536 & 66 & 0.719 & 1.532 & 0.034 & -0.550 & 65.8 & 0.614 & 1.595 & -0.094 & -0.578 \\
\hline 69.1 & 0.709 & 1.567 & 0.103 & $\begin{array}{c}-0.574 \\
\end{array}$ & 69 & 0.646 & 1.569 & 0.041 & -0.562 & 69 & 0.527 & 1.587 & -0.077 & -0.581 \\
\hline 72 & 0.647 & 1.603 & 0.120 & -0.578 & 72 & 0.534 & 1.621 & 0.007 & -0.592 & 71.9 & 0.400 & 1.609 & -0.120 & -0.579 \\
\hline 75.1 & 0.530 & 1.604 & 0.100 & -0.581 & 74.9 & 0.464 & 1.627 & 0.024 & -0.605 & 74.9 & 0.304 & 1.625 & -0.130 & -0.582 \\
\hline 78.2 & 0.440 & 1.603 & 0.103 & -0.575 & 78.1 & 0.349 & 1.644 & 0.003 & -0.599 & 78 & 0.179 & 1.650 & -0.168 & -0.611 \\
\hline 81.1 & 0.346 & 1.669 & 0.083 & -0.606 & 81 & 0.263 & 1.687 & -0.004 & -0.622 & 81 & 0.076 & 1.626 & -0.180 & -0.593 \\
\hline 84.1 & 0.241 & 1.661 & 0.069 & -0.608 & 84 & 0.143 & 1.658 & -0.032 & -0.608 & 84 & 0.002 & 1.621 & -0.167 & -0.599 \\
\hline 87.1 & 0.149 & 1.664 & 0.064 & -0.601 & 87 & 0.040 & 1.659 & -0.047 & -0.597 & 86.9 & -0.093 & 1.612 & -0.180 & -0.564 \\
\hline 90 & 0.050 & 1.645 & 0.050 & -0.599 & 90 & -0.064 & 1.668 & -0.064 & -0.619 & 89.8 & -0.216 & 1.592 & -0.222 & -0.583 \\
\hline
\end{tabular}


Table 4.2A: Spoiler-Flap 2-D Wind Tunnel Data 60, 90

\begin{tabular}{|c|c|c|c|c|c|c|c|c|c|}
\hline \multirow{2}{*}{$\begin{array}{c}\mathrm{AOA} \\
\text { Degrees }\end{array}$} & \multicolumn{4}{|c|}{ Deflection 60} & \multirow{2}{*}{$\begin{array}{c}\text { AOA } \\
\text { Degrees }\end{array}$} & \multicolumn{4}{|c|}{ Deflection 90} \\
\hline & Cl & $C_{d}$ & $c_{s}$ & $C_{m(1 / 4)}$ & & Cl & $C_{d}$ & - $\mathrm{c}_{\mathrm{s}}$ & $C_{m(1 / 4)}$ \\
\hline-6.1 & 0.151 & 0.548 & -0.561 & -0.182 & -6.1 & 0.202 & 0.678 & -0.695 & -0.214 \\
\hline-3.1 & 0.270 & 0.552 & -0.566 & -0.181 & -3.1 & 0.171 & 0.692 & -0.701 & -0.228 \\
\hline 0 & 0.376 & 0.589 & -0.589 & -0.194 & 0 & 0.204 & 0.706 & -0.706 & -0.241 \\
\hline 3 & 0.410 & 0.587 & -0.565 & -0.191 & 2.9 & 0.256 & 0.746 & -0.732 & -0.245 \\
\hline 6 & 0.495 & 0.585 & -0.530 & -0.195 & 5.9 & 0.294 & 0.711 & -0.677 & -0.255 \\
\hline 8.9 & 0.638 & 0.569 & -0.463 & -0.190 & 9 & 0.315 & 0.736 & $\begin{array}{l}-0.677 \\
\end{array}$ & -0.245 \\
\hline 11.9 & 0.752 & 0.558 & -0.391 & -0.185 & 12 & 0.330 & 0.745 & -0.660 & -0.247 \\
\hline 15 & 0.704 & 0.618 & -0.415 & -0.196 & 15 & 0.359 & 0.737 & -0.619 & -0.243 \\
\hline 17.9 & 0.674 & 0.675 & -0.435 & -0.219 & 18 & 0.372 & 0.715 & -0.565 & -0.243 \\
\hline 20.9 & 0.591 & 0.767 & -0.506 & -0.250 & 21 & 0.320 & 0.704 & -0.543 & -0.225 \\
\hline 23.8 & 0.621 & 0.873 & -0.548 & -0.288 & 24 & 0.361 & 0.860 & -0.639 & -0.267 \\
\hline 27 & 0.655 & 0.953 & -0.551 & -0.320 & 26.9 & 0.336 & 0.904 & -0.654 & -0.286 \\
\hline 29.9 & 0.663 & 0.895 & -0.446 & -0.292 & 29.9 & 0.346 & 0.899 & -0.607 & -0.290 \\
\hline 32.9 & 0.654 & 0.942 & -0.435 & -0.309 & 33.1 & 0.377 & 0.847 & -0.504 & -0.284 \\
\hline 36 & 0.650 & 0.988 & -0.417 & -0.329 & 36 & 0.334 & 0.886 & -0.520 & -0.281 \\
\hline 38.9 & 0.647 & 1.044 & -0.406 & -0.348 & 39 & 0.331 & 0.930 & -0.515 & -0.296 \\
\hline 41.9 & 0.615 & 1.091 & -0.401 & -0.367 & 42 & 0.327 & 0.950 & -0.487 & -0.309 \\
\hline 45 & 0.579 & 1.133 & -0.392 & -0.382 & 44.9 & 0.271 & 0.961 & -0.489 & -0.309 \\
\hline 48 & 0.530 & 1.218 & -0.421 & -0.411 & 47.9 & 0.225 & 0.992 & -0.498 & -0.322 \\
\hline 51 & 0.506 & 1.318 & -0.436 & -0.457 & 50.9 & 0.213 & 1.022 & -0.479 & -0.324 \\
\hline 54 & 0.398 & 1.350 & -0.472 & -0.466 & 53.9 & 0.151 & 1.018 & -0.478 & -0.333 \\
\hline 56.9 & 0.356 & 1.374 & -0.453 & -0.482 & 57 & 0.081 & 1.028 & -0.492 & -0.334 \\
\hline 60 & 0.270 & 1.383 & -0.458 & -0.478 & 59.9 & 0.022 & 1.011 & $\begin{array}{l}-0.488 \\
\end{array}$ & -0.334 \\
\hline 62.9 & 0.194 & 1.387 & -0.459 & -0.480 & 63 & -0.068 & 1.006 & -0.517 & -0.331 \\
\hline 66 & 0.115 & 1.374 & -0.453 & -0.477 & 65.9 & -0.127 & 0.999 & -0.524 & -0.321 \\
\hline 68.8 & 0.048 & 1.372 & -0.452 & -0.483 & 68.9 & -0.201 & 0.972 & -0.537 & -0.308 \\
\hline \begin{tabular}{ll|}
71.9 \\
\end{tabular} & -0.025 & 1.369 & -0.449 & $\begin{array}{c}-0.478 \\
\end{array}$ & 71.9 & -0.264 & 0.944 & -0.544 & -0.305 \\
\hline \begin{tabular}{ll|}
74.8 \\
\end{tabular} & -0.084 & 1.355 & -0.436 & -0.475 & 74.9 & -0.337 & 0.931 & -0.568 & -0.294 \\
\hline 78 & -0.166 & 1.335 & -0.440 & -0.462 & 78 & -0.399 & 0.895 & -0.576 & -0.279 \\
\hline 81 & -0.229 & 1.300 & -0.430 & -0.448 & 80.9 & -0.480 & 0.864 & -0.611 & -0.246 \\
\hline 83.9 & -0.305 & 1.276 & -0.438 & -0.438 & 83.9 & -0.795 & 0.776 & -0.873 & -0.225 \\
\hline 86.9 & -0.378 & 1.249 & -0.445 & -0.427 & 86.9 & -0.935 & 0.719 & -0.973 & -0.209 \\
\hline 89.9 & -0.436 & 1.214 & -0.438 & -0.414 & 89.8 & -1.056 & 0.646 & -1.059 & -0.225 \\
\hline
\end{tabular}


Appendix B

Phoenix 7.9-M Blade Spoiler-Flap Loads Data 
THE WIND TURBINE $=$ MICON 65/13

\begin{tabular}{|c|c|c|c|c|c|c|c|c|c|}
\hline \multirow[b]{2}{*}{ DENSITY $=$} & \multicolumn{8}{|c|}{ PHYSICAL AND GEOMETRIC CONSTANTS USED TO FOR THE LOADS ANALYSIS } & $\begin{array}{l}\text { Spanwise } \\
\text { Location }\end{array}$ \\
\hline & 0.002377 & $\mathrm{lbf}^{*} \sec ^{\wedge} \mathbf{2} / \mathrm{ft}^{\wedge} 4$ & $\mathbf{c 1 5}=$ & 2.38 & S15 $=$ & 1.67 & twist15= & 0.25 & BS 218.4 \\
\hline VISCOSITY $=$ & 3.801E-07 & $\mathrm{lb}^{\star} \sec / \mathrm{ft}^{\wedge} \mathbf{2}$ & $\mathbf{c 1 6}=$ & 2.17 & $\mathbf{S 1 6}=$ & 1.52 & twist16= & -0.53 & BS 235.2 \\
\hline $\mathbf{R P M}=$ & 47.7 & $\mathrm{rev} / \mathrm{min}$ & $\mathbf{c 1 7}=$ & 1.94 & S17 $=$ & 1.36 & twist17= & -0.47 & BS 252.0 \\
\hline \# SEGMENTS= & 20 & & $\mathbf{c 1 9}=$ & 1.44 & $\mathbf{S 1 9}=$ & 1.01 & twist19= & -0.60 & BS 285.6 \\
\hline BLADE LENGTH= & 28.08 & ft & & & & & & & \\
\hline DEVICE CHORD $=$ & 0.5 & & & & & & & & \\
\hline DEVICE ANGLE $=$ & $\mathbf{0}$ & DEGREES & & & & & & & \\
\hline
\end{tabular}

\begin{tabular}{|c|c|c|c|c|c|c|c|}
\hline & $\begin{array}{l}\text { Blade } \\
\text { Sta. } 15\end{array}$ & $\begin{array}{l}\text { Blade } \\
\text { Sta. } 16\end{array}$ & $\begin{array}{l}\text { Blade } \\
\text { Sta. } 17\end{array}$ & $\begin{array}{c}\text { Blade } \\
\text { Sta. } 18 \\
\end{array}$ & $\begin{array}{c}\text { Blade } \\
\text { Sta. } 19 \\
\end{array}$ & $\begin{array}{c}\text { DEVICE } \\
\text { totals } \\
\end{array}$ & $\begin{array}{c}\text { DEVICE } \\
\text { totals }\end{array}$ \\
\hline$V_{0}(\mathrm{~m} / \mathrm{sec})$ & $\begin{array}{c}\text { Force- } \\
\text { Normal lb }\end{array}$ & \begin{tabular}{|c} 
Force-Normal \\
lb
\end{tabular} & \begin{tabular}{|c|} 
Force-Normal \\
lb
\end{tabular} & \begin{tabular}{|c} 
Force-Normal \\
lb
\end{tabular} & \begin{tabular}{|c} 
Force-Normal \\
lb
\end{tabular} & $\begin{array}{c}\text { Total Force- } \\
\text { Normal lb }\end{array}$ & $\begin{array}{c}\text { Spanwise (cp) } \\
\text { \% Device } \\
\text { span }\end{array}$ \\
\hline 10.0 & 19.2 & 19.7 & 19.7 & 19.2 & 18.1 & 95.9 & 0.494 \\
\hline 20.0 & 31.4 & 27.6 & 26.5 & 24.3 . & 26.5 & 136.3 & 0.481 \\
\hline 30.0 & 54.9 & 52.7 & 45.9 & 41.8 & 42.0 & 237.3 & 0.469 \\
\hline 40.0 & 87.4 & 82.4 & 71.0 & 63.6 & 64.1 & 368.5 & 0.464 \\
\hline 50.0 & 127.7 & 118.9 & 106.4 & 94.2 & 91.9 & 539.2 & 0.464 \\
\hline 57.5 & 168.8 & 156.1 & 141.2 & 115.4 & 119.5 & 701.0 & 0.460 \\
\hline & $\begin{array}{l}\text { Blade } \\
\text { Sta. } 15\end{array}$ & $\begin{array}{l}\text { Blade } \\
\text { Sta. } 16\end{array}$ & $\begin{array}{l}\text { Blade } \\
\text { Sta. } 17\end{array}$ & $\begin{array}{l}\text { Blade } \\
\text { Sta. } 18\end{array}$ & $\begin{array}{l}\text { Blade } \\
\text { Sta. } 19\end{array}$ & $\begin{array}{c}\text { DEVICE } \\
\text { totals }\end{array}$ & $\begin{array}{c}\text { DEVICE } \\
\text { totals }\end{array}$ \\
\hline $\mathrm{Vo}_{0}(\mathrm{~m} / \mathrm{sec})$ & $\begin{array}{c}\text { Moment } \\
\text { in-lb }\end{array}$ & $\begin{array}{c}\text { Moment } \\
\text { in-lb }\end{array}$ & $\begin{array}{c}\text { Moment } \\
\text { in-lb }\end{array}$ & $\begin{array}{c}\text { Moment } \\
\text { in- lb }\end{array}$ & $\begin{array}{c}\text { Moment } \\
\text { in-lb }\end{array}$ & $\begin{array}{c}\text { Total M } \\
\text { in- lb }\end{array}$ & $\begin{array}{c}\text { Spanwise } \\
\text { (cm) \% } \\
\text { Device span }\end{array}$ \\
\hline 10.0 & 33.7 & 38.3 & 34.3 & 29.3 & 23.4 & 158.9 & 0.463 \\
\hline 20.0 & 56.7 & 46.5 & 40.0 & 28.8 & 26.7 & 198.7 & 0.422 \\
\hline 30.0 & 106.7 & 93.4 & 72.9 & 58.1 & 48.2 & 379.3 & 0.420 \\
\hline 40.0 & 172.3 & 148.1 & 115.2 & 90.3 & 74.8 & 600.7 & 0.416 \\
\hline 50.0 & 250.6 & 212.6 & 174.0 & 134.8 & 109.9 & 881.9 & 0.419 \\
\hline 57.5 & 323.9 & 272.8 & 221.0 & 161.7 & 142.2 & 1121.6 & 0.415 \\
\hline
\end{tabular}

\begin{tabular}{|c|c|c|c|}
\hline $\begin{array}{c}\text { HINGE } \\
\text { Reactions }\end{array}$ & $\begin{array}{c}\text { HINGE } \\
\text { Reactions }\end{array}$ & $\begin{array}{c}\text { HINGE } \\
\text { Reactions }\end{array}$ & $\begin{array}{c}\text { HINGE } \\
\text { Reactions }\end{array}$ \\
\hline $\begin{array}{c}\text { BS 294 } \\
\text { (RHn 294) } \\
\text { (lbs) }\end{array}$ & $\begin{array}{c}\text { BS 294 } \\
\text { (RHc 294) } \\
\text { (lbs) }\end{array}$ & $\begin{array}{c}\text { BS 210 } \\
\text { (RHn 210) } \\
\text { (lbs) }\end{array}$ & $\begin{array}{c}\text { BS 210 } \\
\text { (RHc 210) } \\
\text { (lbs) }\end{array}$ \\
\hline 47.36 & 0.00 & 48.51 & 0.00 \\
\hline 67.31 & 0.00 & 68.95 & 0.00 \\
\hline 117.24 & 0.00 & 120.09 & 0.00 \\
\hline 182.05 & 0.00 & 186.47 & 0.00 \\
\hline 266.35 & 0.00 & 272.82 & 0.00 \\
\hline 346.27 & 0.00 & 354.68 & 0.00 \\
\hline Magnet & Magnet & Magnet & \\
\hline Reactions & Reactions & Reactions & \\
\hline $\begin{array}{c}\text { BS 294 } \\
\text { (RMn 294) }\end{array}$ & $\begin{array}{c}\text { BS 240 } \\
\text { (RMn 240) }\end{array}$ & $\begin{array}{c}\text { BS 210 } \\
\text { (RMn 210) }\end{array}$ & \\
\hline (in-lb) & (in-lb) & (in-lb) & \\
\hline 47.67 & 79.44 & 63.55 & \\
\hline 59.61 & 99.34 & 79.48 & \\
\hline 113.80 & 189.66 & 151.73 & \\
\hline 180.21 & 300.35 & 240.28 & \\
\hline 264.56 & 440.93 & 352.74 & \\
\hline 336.48 & 560.80 & 448.64 & \\
\hline
\end{tabular}

\begin{tabular}{|c|c|c|c|c|c|c|c|c|c|c|}
\hline$\Omega$ & (cg) position & Device & Centrifugal & Centrifugal & (cg) position & & & ifugal Load & & \\
\hline $\mathrm{rad} / \mathrm{sec}$ & pivot offset & Mass & Force & Force & 210 offset & (RHc 294) & (RHn 294) & (RHc 210) & (RHn 210) & (Fz 210) \\
\hline & m & $\mathrm{kg}$ & Newton & lb & in & $\mathbf{l b}$ & lb & lb & lb & lb \\
\hline 5.00 & 6.82 & 17 & 2723.5 & 612.3 & 3.63 & 26 & 0 & -26 & 0 & 612 \\
\hline
\end{tabular}


THE WIND TURBINE = MICON 65/13

\begin{tabular}{|c|c|c|c|c|c|c|c|c|c|}
\hline & \multicolumn{8}{|c|}{ PHYSICAL AND GEOMETRIC CONSTANTS USED TO FOR THE LOADS ANALYSIS } & \multirow{2}{*}{$\begin{array}{l}\text { Spanwise } \\
\text { Location }\end{array}$} \\
\hline & & & chords at section & ft & & $\mathrm{ft}^{\wedge} \mathbf{2}$ & & DEGREES & \\
\hline DENSITY $=$ & 0.002377 & $\mathrm{lbf} \mathrm{sec}^{\wedge} 2 / \mathrm{ft}^{\wedge} 4$ & $\mathrm{c} 15=$ & 2.38 & S15 $=$ & 1.67 & twist15= & 0.25 & BS 218.4 \\
\hline VISCOSITY $=$ & $3.801 \mathrm{E}-07$ & lbf*sec / ft^2 & $\mathbf{c 1 6}=$ & 2.17 & S16 $=$ & 1.52 & twist16= & -0.53 & BS 235.2 \\
\hline $\mathbf{R P M}=$ & 47.7 & $\mathrm{rev} / \mathrm{min}$ & $\mathbf{c 1 7}=$ & 1.94 & $\mathbf{S 1 7}=$ & 1.36 & twist17= & -0.47 & BS 252.0 \\
\hline WIND SPEED $=$ & $10-60$ & $\mathrm{~m} / \mathrm{sec}$ & c18 = & 1.70 & S18 $=$ & 1.19 & twist18= & -0.53 & BS 268.8 \\
\hline \# SEGMENTS= & 20 & & c19 = & 1.44 & S19 $=$ & 1.01 & twist19= & -0.60 & BS 285.6 \\
\hline BLADE LENGTH= & 28.08 & ft & & & & & & & \\
\hline DEVICE CHORD $=$ & 0.5 & C & & & & & & & \\
\hline DEVICE ANGLE $=$ & 10 & DEGREES & & & & & & & \\
\hline
\end{tabular}

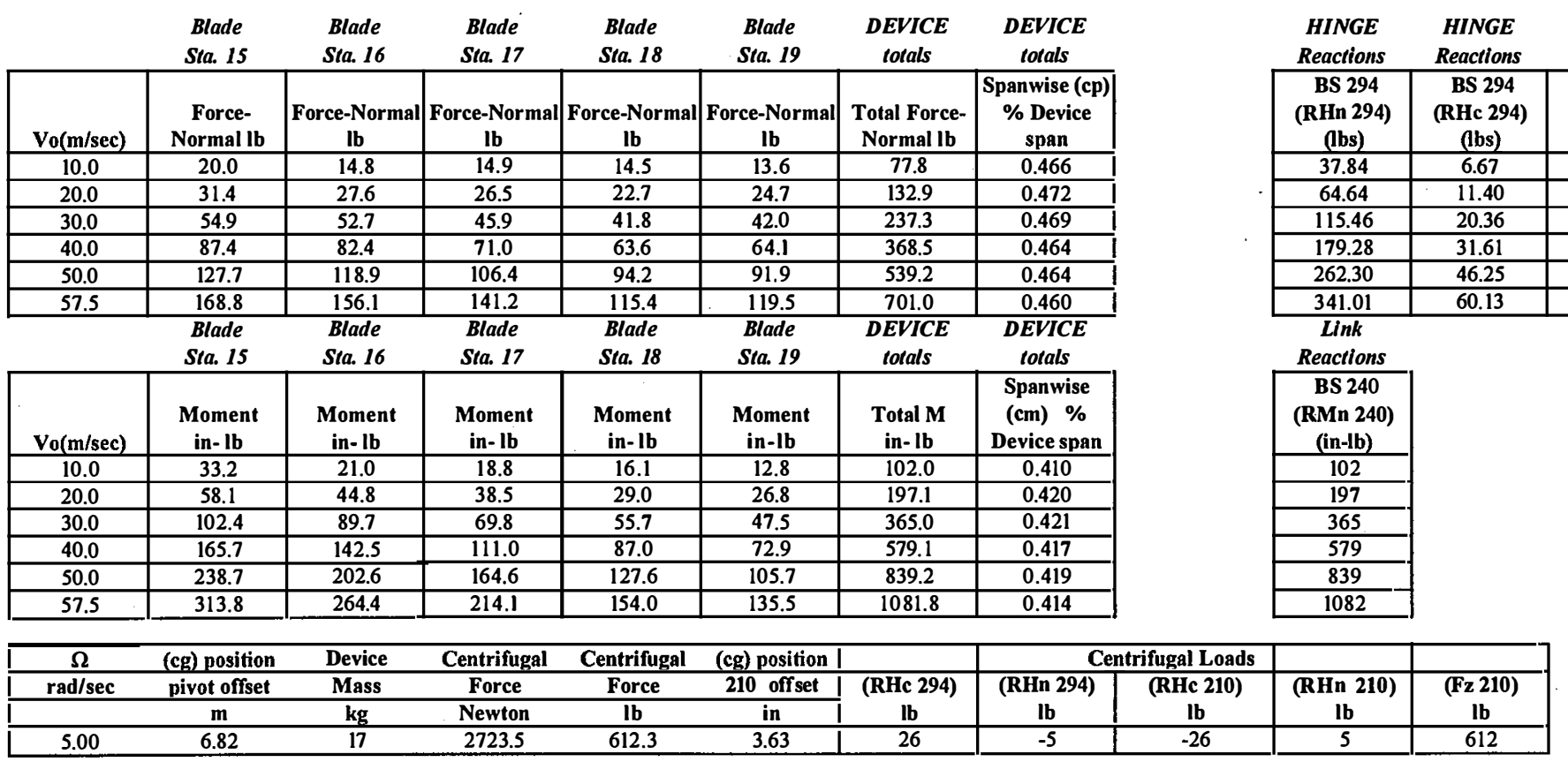


THE WIND TURBINE $=\quad$ MICON 65/13

\begin{tabular}{|c|c|c|c|c|c|c|c|c|c|}
\hline & \multicolumn{8}{|c|}{ PHYSICAL AND GEOMETRIC CONSTANTS USED TO FOR THE LOADS ANALYSIS } & $\begin{array}{l}\text { Spanwise } \\
\text { Location }\end{array}$ \\
\hline VISCOSITY $=$ & $3.801 \mathrm{E}-07$ & $\mathrm{lb}^{\star} \mathrm{sec} / \mathrm{ft}^{\wedge} \mathbf{2}$ & $\mathbf{c 1 6}=$ & 2.17 & S16 $=$ & 1.52 & twist16= & -0.53 & BS 235.2 \\
\hline $\mathbf{R P M}=$ & 47.7 & $\mathrm{rev} / \mathrm{min}$ & $\mathbf{c 1 7}=$ & 1.94 & $\mathbf{S 1 7}=$ & 1.36 & twist17= & -0.47 & BS 252.0 \\
\hline \# SEGMENTS= & 20 & & $\mathbf{c 1 9}=$ & 1.44 . & $\mathbf{S 1 9}=$ & 1.01 & twist19= & -0.60 & BS 285.6 \\
\hline BLADE LENGTH= & 28.08 & ft & & & & & & & \\
\hline DEVICE CHORD $=$ & 0.5 & $\mathbf{C}$ & & & & & & & \\
\hline DEVICE ANGLE $=$ & 60 & DEGREES & & & & & & & \\
\hline
\end{tabular}

\begin{tabular}{|c|c|c|c|c|c|c|c|c|c|c|}
\hline & $\begin{array}{c}\text { Blade } \\
\text { Sta. } 15\end{array}$ & $\begin{array}{c}\text { Blade } \\
\text { Sta. } 16\end{array}$ & $\begin{array}{c}\text { Blade } \\
\text { Sta. } 17\end{array}$ & $\begin{array}{c}\text { Blade } \\
\text { Sta. } 18\end{array}$ & $\begin{array}{c}\text { Blade } \\
\text { Sta. } 19\end{array}$ & $\begin{array}{c}\text { DEVICE } \\
\text { totals }\end{array}$ & $\begin{array}{c}\text { DEVICE } \\
\text { totals }\end{array}$ & & $\begin{array}{c}\text { HINGE } \\
\text { Reactions }\end{array}$ & $\begin{array}{c}\text { HINGE } \\
\text { Reactions }\end{array}$ \\
\hline$V_{0}(\mathrm{~m} / \mathrm{sec})$ & $\begin{array}{c}\text { Force- } \\
\text { Normal lb }\end{array}$ & $\begin{array}{c}\text { Force-Normal } \\
\text { lb }\end{array}$ & $\begin{array}{c}\text { Force-Normal } \\
\text { lb }\end{array}$ & \begin{tabular}{|c|} 
Force-Normal \\
lb
\end{tabular} & \begin{tabular}{|c|} 
Force-Normal \\
lb
\end{tabular} & $\begin{array}{c}\text { Total Force- } \\
\text { Normal lb }\end{array}$ & $\begin{array}{c}\text { Spanwise (cp) } \\
\text { \% Device } \\
\text { span }\end{array}$ & & $\begin{array}{c}\text { BS 294 } \\
\text { (RHn 294) } \\
\text { (lbs) }\end{array}$ & $\begin{array}{c}\text { BS 294 } \\
\text { (RHc 294) } \\
\text { (bs) }\end{array}$ \\
\hline 10.0 & 36.0 & 39.9 & 40.0 & 39.0 & 36.6 & 191.5 & 0.500 & & 47.31 & 81.95 \\
\hline 20.0 & 44.8 & 42.9 & 41.2 & 37.9 & 41.3 & 208.1 & 0.488 & & 51.39 & 89.01 \\
\hline 30.0 & 56.6 & 54.4 & 51.4 & 46.8 & 50.3 & 259.4 & 0.484 & & 64.07 & 110.97 \\
\hline 40.0 & 69.1 & 65.2 & 67.2 & 60.2 & 62.6 & 324.3 & 0.489 & & 80.09 & 138.72 \\
\hline 50.0 & 94.3 & 87.8 & 77.9 & 68.9 & 72.6 & 401.6 & 0.469 & & 99.19 & 171.81 \\
\hline 57.5 & 114.4 & 105.7 & 95.7 & 85.2 & 88.2 & 489.2 & 0.470 & & 120.82 & 209.27 \\
\hline & $\begin{array}{c}\text { Blade } \\
\text { Sta. } 15 \\
\end{array}$ & $\begin{array}{l}\text { Blade } \\
\text { Sta. } 16 \\
\end{array}$ & $\begin{array}{l}\text { Blade } \\
\text { Sta. } 17 \\
\end{array}$ & $\begin{array}{l}\text { Blade } \\
\text { Sta. } 18 \\
\end{array}$ & $\begin{array}{l}\text { Blade } \\
\text { Sta. } 19\end{array}$ & $\begin{array}{c}\text { DEVICE } \\
\text { totals } \\
\end{array}$ & $\begin{array}{c}\text { DEVICE } \\
\text { totals } \\
\end{array}$ & & $\begin{array}{c}\text { Link } \\
\text { Reactions }\end{array}$ & \\
\hline$V_{0}(\mathrm{~m} / \mathrm{sec})$ & $\begin{array}{c}\text { Moment } \\
\text { in-lb }\end{array}$ & $\begin{array}{c}\text { Moment } \\
\text { in-lb }\end{array}$ & $\begin{array}{c}\text { Moment } \\
\text { in- lb }\end{array}$ & $\begin{array}{c}\text { Moment } \\
\text { in- lb }\end{array}$ & $\begin{array}{c}\text { Moment } \\
\text { in-lb }\end{array}$ & $\begin{array}{c}\text { Total M } \\
\text { in- lb }\end{array}$ & \begin{tabular}{|c|} 
Spanwise \\
$(\mathbf{c m}) \%$ \\
Device span
\end{tabular} & & $\begin{array}{c}\text { BS 240 } \\
\text { (RMn 240) } \\
\text { (in-lb) }\end{array}$ & \\
\hline 10.0 & 21.5 & 33.0 & 29.6 & 25.2 & 20.1 & 129.4 & 0.484 & & 129 & \\
\hline 20.0 & 12.0 & 11.3 & 9.7 & 9.7 & 9.0 & 51.7 & 0.470 & & 52 & \\
\hline 30.0 & 15.8 & 13.8 & 11.5 & 9.2 & 8.1 & 58.4 & 0.431 & & 58 & \\
\hline 40.0 & 6.7 & 5.7 & 14.8 & 11.6 & 9.2 & 48.1 & 0.546 & & 48 & \\
\hline 50.0 & 3.0 & 2.5 & 2.6 & 2.0 & 4.3 & 14.5 & 0.528 & & 14 & \\
\hline 57.5 & 0.8 & 0.6 & 0.5 & 1.9 & 1.7 & 5.5 & 0.615 & & 6 & \\
\hline $\bar{\Omega}$ & (cg) position & Device & Centrifugal & Centrifugal & (cg) position & & \multicolumn{2}{|c|}{ Centrifugal Loads } & & \\
\hline $\mathrm{rad} / \mathrm{sec}$ & pivot offset & Mass & Force & Force & 210 off set & (RHc 294) & (RHn 294) & (RHc 210) & (RHn 210) & (Fz 210) \\
\hline & $\mathbf{m}$ & $\mathrm{kg}$ & Newton & $\mathbf{I b}$ & in & lb & lb & lb & $\mathbf{l b}$ & $\mathbf{l b}$ \\
\hline 5.00 & 6.82 & 17 & 2723.5 & 612.3 & 3.63 & 13 & -23 & -13 & 23 & 612 \\
\hline
\end{tabular}


THE WIND TURBINE $=\quad$ MICON 65/13

\begin{tabular}{|c|c|c|c|c|c|c|c|c|c|}
\hline & \multicolumn{8}{|c|}{ PHYSICAL AND GEOMETRIC CONSTANTS USED TO FOR THE LOADS ANALYSIS } & \multirow{2}{*}{$\begin{array}{l}\text { Spanwise } \\
\text { Location }\end{array}$} \\
\hline & & & chords at section & ft & & $\mathbf{f t}^{\wedge 2}$ & & DEGREES & \\
\hline VISCOSITY $=$ & 3.801E-07 & $\mathbf{l b f}{ }^{*} \sec / \mathrm{ft}^{\wedge} \mathbf{2}$ & $\mathbf{c 1 6}=$ & 2.17 & S16 $=$ & 1.52 & twist16= & -0.53 & BS 235.2 \\
\hline . $\mathbf{R P M}=$ & 47.7 & $\operatorname{rev} / \min$ & $\mathbf{c 1 7}=$ & 1.94 & $\mathbf{S 1 7}=$ & 1.36 & twist17= & -0.47 & BS 252.0 \\
\hline \# SEGMENTS= & 20 & & $\mathbf{c 1 9}=$ & 1.44 & $\mathbf{S 1 9}=$ & 1.01 & twist19= & -0.60 & BS 285.6 \\
\hline BLADE LENGTH= & 28.08 & ft & & & & & & & \\
\hline DEVICE CHORD $=$ & 0.5 & C & & & & & & & \\
\hline DEVICE ANGLE $=$ & 90 & DEGREES & & & & & & & \\
\hline
\end{tabular}

\begin{tabular}{|c|c|c|c|c|c|c|c|}
\hline & $\begin{array}{c}\text { Blade } \\
\text { Sta. } 15\end{array}$ & $\begin{array}{c}\text { Blade } \\
\text { Sta. } 16\end{array}$ & $\begin{array}{l}\text { Blade } \\
\text { Sta. } 17\end{array}$ & $\begin{array}{l}\text { Blade } \\
\text { Sta. } 18\end{array}$ & $\begin{array}{l}\text { Blade } \\
\text { Sta. } 19\end{array}$ & $\begin{array}{c}\text { DEVICE } \\
\text { totals }\end{array}$ & $\begin{array}{c}\text { DEVICE } \\
\text { totals }\end{array}$ \\
\hline$V_{0}(m / s e c)$ & $\begin{array}{c}\text { Force- } \\
\text { Normal lb }\end{array}$ & \begin{tabular}{|c} 
Force-Normal \\
lb
\end{tabular} & $\begin{array}{c}\text { Force-Normal } \\
\text { lb }\end{array}$ & $\begin{array}{c}\text { For ce-Norma } \\
\text { lb }\end{array}$ & \begin{tabular}{|c|} 
Force-Normal \\
lb
\end{tabular} & $\begin{array}{c}\text { Total Force- } \\
\text { Normal lb }\end{array}$ & \begin{tabular}{|c} 
Spanwise (cp) \\
\% Device \\
span
\end{tabular} \\
\hline 10.0 & 62.9 & 73.4 & 73.4 & 71.5 & 67.3 & 348.5 & 0.504 \\
\hline 20.0 & 39.1 & 35.7 & 34.3 & 53.2 & 58.0 & 220.4 & 0.550 \\
\hline 30.0 & 44.7 & 42.9 & 43.8 & 39.9 & 47.5 & 218.8 & 0.502 \\
\hline 40.0 & 60.2 & 56.7 & 48.7 & 43.6 & 45.5 & 254.7 & 0.467 \\
\hline 50.0 & 96.9 & 90.2 & 67.9 & 60.1 & 63.2 & 378.3 & 0.448 \\
\hline 57.5 & 123.8 & 114.4 & 103.5 & 87.5 & 90.6 & 519.9 & 0.464 \\
\hline & $\overline{a d e}$ & $\overline{a d e}$ & Blade & $\overline{l a d e}$ & $\overline{l a d e}$ & $\overline{D E V I C E}$ & $\overline{E V I C E}$ \\
\hline
\end{tabular}

\begin{tabular}{|c|c|c|c|}
$\begin{array}{c}\text { HINGE } \\
\text { Reactions }\end{array}$ & $\begin{array}{c}\text { HINGE } \\
\text { Reactions }\end{array}$ & $\begin{array}{c}\text { HINGE } \\
\text { Reactions }\end{array}$ & $\begin{array}{c}\text { HINGE } \\
\text { Reactions }\end{array}$ \\
\hline $\begin{array}{c}\text { BS 294 } \\
\text { (RIIn 294) } \\
\text { (bs) }\end{array}$ & $\begin{array}{c}\text { BS 294 } \\
\text { (RHc 294) } \\
\text { (lbs) }\end{array}$ & $\begin{array}{c}\text { BS 210 } \\
\text { (RHn 210) } \\
\text { (lbs) }\end{array}$ & $\begin{array}{c}\text { BS 210 } \\
(\text { RHc 210) } \\
\text { (lbs) }\end{array}$ \\
\hline 0.00 & 172.16 & 0.00 & 176.34 \\
\hline 0.00 & 108.86 & 0.00 & 111.51 \\
\hline 0.00 & 108.07 & 0.00 & 110.70 \\
\hline 0.00 & 125.82 & 0.00 & 128.88 \\
\hline 0.00 & 186.90 & 0.00 & 191.44 \\
\hline 0.00 & 256.82 & 0.00 & 263.06 \\
\hline
\end{tabular}

\begin{tabular}{|c|c|c|c|c|c|c|c|}
\hline & Sta. 15 & Sta. 16 & Sta. 17 & Sta. 18 & Sta. 19 & totals & totals \\
\hline$V_{0}(\mathrm{~m} / \mathrm{sec})$ & $\begin{array}{c}\text { Moment } \\
\text { in- lb }\end{array}$ & $\begin{array}{c}\text { Moment } \\
\text { in-lb }\end{array}$ & $\begin{array}{c}\text { Moment } \\
\text { in-lb }\end{array}$ & $\begin{array}{c}\text { Moment } \\
\text { in-lb. }\end{array}$ & $\begin{array}{c}\text { Moment } \\
\text { in-lb }\end{array}$ & $\begin{array}{c}\text { Total M } \\
\text { in-lb } \\
\end{array}$ & $\begin{array}{c}\text { Spanwise } \\
\text { (cm) \% } \\
\text { Device span }\end{array}$ \\
\hline 10.0 & 61.1 & 76.0 & 68.1 & 58.1 & 46.4 & 309.7 & 0.469 \\
\hline 20.0 & -15.9 & -11.9 & -10.2 & 23.9 & 22.1 & 8.0 & 3.277 \\
\hline 30.0 & -33.2 & -29.1 & -19.8 & -15.8 & -9.9 & -107.8 & 0.389 \\
\hline 40.0 & -54.2 & -46.6 & -43.7 & -34.3 & -28.9 & -207.6 & 0.439 \\
\hline 50.0 & -44.4 & -37.7 & -45.8 & -35.5 & -34.6 & -198.0 & 0.478 \\
\hline 57.5 & -37.9 & -32.0 & -25.9 & -28.6 & -25.2 & -149.6 & 0.461 \\
\hline
\end{tabular}

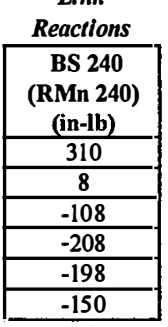

\begin{tabular}{|c|c|c|c|c|c|c|c|c|c|c|}
\hline $\bar{\Omega}$ & (cg) position & Device & Centrifugal & Centrifugal & (cg) position & & & ifugal Loads & & \\
\hline $\mathrm{rad} / \mathrm{sec}$ & pivot offset & Mass & Force & Force & 210 off set & (RHc 294) & (RHn 294) & (RHc 210) & (RHn 210) & $(F z 210)$ \\
\hline & $\mathbf{m}$ & $\mathbf{k g}$ & Newton & $\mathbf{I b}$ & in & lb & lb & lb & lb & lb \\
\hline 5.00 & 6.82 & 17 & 2723.5 & 612.3 & 3.63 & 0 & -26 & 0 & 26 & 612 \\
\hline
\end{tabular}


THE WIND TURBINE $=$ MICON 65/13

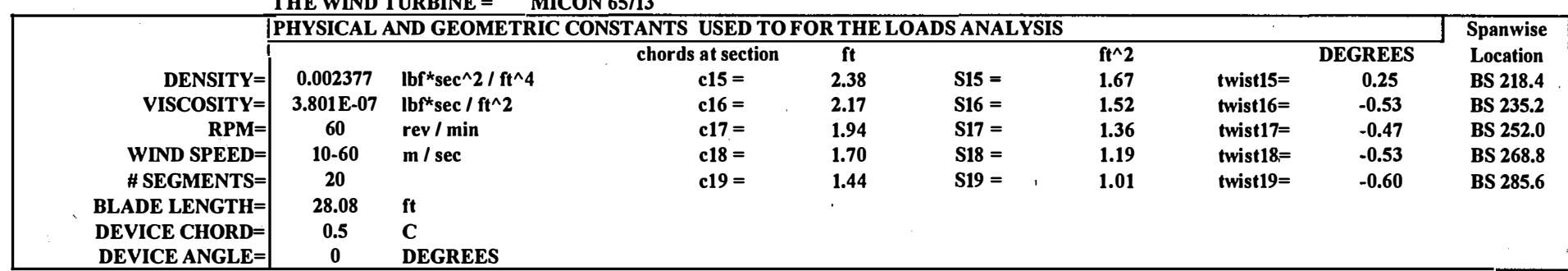

\begin{tabular}{|c|c|c|c|c|c|c|c|c|c|c|c|c|}
\hline & $\begin{array}{l}\text { Blade } \\
\text { Sta. } 15\end{array}$ & $\begin{array}{l}\text { Blade } \\
\text { Sta. } 16\end{array}$ & $\begin{array}{l}\text { Blade } \\
\text { Sta. } 17\end{array}$ & $\begin{array}{l}\text { Blade } \\
\text { Sta. } 18\end{array}$ & $\begin{array}{l}\text { Blade } \\
\text { Sta. } 19\end{array}$ & $\begin{array}{c}\text { DEVICE } \\
\text { totals }\end{array}$ & $\begin{array}{c}\text { DEVICE } \\
\text { totals }\end{array}$ & & $\begin{array}{c}\text { HINGE } \\
\text { Reactions }\end{array}$ & $\begin{array}{c}\text { HINGE } \\
\text { Reactions }\end{array}$ & $\begin{array}{c}\text { HINGE } \\
\text { Reactions }\end{array}$ & $\begin{array}{c}\text { HINGE } \\
\text { Reactions }\end{array}$ \\
\hline $\mathrm{Vo}(\mathrm{m} / \mathrm{sec})$ & $\begin{array}{c}\text { Force- } \\
\text { Normal lb }\end{array}$ & \begin{tabular}{|c|} 
Force-Normal \\
lb
\end{tabular} & $\begin{array}{c}\text { Force-Normal } \\
\mathbf{l b}\end{array}$ & \begin{tabular}{|c|} 
Force-Normal \\
lb
\end{tabular} & $\begin{array}{c}\text { Force-Normal } \\
\text { lb }\end{array}$ & $\begin{array}{c}\text { Total Force- } \\
\text { Normal lb }\end{array}$ & \begin{tabular}{|c|} 
Spanwise (cp) \\
\% Device \\
span
\end{tabular} & & $\begin{array}{c}\text { BS 294 } \\
\text { (RHn 294) } \\
\text { (Obs) }\end{array}$ & $\begin{array}{c}\text { BS 294 } \\
\text { (RHc 294) } \\
\text { (lbs) }\end{array}$ & $\begin{array}{c}\text { BS 210 } \\
\text { (RHn 210) } \\
\text { (lbs) }\end{array}$ & $\begin{array}{c}\text { BS 210 } \\
\text { (RHc 210) } \\
\text { (jbs) }\end{array}$ \\
\hline 10.0 & 29.4 & 30.2 & 30.4 & 29.7 & 28.0 & 147.6 & 0.495 & & 72.94 & 0.00 & 74.71 & 0.00 \\
\hline 20.0 & 39.3 & 39.1 & 37.8 & 35.4 & 31.1 & 182.7 & 0.478 & & 90.25 & 0.00 & 92.44 & 0.00 \\
\hline 30.0 & 62.6 & 61.0 & 51.5 & 47.5 & 45.9 & 268.4 & 0.465 & & 132.60 & 0.00 & 135.82 & 0.00 \\
\hline 40.0 & 95.6 & 91.5 & 82.3 & 69.2 & 73.9 & 412.5 & 0.468 & & 203.79 & 0.00 & 208.74 & 0.00 \\
\hline 50.0 & 137.2 & 129.5 & 111.5 & 100.0 & 100.8 & 579.0 & 0.465 & & 286.04 & 0.00 & 292.99 & 0.00 \\
\hline 57.5 & 175.4 & 164.1 & 140.6 & 125.1 & 122.2 & 727.3 & 0.460 & & 359.28 & 0.00 & 368.00 & 0.00 \\
\hline & $\begin{array}{l}\text { Blade } \\
\text { Sta. } 15\end{array}$ & $\begin{array}{l}\text { Blade } \\
\text { Sta. } 16\end{array}$ & $\begin{array}{l}\text { Blade } \\
\text { Sta. } 17\end{array}$ & $\begin{array}{l}\text { Blade } \\
\text { Sta. } 18\end{array}$ & $\begin{array}{l}\text { Blade } \\
\text { Sta. } 19\end{array}$ & $\begin{array}{c}\text { DEVICE } \\
\text { totals }\end{array}$ & $\begin{array}{l}\text { DEVICE } \\
\text { totals }\end{array}$ & & $\begin{array}{c}\text { Magnet } \\
\text { Reactions }\end{array}$ & $\begin{array}{c}\text { Magnet } \\
\text { Reactions }\end{array}$ & $\begin{array}{c}\text { Magnet } \\
\text { Reactions }\end{array}$ & \\
\hline$V_{0}(m / s e c)$ & $\begin{array}{c}\text { Moment } \\
\text { in-lb }\end{array}$ & $\begin{array}{c}\text { Moment } \\
\text { in- lb }\end{array}$ & $\begin{array}{l}\text { Moment } \\
\text { in-lb }\end{array}$ & $\begin{array}{c}\text { Moment } \\
\text { in-lb }\end{array}$ & $\begin{array}{c}\text { Moment } \\
\text { in-lb }\end{array}$ & $\begin{array}{c}\text { Total M } \\
\text { in-lb }\end{array}$ & $\begin{array}{c}\text { Spanwise } \\
(\mathrm{cm}) \% \\
\text { Device span }\end{array}$ & & $\begin{array}{c}\text { BS 294 } \\
\text { (RMn 294) } \\
\text { (in-1b) }\end{array}$ & $\begin{array}{c}\text { BS 240 } \\
\text { (RMn 240) } \\
\text { (in-lb) }\end{array}$ & $\begin{array}{c}\text { BS 210 } \\
\text { (RMn 210) } \\
\text { (in-lb) }\end{array}$ & \\
\hline 10.0 & 81.5 & 76.5 & 68.8 & 58.8 & 47.1 & 332.7 & 0.448 & & 99.81 & 166.34 & 133.07 & \\
\hline 20.0 & 65.3 & 58.4 & 50.6 & 41.5 & 32.9 & 248.7 & 0.434 & & 74.62 & 124.36 & 99.49 & \\
\hline 30.0 & 118.3 & 105.1 & 75.9 & 61.2 & 51.5 & 412.1 & 0.414 & & 123.62 & 206.03 & 164.82 & \\
\hline 40.0 & 183.9 & 160.4 & 130.5 & 96.2 & 87.3 & 658.4 & 0.422 & & 197.51 & 329.19 & 263.35 & \\
\hline 50.0 & 270.5 & 232.6 & 181.0 & 142.0 & 117.7 & 943.8 & 0.416 & & 283.13 & 471.88 & 377.51 & \\
\hline 57.5 & 351.3 & 299.6 & 226.1 & 176.1 & 147.4 & 1200.6 & 0.411 & & 360.18 & 600.30 & 480.24 & \\
\hline$\Omega$ & (cg) position & Device & Centrifugal & Centrifugal & (c) position & & Cen & rifugal Loads & & & & \\
\hline $\mathrm{rad} / \mathrm{sec}$ & pivot off set & Mass & Force & Force & 210 offset & (RHc 294) & (RHn 294) & (RHc 210) & (RHn 210) & (Fz 210) & & \\
\hline & $\mathrm{m}$ & $\mathrm{kg}$ & Newton & lb & in & lb & lb & lb & lb & lb & & \\
\hline 6.28 & 6.82 & 17 & 4309.1 & 968.8 & 3.63 & 42 & 0 & -42 & 0 & 969 & & \\
\hline
\end{tabular}


THE WIND TURBINE $=$ MICON 65/13

\begin{tabular}{|c|c|c|c|c|c|c|c|c|c|}
\hline & \multicolumn{8}{|c|}{ PHYSICAL AND GEOMETRIC CONSTANTS USED TO FOR THE LOADS ANALYSIS } & \multirow{2}{*}{$\begin{array}{l}\text { Spanwise } \\
\text { Location }\end{array}$} \\
\hline & & & chords at section & ft & & $\mathrm{ft}^{\wedge} \mathbf{2}$ & & DEGREES & \\
\hline DENSITY $=$ & 0.002377 & $\mathrm{lb}^{\star} \sec ^{\wedge} 2 / \mathrm{ft}^{\wedge} 4$ & $\mathbf{c 1 5}=$ & 2.38 & S15 $=$ & 1.67 & twist15= & 0.25 & BS 218.4 \\
\hline VISCOSITY $=$ & 3.801E-07 & $\mathbf{l b f} \mathbf{f}^{\star} \sec / \mathrm{ft}^{\wedge} \mathbf{2}$ & c16 $=$ & 2.17 & $S 16=$ & 1.52 & twist16 $=$ & -0.53 & BS 235.2 \\
\hline $\mathbf{R P M}=$ & 60 & $\mathrm{rev} / \mathrm{min}$ & c17 $=$ & 1.94 & S17 $=$ & 1.36 & twist17= & -0.47 & BS 252.0 \\
\hline WIND SPEED $=$ & $10-60$ & $\mathrm{~m} / \mathrm{sec}$ & c18 = & 1.70 & $S 18=$ & 1.19 & twist $18=$ & -0.53 & BS 268.8 \\
\hline \# SEGMENTS= & 20 & & c19 $=$ & 1.44 & $\mathbf{S} 19=$ & 1.01 & twist19= & -0.60 & BS 285.6 \\
\hline BLADE LENGTH= & 28.08 & ft & & & & & & & \\
\hline DEVICE CHORD $=$ & 0.5 & & & & & & & & \\
\hline DEVICE ANGLE $=$ & 10 & DEGREES & & & & & & & \\
\hline
\end{tabular}

\begin{tabular}{|c|c|c|c|c|c|c|c|}
\hline & $\begin{array}{c}\text { Blade } \\
\text { Sta. } 15\end{array}$ & $\begin{array}{l}\text { Blade } \\
\text { Sta. } 16\end{array}$ & $\begin{array}{c}\text { Blade } \\
\text { Sta. } 17\end{array}$ & $\begin{array}{c}\text { Blade } \\
\text { Sta. } 18\end{array}$ & $\begin{array}{l}\text { Blade } \\
\text { Sta. } 19\end{array}$ & $\begin{array}{c}\text { DEVICE } \\
\text { totals }\end{array}$ & $\begin{array}{c}\text { DEVICE } \\
\text { totals }\end{array}$ \\
\hline$V_{0}(\mathrm{~m} / \mathrm{sec})$ & $\begin{array}{c}\text { Force- } \\
\text { Normal lb }\end{array}$ & $\begin{array}{c}\text { Force-Normal } \\
\text { Ib }\end{array}$ & $\begin{array}{c}\text { Force-Normal } \\
\text { lb }\end{array}$ & \begin{tabular}{|c} 
Force-Normal \\
lb
\end{tabular} & $\begin{array}{c}\text { Force-Normal } \\
\text { lb }\end{array}$ & $\begin{array}{l}\text { Total Force- } \\
\text { Normal lb }\end{array}$ & \begin{tabular}{|c}
$\begin{array}{c}\text { Spanwise (cp) } \\
\% \text { Device } \\
\text { span }\end{array}$ \\
\end{tabular} \\
\hline 10.0 & 17.8 & 18.4 & 18.5 & 18.0 & 17.0 & 89.7 & 0.495 \\
\hline 20.0 & 36.7 & 37.2 & 36.0 & 33.7 & 35.1 & 178.6 & 0.493 \\
\hline 30.0 & 62.6 & 61.0 & 51.5 & 47.5 & 45.9 & 268.4 & 0.465 \\
\hline 40.0 & 95.6 & 91.5 & 82.3 & 69.2 & 73.9 & 412.5 & 0.468 \\
\hline 50.0 & 137.2 & 129.5 & 111.5 & 100.0 & 100.8 & 579.0 & 0.465 \\
\hline 57.5 & 175.4 & 164.1 & .140 .6 & 125.1 & 122.2 & 727.3 & 0.460 \\
\hline & $\begin{array}{l}\text { Blade } \\
\text { Sta. } 15\end{array}$ & $\begin{array}{c}\text { Blade } \\
\text { Sta. } 16\end{array}$ & $\begin{array}{l}\text { Blade } \\
\text { Sta. } 17\end{array}$ & $\begin{array}{c}\text { Blade } \\
\text { Sta. } 18\end{array}$ & $\begin{array}{c}\text { Blade } \\
\text { Sta. } 19\end{array}$ & $\begin{array}{c}\text { DEVICE } \\
\text { totals }\end{array}$ & $\begin{array}{c}\text { DEVICE } \\
\text { totals }\end{array}$ \\
\hline
\end{tabular}

\begin{tabular}{|c|c|c|c|}
\hline $\begin{array}{c}\text { HINGE } \\
\text { Reactions }\end{array}$ & $\begin{array}{c}\text { HINGE } \\
\text { Reactions }\end{array}$ & $\begin{array}{c}\text { HINGE } \\
\text { Reactions }\end{array}$ & $\begin{array}{c}\text { HINGE } \\
\text { Reactions }\end{array}$ \\
\hline $\begin{array}{c}\text { BS 294 } \\
\text { (RHn 294) } \\
\text { (lbs) }\end{array}$ & $\begin{array}{c}\text { BS 294 } \\
\text { (RHc 294) } \\
\text { (lbs) }\end{array}$ & $\begin{array}{c}\text { BS 210 } \\
\text { (RHn 210) } \\
\text { (lbs) }\end{array}$ & $\begin{array}{c}\text { BS 210 } \\
\text { (RHc 210) } \\
\text { (lbs) }\end{array}$ \\
\hline 43.63 & 7.69 & 44.69 & 7.88 \\
\hline 86.91 & 15.32 & 89.02 & 15.70 \\
\hline 130.59 & 23.03 & 133.76 & 23.59 \\
\hline 200.70 & 35.39 & 205.57 & 36.25 \\
\hline 281.70 & 49.67 & 288.54 & 50.88 \\
\hline 353.82 & 62.39 & 362.41 & 63.90 \\
\hline
\end{tabular}

\begin{tabular}{|c|c|c|c|c|c|c|c|}
\hline \multicolumn{1}{c}{ Sta. 15 } & \multicolumn{1}{c}{ Sta. 16 } & Sta. 17 & Sta. 18 & Sta. 19 & totals & totals \\
\hline Vo(m/sec) & $\begin{array}{c}\text { Moment } \\
\text { in-lb }\end{array}$ & $\begin{array}{c}\text { Moment } \\
\text { in-lb }\end{array}$ & $\begin{array}{c}\text { Moment } \\
\text { in- lb }\end{array}$ & $\begin{array}{c}\text { Moment } \\
\text { in-1b }\end{array}$ & $\begin{array}{c}\text { Moment } \\
\text { in- Ib }\end{array}$ & $\begin{array}{c}\text { Total M } \\
\text { in- lb }\end{array}$ & $\begin{array}{c}\text { Spanwise } \\
\text { (cm) \% } \\
\text { Device span }\end{array}$ \\
\hline 10.0 & 26.6 & 25.0 & 22.4 & 19.2 & 15.4 & 108.6 & 0.448 \\
\hline 20.0 & 65.6 & 60.7 & 52.6 & 43.1 & 37.8 & 259.7 & 0.444 \\
\hline 30.0 & 116.4 & 103.4 & 77.7 & 62.7 & 49.6 & 409.8 & 0.415 \\
\hline 40.0 & 179.2 & 156.3 & 125.3 & 92.2 & 83.6 & 636.6 & 0.420 \\
\hline 50.0 & 260.2 & 223.8 & 174.4 & 136.8 & 114.6 & 909.8 & 0.417 \\
\hline 57.5 & 332.5 & 283.5 & 217.5 & 169.4 & 142.0 & 1144.9 & 0.414 \\
\hline
\end{tabular}

\begin{tabular}{|c|}
\hline Reactions \\
(RMn 240) \\
(in-1b) \\
\hline 109 \\
\hline 260 \\
\hline 410 \\
\hline 637 \\
\hline 910 \\
\hline 1145 \\
\hline
\end{tabular}

\begin{tabular}{|c|c|c|c|c|c|c|c|c|c|c|}
\hline $\bar{\Omega}$ & (cg) position & Device & Centrifugal & Centrifugal & (cg) position & & & ifugal Loads & & \\
\hline $\mathrm{rad} / \mathrm{sec}$ & pivot offset & Mass & Force & Force & 210 offset & (RHc 294) & (RHn 294) & (RHc 210) & $(\operatorname{RBn} 210)$ & $(\mathrm{Fz} 210)$ \\
\hline & $\mathbf{m}$ & kg & Newton & $\mathbf{l b}$ & in & lb & lb & lb & lb & lb \\
\hline 6.28 & 6.82 & 17 & 4309.1 & 968.8 & 3.63 & 41 & -7 & -41 & 7 & 969 \\
\hline
\end{tabular}


THE WIND TURBINE $=$ MICON 65/13

\begin{tabular}{|c|c|c|c|c|c|c|c|c|c|}
\hline & \multicolumn{8}{|c|}{ PHYSICAL AND GEOMETRIC CONST ANTS USED TO FOR THE LOADS ANALYSIS } & \multirow{2}{*}{$\begin{array}{l}\text { Spanwise } \\
\text { Location } \\
\text { BS 218.4 }\end{array}$} \\
\hline & & & chords at section & ft & & $\mathrm{ft}^{\wedge} \mathbf{2}$ & & DEGREES & \\
\hline VISCOSITY $=$ & 3.801E-07 & $\mathbf{l b { } ^ { \star }} \sec / \mathrm{ft}^{\wedge} \mathbf{2}$ & $\mathbf{c 1 6}=$ & 2.17 & S16 $=$ & 1.52 & twist16= & -0.53 & BS 235.2 \\
\hline $\mathbf{R P M}=$ & 60 & $\mathrm{rev} / \mathrm{min}$ & $\mathbf{c 1 7}=$ & 1.94 & $\mathbf{S} 17=$ & 1.36 & twist17= & -0.47 & BS 252.0 \\
\hline \# SEGMENTS= & 20 & & $\mathbf{c 1 9}=$ & 1.44 & $\mathbf{S 1 9}=$ & 1.01 & twist19= & -0.60 & BS 285.6 \\
\hline BLADE LENGTH $=$ & 28.08 & ft & & & & & & & \\
\hline DEVICE CHORD $=$ & 0.5 & C & & & & & & & \\
\hline DEVICE ANGLE = & 60 & DEGREES & & & & & & & \\
\hline
\end{tabular}

\begin{tabular}{|c|c|c|c|c|c|c|c|c|c|c|}
\hline & $\begin{array}{l}\text { Blade } \\
\text { Sta. } 15\end{array}$ & $\begin{array}{c}\text { Blade } \\
\text { Sta. } 16\end{array}$ & $\begin{array}{c}\text { Blade } \\
\text { Sta. } 17\end{array}$ & $\begin{array}{c}\text { Blade } \\
\text { Sta. } 18\end{array}$ & $\begin{array}{c}\text { Blade } \\
\text { Sta. } 19\end{array}$ & $\begin{array}{c}\text { DEVICE } \\
\text { totals }\end{array}$ & $\begin{array}{c}\text { DEVICE } \\
\text { totals }\end{array}$ & & $\begin{array}{c}\text { HINGE } \\
\text { Reactions }\end{array}$ & $\begin{array}{c}\text { HINGE } \\
\text { Reactions }\end{array}$ \\
\hline$V_{0}(\mathrm{~m} / \mathrm{sec})$ & $\begin{array}{c}\text { Force- } \\
\text { Normal lb }\end{array}$ & \begin{tabular}{|c} 
Force-Normal \\
lb
\end{tabular} & $\begin{array}{c}\text { Force-Normal } \\
\text { lb }\end{array}$ & \begin{tabular}{|c} 
Force-Normal \\
lb
\end{tabular} & $\begin{array}{c}\text { Force-Normal } \\
\text { lb }\end{array}$ & $\begin{array}{l}\text { Total Force- } \\
\text { Normal lb }\end{array}$ & \begin{tabular}{|c|} 
Spanwise (cp) \\
\% Device \\
span
\end{tabular} & & $\begin{array}{c}\text { BS 294 } \\
\text { (RHn 294) } \\
\text { (lbs) }\end{array}$ & $\begin{array}{c}\text { BS 294 } \\
\text { (RHc 294) } \\
\text { (lbs) }\end{array}$ \\
\hline 10.0 & 62.3 & 64.2 & 64.4 & 62.9 & 59.3 & 313.2 & 0.495 & & 77.36 & 133.98 \\
\hline 20.0 & 61.3 & 51.9 & 50.3 & 47.0 & 53.5 & 264.0 & 0.484 & & 65.20 & 112.93 \\
\hline 30.0 & 74.8 & 72.9 & 73.6 & 67.8 & 71.4 & 360.4 & 0.493 & & 89.03 & 154.20 \\
\hline 40.0 & 93.4 & 89.4 & 84.9 & 77.5 & 82.7 & 427.9 & 0.484 & & 105.70 & 183.08 \\
\hline 50.0 & 108.5 & 102.3 & 105.6 & 94.6 & 98.5 & 509.5 & 0.489 & & 125.85 & 217.98 \\
\hline \multirow[t]{2}{*}{57.5} & 128.3 & 120.1 & 111.1 & 98.8 & 115.6 & 574.0 & 0.484 & & 141.79 & 245.59 \\
\hline & $\begin{array}{l}\text { Blade } \\
\text { Sta. } 15 \\
\end{array}$ & $\begin{array}{l}\text { Blade } \\
\text { Sta. } 16 \\
\end{array}$ & $\begin{array}{c}\text { Blade } \\
\text { Sta. } 17 \\
\end{array}$ & $\begin{array}{l}\text { Blade } \\
\text { Sta. } 18 \\
\end{array}$ & $\begin{array}{c}\text { Blade } \\
\text { Sta. } 19 \\
\end{array}$ & $\begin{array}{c}\text { DEVICE } \\
\text { totals }\end{array}$ & $\begin{array}{c}\text { DEVICE } \\
\text { totals }\end{array}$ & & $\begin{array}{c}\text { Link } \\
\text { Reactions }\end{array}$ & \\
\hline$V_{0}(\mathrm{~m} / \mathrm{sec})$ & $\begin{array}{c}\text { Moment } \\
\text { in- lb }\end{array}$ & $\begin{array}{c}\text { Moment } \\
\text { in-lb }\end{array}$ & $\begin{array}{c}\text { Moment } \\
\text { in-lb }\end{array}$ & $\begin{array}{c}\text { Moment } \\
\text { in-lb }\end{array}$ & $\begin{array}{c}\text { Moment } \\
\text { in- lb }\end{array}$ & $\begin{array}{c}\text { Total M } \\
\text { in-lb }\end{array}$ & \begin{tabular}{c|} 
Spanwise \\
$(\mathrm{cm}) \%$ \\
Device span
\end{tabular} & & $\begin{array}{c}\text { BS 240 } \\
\text { (RMn 240) } \\
\text { (in-lb) }\end{array}$ & \\
\hline 10.0 & 73.3 & 68.8 & 61.9 & 52.9 & 42.4 & 299.3 & 0.448 & & 299 & \\
\hline 20.0 & 21.9 & 20.0 & 17.3 & 14.2 & 16.6 & 90.0 & 0.463 & & 90 & \\
\hline 30.0 & 19.8 & 17.5 & 16.0 & 12.9 & 12.6 & 78.8 & 0.452 & & 79 & \\
\hline 40.0 & 22.7 & 19.8 & 19.3 & 15.2 & 13.8 & 90.8 & 0.451 & & 91 & \\
\hline 50.0 & 10.5 & 9.0 & 23.3 & 18.3 & 14.5 & 75.5 & 0.546 & & 76 & \\
\hline 57.5 & 5.3 & 4.5 & 8.8 & 6.8 & 19.0 & 44.4 & 0.634 & & 44 & \\
\hline $\bar{\Omega}$ & (cg) position & Device & Centrifugal & Centrifugal & (cg) position & & & fifugal Loads & & \\
\hline \multirow[t]{2}{*}{$\mathrm{rad} / \mathrm{sec}$} & pivot offset & Mass & Force & Force & 210 offset & (RHc 294) & (RHn 294) & (RHc 210) & (RHn 210) & (Fz 210) \\
\hline & $\mathbf{m}$ & $\mathrm{kg}$ & Newton & $\mathbf{l b}$ & in & $\mathbf{l b}$ & $\mathbf{l b}$ & $\mathbf{l b}$ & $\mathbf{l b}$ & $\mathbf{l b}$ \\
\hline 6.28 & 6.82 & 17 & 4309.1 & 968.8 & 3.63 & 21 & -36 & -21 & 36 & 969 \\
\hline
\end{tabular}


THE WIND TURBINE $=\quad$ MICON 65/13

\begin{tabular}{|c|c|c|c|c|c|c|c|c|c|}
\hline \multirow{4}{*}{$\begin{array}{r}\text { DENSITY }= \\
\text { VISCOSITY }\end{array}$} & \multicolumn{8}{|c|}{ PHYSICAL AND GEOMETRIC CONSTANTS USED TO FOR THE LOADS ANALYSIS } & \multirow{3}{*}{$\begin{array}{l}\text { Spanwise } \\
\text { Location } \\
\text { BS 218.4 }\end{array}$} \\
\hline & & & chords at section & ft & & $\mathbf{f t} \mathbf{A}^{\wedge}$ & & DEGREES & \\
\hline & 0.002377 & $1 \mathrm{lb}^{\star} \sec ^{\wedge} \mathbf{2} / \mathrm{ft}^{\wedge} 4$ & $\mathbf{c 1 5}=$ & 2.38 & S15 $=$ & 1.67 & twist15= & 0.25 & \\
\hline & 3.801E-07 & $\mathrm{lbf}^{\star} \sec / \mathrm{ft}^{\wedge} \mathrm{2}$ & $\mathbf{c 1 6}=$ & 2.17 & S16 $=$ & 1.52 & twist16= & -0.53 & BS 235.2 \\
\hline $\mathbf{R P M}=$ & 60 & $\mathrm{rev} / \mathrm{min}$ & $\mathbf{c 1 7}=$ & 1.94 & S17 $=$ & 1.36 & twist17= & -0.47 & BS 252.0 \\
\hline WIND SPEED $=$ & $10-60$ & $\mathrm{~m} / \mathrm{sec}$ & $\mathbf{c} 18=$ & 1.70 & S18 $=$ & 1.19 & twist 18= & -0.53 & BS 268.8 \\
\hline \# SEGMENTS= & 20 & & $\mathrm{c} 19=$ & 1.44 & $\mathbf{S} 19=$ & 1.01 & twist19= & -0.60 & BS.285.6 \\
\hline BLADE LENGTH= & 28.08 & ft & & & & & & & \\
\hline DEVICE CHORD= & 0.5 & $\mathbf{C}$ & & & & & & & \\
\hline DEVICE ANGLE $=$ & 90 & DEGREES & & & & & & & \\
\hline
\end{tabular}

\begin{tabular}{|c|c|c|c|c|c|c|c|}
\hline & $\begin{array}{l}\text { Blade } \\
\text { Sta. } 15\end{array}$ & $\begin{array}{c}\text { Blade } \\
\text { Sta. } 16\end{array}$ & $\begin{array}{l}\text { Blade } \\
\text { Sta. } 17\end{array}$ & $\begin{array}{c}\text { Blade } \\
\text { Sta. } 18\end{array}$ & $\begin{array}{c}\text { Blade } \\
\text { Sta. } 19\end{array}$ & $\begin{array}{c}\text { DEVICE } \\
\text { totals }\end{array}$ & $\begin{array}{c}\text { DEVICE } \\
\text { totals }\end{array}$ \\
\hline$V_{0}(\mathrm{~m} / \mathrm{sec})$ & $\begin{array}{c}\text { Force- } \\
\text { Normal lb }\end{array}$ & $\begin{array}{c}\text { Force-Normal } \\
\text { lb }\end{array}$ & $\begin{array}{c}\text { Force-Normal } \\
\text { lb }\end{array}$ & $\begin{array}{c}\text { Force-Normal } \\
\text { lb }\end{array}$ & $\begin{array}{c}\text { Force-Normal } \\
\text { lb }\end{array}$ & $\begin{array}{c}\text { Total Force- } \\
\text { Normal lb }\end{array}$ & $\begin{array}{c}\text { Spanwise (cp) } \\
\text { \% Device } \\
\text { span }\end{array}$ \\
\hline 10.0 & 115.3 & 118.7 & 119.2 & 116.4 & 109.8 & 579.4 & 0.495 \\
\hline 20.0 & 86.2 & 91.0 & 88.1 & 82.4 & 92.6 & 440.2 & 0.502 \\
\hline 30.0 & 70.7 & 68.9 & 64.1 & 59.1 & 59.4 & 322.2 & 0.480 \\
\hline 40.0 & 67.9 & 65.0 & 67.0 & 66.0 & 70.5 & 336.5 & 0.504 \\
\hline 50.0 & 94.5 & 89.1 & 76.5 & 68.5 & 71.6 & 400.2 & 0.467 \\
\hline 57.5 & 111.8 & 104.6 & 96.8 & 86.1 & 83.7 & 483.1 & 0.469 \\
\hline & & & 5 & 5 & 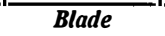 & $\overline{D E V I C L}$ & EVICE \\
\hline
\end{tabular}

\begin{tabular}{|c|c|c|c|}
\hline $\begin{array}{c}\text { HINGE } \\
\text { Reactions }\end{array}$ & $\begin{array}{c}\text { HINGE } \\
\text { Reactions }\end{array}$ & $\begin{array}{c}\text { HINGE } \\
\text { Reactions }\end{array}$ & $\begin{array}{c}\text { HINGE } \\
\text { Reactions }\end{array}$ \\
\hline $\begin{array}{c}\text { BS 294 } \\
\text { (RHn 294) } \\
\text { (abs) }\end{array}$ & $\begin{array}{c}\text { BS 294 } \\
\text { (RHc 294) } \\
\text { (lbs) }\end{array}$ & $\begin{array}{c}\text { BS 210 } \\
\text { (RHn 210) } \\
\text { (lbs) }\end{array}$ & $\begin{array}{c}\text { BS 210 } \\
\text { (RHc 210) } \\
\text { (lbs) }\end{array}$ \\
\hline 0.00 & 286.22 & 0.00 & 293.17 \\
\hline 0.00 & 217.46 & 0.00 & $222: 74$ \\
\hline 0.00 & 159.19 & 0.00 & 163.05 \\
\hline 0.00 & 166.21 & 0.00 & 170.25 \\
\hline 0.00 & 197.70 & 0.00 & 202.50 \\
\hline 0.00 & 238.65 & 0.00 & 244.45 \\
\hline
\end{tabular}

\begin{tabular}{|c|c|c|c|c|c|c|c|}
\multicolumn{1}{c}{ Sta. 15 } & Sta. 16 & Sta. 17 & Sta. 18 & Sta. 19 & totals & totals \\
\hline Vo(m/sec) & $\begin{array}{c}\text { Moment } \\
\text { in-1b }\end{array}$ & $\begin{array}{c}\text { Moment } \\
\text { in-1b }\end{array}$ & $\begin{array}{c}\text { Moment } \\
\text { in- lb }\end{array}$ & $\begin{array}{c}\text { Moment } \\
\text { in-lb }\end{array}$ & $\begin{array}{c}\text { Moment } \\
\text { in- lb }\end{array}$ & $\begin{array}{c}\text { Total M } \\
\text { in- lb }\end{array}$ & $\begin{array}{c}\text { Spanwise } \\
\text { (cm) \% } \\
\text { Device span }\end{array}$ \\
\hline 10.0 & 146.7 & 137.7 & 123.8 & 105.9 & 84.8 & 598.9 & 0.448 \\
\hline 20.0 & 54.1 & 61.5 & 53.3 & 43.6 & 48.0 & 260.5 & 0.477 \\
\hline 30.0 & -24.4 & -21.6 & -21.3 & -17.2 & -13.1 & -97.6 & 0.445 \\
\hline 40.0 & -71.0 & -61.9 & -40.6 & -26.2 & -23.7 & -223.4 & 0.383 \\
\hline 50.0 & -85.1 & -73.2 & -68.6 & -53.9 & -45.4 & -326.2 & 0.440 \\
\hline 57.5 & -92.6 & -79.0 & -71.1 & -55.4 & -55.9 & -354.0 & 0.445 \\
\hline
\end{tabular}

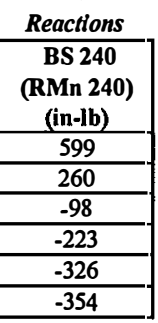

\begin{tabular}{|c|c|c|c|c|c|c|c|c|c|c|}
\hline $\boldsymbol{\Omega}$ & (cg) position & Device & Centrifugal & Centrifugal & (cg) position & & \multicolumn{2}{|c|}{ Centrifugal Loads } & & \\
\hline $\mathrm{rad} / \mathrm{sec}$ & pivot offset & Mass & Force & Force & 210 off set & (RHc 294) & (RHn 294) & (RHc 210) & (RHn 210) & $\overline{(F z 210)}$ \\
\hline & $\mathbf{m}$ & $\mathrm{kg}$ & Newton & $\mathbf{l b}$ & in & $\mathbf{l b}$ & $\mathbf{l b}$ & $\mathbf{l b}$ & $\mathbf{l b}$ & lb \\
\hline 6.28 & 6.82 & 17 & 4309.1 & 968.8 & 3.63 & 0 & -42 & 0 & 42 & 969 \\
\hline
\end{tabular}


THE WIND TURBINE $=$ MICON 65/13

\begin{tabular}{|c|c|c|c|c|c|c|c|c|c|}
\hline \multirow[b]{2}{*}{ DENSITY $=$} & \multicolumn{8}{|c|}{ PHYSICAL AND GEOMETRIC CONSTANTS USED TO FOR THE LOADS ANALYSIS } & $\begin{array}{l}\text { Spanwise } \\
\text { Location }\end{array}$ \\
\hline & 0.002377 & 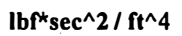 & $\mathbf{c 1 5}=$ & 2.38 & S15 $=$ & 1.67 & twist15= & 0.25 & BS 218.4 \\
\hline VISCOSITY $=$ & 3.801E-07 & lbf*sec / ft^ ${ }^{\wedge}$ & c16 = & 2.17 & $\mathrm{~S} 16=$ & 1.52 & twist16= & -0.53 & BS 235.2 \\
\hline $\mathbf{R P M}=$ & 65 & $\mathrm{rev} / \mathrm{min}$ & $\mathbf{c 1 7}=$ & 1.94 & $\mathbf{S 1 7}=$ & 1.36 & twist17= & -0.47 & BS 252.0 \\
\hline \# SEGMENTS= & 20 & & $\mathbf{c 1 9}=$ & 1.44 & $\mathbf{S} 19=$ & 1.01 & twist19= & -0.60 & BS 285.6 \\
\hline BLADE LENGTH= & 28.08 & ft & & & & & & & \\
\hline DEVICE CHORD $=$ & 0.5 & C & & & & & & & \\
\hline DEVICE ANGLE $=$ & 0 & DEGREES & & & & & & & \\
\hline
\end{tabular}

\begin{tabular}{|c|c|c|c|c|c|c|c|}
\hline & $\begin{array}{l}\text { Blade } \\
\text { Sta. } 15\end{array}$ & $\begin{array}{l}\text { Blade } \\
\text { Sta. } 16\end{array}$ & $\begin{array}{c}\text { Blade } \\
\text { Sta. } 17\end{array}$ & $\begin{array}{c}\text { Blade } \\
\text { Sta. } 18\end{array}$ & $\begin{array}{l}\text { Blade } \\
\text { Sta. } 19\end{array}$ & $\begin{array}{c}\text { DEVICE } \\
\text { totals }\end{array}$ & $\begin{array}{c}\text { DEVICE } \\
\text { totals }\end{array}$ \\
\hline$V_{0}(\mathrm{~m} / \mathrm{sec})$ & $\begin{array}{c}\text { Force- } \\
\text { Normal lb }\end{array}$ & $\begin{array}{c}\text { Force-Normal } \\
\text { lb }\end{array}$ & $\begin{array}{c}\text { Force-Normal } \\
\text { lb }\end{array}$ & $\begin{array}{c}\text { Force-Normal } \\
\text { lb }\end{array}$ & \begin{tabular}{|c|} 
Force-Normal \\
lb
\end{tabular} & $\begin{array}{c}\text { Total Force- } \\
\text { Normal lb }\end{array}$ & $\begin{array}{c}\text { Spanwise (cp) } \\
\text { \% Device } \\
\text { span }\end{array}$ \\
\hline 10.0 & 42.7 & 44.0 & 44.3 & 43.3 & 40.8 & 215.1 & 0.496 \\
\hline 20.0 & 44.8 & 44.6 & 43.3 & 40.6 & 44.7 & 218.1 & 0.496 \\
\hline 30.0 & 69.5 & 60.5 & 57.7 & 47.8 & 51.9 & 287.4 & 0.467 \\
\hline 40.0 & 99.9 & 96.1 & 83.7 & 76.3 & 76.9 & 432.9 & 0.470 \\
\hline 50.0 & 136.7 & 129.7 & 115.0 & 103.6 & 105.4 & 590.4 & 0.470 \\
\hline 60.0 & 195.8 & 183.6 & 157.7 & 140.6 & 137.6 & 815.3 & 0.461 \\
\hline & $\begin{array}{c}\text { Blade } \\
\text { Sta. } 15\end{array}$ & $\begin{array}{l}\text { Blade } \\
\text { Sta. } 16 \\
\end{array}$ & $\begin{array}{c}\text { Blade } \\
\text { Sta. } 17 \\
\end{array}$ & $\begin{array}{c}\text { Blade } \\
\text { Sta. } 18 \\
\end{array}$ & $\begin{array}{c}\text { Blade } \\
\text { Sta. } 19\end{array}$ & $\begin{array}{c}\text { DEVICE } \\
\text { totals } \\
\end{array}$ & $\begin{array}{c}\text { DEVICE } \\
\text { totals }\end{array}$ \\
\hline$V_{0}(\mathrm{~m} / \mathrm{sec})$ & $\begin{array}{c}\text { Moment } \\
\text { in-lb }\end{array}$ & $\begin{array}{c}\text { Moment } \\
\text { in-lb }\end{array}$ & $\begin{array}{c}\text { Moment } \\
\text { in-lb }\end{array}$ & $\begin{array}{c}\text { Moment } \\
\text { in-lb }\end{array}$ & $\begin{array}{l}\text { Moment } \\
\text { in- lb }\end{array}$ & $\begin{array}{c}\text { Total M } \\
\text { in- lb }\end{array}$ & $\begin{array}{c}\text { Spanwise } \\
\text { (cm) \% } \\
\text { Device span }\end{array}$ \\
\hline 10.0 & 118.5 & 111.4 & 100.2 & 85.8 & 68.7 & 484.6 & 0.448 \\
\hline 20.0 & 73.5 & 66.7 & 61.7 & 50.7 & 47.4 & 300.0 & 0.455 \\
\hline 30.0 & 131.5 & 99.5 & 85.1 & 63.1 & 58.2 & 437.4 & 0.416 \\
\hline 40.0 & 194.2 & 170.3 & 133.0 & 106.1 & 88.2 & 691.8 & 0.420 \\
\hline 50.0 & 272.0 & 235.1 & 180.5 & 142.3 & 124.4 & 954.1 & 0.419 \\
\hline 60.0 & 392.4 & 335.3 & 253.6 & 197.9 & 166.0 & 1345.2 & 0.412 \\
\hline
\end{tabular}

\begin{tabular}{|c|c|c|c|}
\hline $\begin{array}{c}\text { HINGE } \\
\text { Reactions }\end{array}$ & $\begin{array}{c}\text { HINGE } \\
\text { Reactions }\end{array}$ & $\begin{array}{c}\text { HINGE } \\
\text { Reactions }\end{array}$ & $\begin{array}{c}\text { HINGE } \\
\text { Reactions }\end{array}$ \\
\hline $\begin{array}{c}\text { BS 294 } \\
\text { (RHn 294) }\end{array}$ & $\begin{array}{c}\text { BS 294 } \\
\text { (RHc 294) }\end{array}$ & $\begin{array}{c}\text { BS 210 } \\
\text { (RHn 210) }\end{array}$ & $\begin{array}{c}\text { BS 210 } \\
\text { (RHc 210) }\end{array}$ \\
\hline$\frac{(\mathrm{bs})}{10626}$ & $\frac{(\mathbf{b s})}{0,00}$ & $\frac{(\text { lbs) }}{108.84}$ & (lbs) \\
\hline 107.74 & 0.00 & 110.36 & 0.00 \\
\hline 141.95 & 0.00 & 145.40 & 0.00 \\
\hline 213.87 & 0.00 & 219.07 & 0.00 \\
\hline 291.66 & 0.00 & 298.75 & 0.00 \\
\hline 402.76 & 0.00 & 412.54 & 0.00 \\
\hline $\begin{array}{c}\text { Magnet } \\
\text { Reactions }\end{array}$ & $\begin{array}{c}\text { Magnet } \\
\text { Reactions }\end{array}$ & $\begin{array}{c}\text { Magnet } \\
\text { Reactions }\end{array}$ & \\
\hline $\begin{array}{c}\text { BS 294 } \\
\text { (RMn 294) } \\
\text { (in-lb) }\end{array}$ & $\begin{array}{c}\text { BS 240 } \\
\text { (RMn 240) } \\
\text { (in-lb) }\end{array}$ & $\begin{array}{c}\text { BS 210 } \\
\text { (RMn 210) } \\
\text { (in-lb) }\end{array}$ & \\
\hline 145.37 & 242.29 & $\frac{(111-10)}{193.83}$ & \\
\hline 90.00 & 150.00 & 120.00 & \\
\hline 131.22 & 218.70 & 174.96 & \\
\hline 207.53 & 345.88 & 276.70 & \\
\hline 286.24 & 477.06 & 381.65 & \\
\hline 403.56 & 672.60 & 538.08 & \\
\hline
\end{tabular}

\begin{tabular}{|c|c|c|c|c|c|c|c|c|c|c|}
\hline$\Omega$ & (cg) position & Device & Centrifugal & Centrifugal & (cg) position & & & rifugal Load & & \\
\hline $\mathrm{rad} / \mathrm{sec}$ & pivot offset & Mass & Force & Force & 210 offset & (RHc 294) & (RHn 294) & (RHc 210) & (RHn 210) & (Fz 210) \\
\hline & $\mathrm{m}$ & $\mathrm{kg}$ & Newton & $\mathbf{I b}$ & in & lb & lb & lb & lb & lb \\
\hline 6.81 & 6.82 & 17 & 5057.3 & 1137.0 & 3.63 & 49 & 0 & -49 & 0 & 1137 \\
\hline
\end{tabular}


THE WIND TURBINE $=\quad$ MICON 65/13

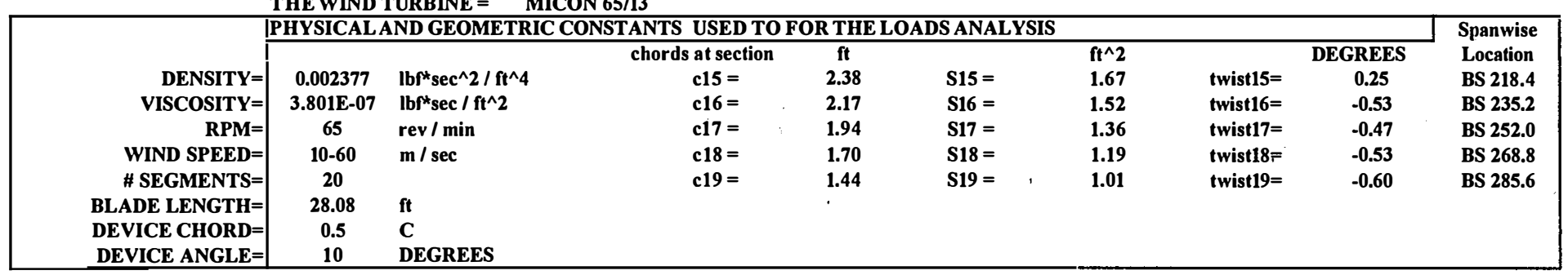

\begin{tabular}{|c|c|c|c|c|c|c|c|}
\hline & $\begin{array}{c}\text { Blade } \\
\text { Sta. } 15\end{array}$ & $\begin{array}{c}\text { Blade } \\
\text { Sta. } 16 \\
\end{array}$ & $\begin{array}{c}\text { Blade } \\
\text { Sta. } 17\end{array}$ & $\begin{array}{l}\text { Blade } \\
\text { Sta. } 18 \\
\end{array}$ & $\begin{array}{c}\text { Blade } \\
\text { Sta. } 19\end{array}$ & $\begin{array}{c}\text { DEVICE } \\
\text { totals }\end{array}$ & $\begin{array}{c}\text { DEVICE } \\
\text { totals }\end{array}$ \\
\hline$V_{0}(\mathrm{~m} / \mathrm{sec})$ & $\begin{array}{c}\text { Force- } \\
\text { Normal lb }\end{array}$ & \begin{tabular}{|c} 
Force-Normal \\
lb
\end{tabular} & $\begin{array}{c}\text { Force-Normal } \\
\mathbf{l b}\end{array}$ & $\begin{array}{c}\text { Force-Normal } \\
\text { lb }\end{array}$ & $\begin{array}{c}\text { Force-Normal } \\
\text { lb }\end{array}$ & $\begin{array}{c}\text { Total Force- } \\
\text { Normal lb } \\
\end{array}$ & \begin{tabular}{|c}
$\begin{array}{c}\text { Spanwise (cp) } \\
\% \text { Device } \\
\text { span }\end{array}$ \\
\end{tabular} \\
\hline 10.0 & 20.8 & 21.4 & 21.5 & 21.0 & 17.4 & 102.1 & 0.486 \\
\hline 20.0 & 42.6 & 42.5 & 39.2 & 36.7 & 40.4 & 201.4 & 0.490 \\
\hline 30.0 & 69.5 & 60.5 & 57.7 & 47.8 & 51.9 & 287.4 & 0.467 \\
\hline 40.0 & 99.9 & 96.1 & 83.7 & 76.3 & 76.9 & 432.9 & 0.470 \\
\hline 50.0 & 136.7 & 129.7 & 115.0 & 103.6 & 105.4 & 590.4 & 0.470 \\
\hline 60.0 & 195.8 & 183.6 & 157.7 & 140.6 & 137.6 & 815.3 & 0.461 \\
\hline
\end{tabular}

\begin{tabular}{|c|c|c|c|}
$\begin{array}{c}\text { HINGE } \\
\text { Reactions }\end{array}$ & \multicolumn{1}{c}{$\begin{array}{c}\text { HINGE } \\
\text { Reactions }\end{array}$} & \multicolumn{1}{c}{$\begin{array}{c}\text { HINGE } \\
\text { Reactions }\end{array}$} & $\begin{array}{c}\text { HINGE } \\
\text { Reactions }\end{array}$ \\
\hline $\begin{array}{c}\text { BS 294 } \\
\text { (RHn 294) } \\
\text { (bs) }\end{array}$ & $\begin{array}{c}\text { BS 294 } \\
\text { (RHc 294) } \\
(\text { (bs) }\end{array}$ & $\begin{array}{c}\text { BS 210 } \\
\text { (RHn 210) } \\
(\mathbf{b s s})\end{array}$ & $\begin{array}{c}\text { BS 210 } \\
(\text { RHc 210) } \\
(\mathbf{b s})\end{array}$ \\
\hline 49.69 & 8.76 & 50.89 & 8.97 \\
\hline 97.97 & 17.27 & 100.35 & 17.69 \\
\hline 139.80 & 24.65 & 143.19 & 25.25 \\
\hline 210.62 & 37.14 & 215.74 & 38.04 \\
\hline 287.23 & 50.65 & 294.21 & 51.88 \\
\hline 396.64 & 69.94 & 406.27 & 71.64 \\
\hline Link
\end{tabular}

\begin{tabular}{|c|c|c|c|c|c|c|c|}
\hline & sa. 13 & 16 & sta. I/ & Sta. 18 & S & totals & totals \\
\hline$V_{0}(\mathrm{~m} / \mathrm{sec})$ & $\begin{array}{c}\text { Moment } \\
\text { in- Ib }\end{array}$ & $\begin{array}{c}\text { Moment } \\
\text { in- Ib }\end{array}$ & $\begin{array}{c}\text { Moment } \\
\text { in-lb }\end{array}$ & $\begin{array}{l}\text { Moment } \\
\text { in-lb }\end{array}$ & $\begin{array}{c}\text { Moment } \\
\text { in-lb }\end{array}$ & $\begin{array}{c}\text { Total } M \\
\text { in-l } \mathbf{b}\end{array}$ & $\begin{array}{l}\text { Spanwise } \\
\text { (cm) \% } \\
\text { Device span }\end{array}$ \\
\hline 10.0 & 30.9 & 29.1 & 26.2 & 22.4 & 14.5 & 123.0 & 0.436 \\
\hline 20.0 & 76.3 & 69.3 & 56.7 & 46.5 & 43.5 & 292.3 & 0.439 \\
\hline 30.0 & 129.4 & 101.9 & 87.1 & 60.7 & 56.0 & 435.2 & 0.414 \\
\hline 40.0 & 186.4 & 163.4 & 127.4 & 101.7 & 86.8 & 665.6 & 0.422 \\
\hline 50.0 & 262.0 & 226.5 & 175.8 & 138.6 & 119.4 & 922.3 & 0.419 \\
\hline 60.0 & 371.3 & 317.3 & 244.0 & 190.4 & 160.0 & 1282.9 & 0.414 \\
\hline
\end{tabular}

Reactions

BS 240
(RMn 240)

\begin{tabular}{c} 
(in-lb) \\
\hline
\end{tabular}

123

$\begin{array}{r}123 \\ \hline 435 \\ \hline\end{array}$

435

\begin{tabular}{|l}
\hline 666 \\
\hline 922 \\
\hline
\end{tabular}

\begin{tabular}{|c|c|c|c|c|c|c|c|c|c|c|}
\hline$\Omega$ & (cg) position & Device & Centrifugal & Centrifugal & (cg) position & & & rifugal Loads & & \\
\hline $\mathrm{rad} / \mathrm{sec}$ & pivot offset & Mass & Force & Force & 210 offset & (RHc 294) & (RHn 294) & (RHc 210) & (RHn 210) & (Fz 210) \\
\hline & $\mathbf{m}$ & $\mathrm{kg}$ & Newton & $\mathbf{I b}$ & in & $\mathbf{l b}$ & lb & lb & $\mathbf{l b}$ & $\mathbf{l b}$ \\
\hline$\overline{6.8}$ & 6.82 & 17 & 5057.3 & 1137.0 & 3.63 & 48 & -9 & -48 & 9 & 1137 \\
\hline
\end{tabular}


THE WIND TURBINE $=$ MICON 65/13

\begin{tabular}{|c|c|c|c|c|c|c|c|c|c|}
\hline & \multicolumn{8}{|c|}{ PHYSICAL AND GEOMETRIC CONSTANTS USED TO FOR THE LOADS ANALYSIS } & \multirow{2}{*}{$\begin{array}{l}\text { Spanwise } \\
\text { Location }\end{array}$} \\
\hline & & & chords at section & ft & & $\mathbf{f t} \mathbf{A}^{\wedge}$ & & DEGREES & \\
\hline VISCOSI'TY= & 3.801E-07 & $\mathrm{lbf}^{\star} \sec / \mathrm{ft}^{\wedge} \mathbf{2}$ & $\mathbf{c 1 6}=$ & 2.17 & S16 $=$ & 1.52 & twist16= & -0.53 & BS 235.2 \\
\hline $\mathbf{R P M}=$ & 65 & $\mathrm{rev} / \mathrm{min}$ & $\mathbf{c 1 7}=$ & 1.94 & S17 $=$ & 1.36 & twist17= & -0.47 & BS 252.0 \\
\hline \# SEGMENTS= & 20 & & $\mathbf{c 1 9}=$ & 1.44 & S19 $=$ & 1.01 & twist19= & -0.60 & BS 285.6 \\
\hline BLADE LENGTH= & 28.08 & ft & & & & & & & \\
\hline DEVICE CHORD= & 0.5 & C & & & & & & & \\
\hline
\end{tabular}

\begin{tabular}{|c|c|c|c|c|c|c|c|}
\hline & $\begin{array}{c}\text { Blade } \\
\text { Sta. } 15\end{array}$ & $\begin{array}{l}\text { Blade } \\
\text { Sta. } 16\end{array}$ & $\begin{array}{c}\text { Blade } \\
\text { Sta. } 17\end{array}$ & $\begin{array}{l}\text { Blade } \\
\text { Sta. } 18\end{array}$ & $\begin{array}{l}\text { Blade } \\
\text { Sta. } 19\end{array}$ & $\begin{array}{c}\text { DEVICE } \\
\text { totals }\end{array}$ & $\begin{array}{c}\text { DEVICE } \\
\text { totals }\end{array}$ \\
\hline$V_{0}(\mathrm{~m} / \mathrm{sec})$ & $\begin{array}{c}\text { Force- } \\
\text { Normal lb }\end{array}$ & $\begin{array}{c}\text { Force-Normal } \\
\text { lb }\end{array}$ & \begin{tabular}{|c} 
Force-Normal \\
$\mathbf{l b}$
\end{tabular} & \begin{tabular}{|c|} 
Force-Normal \\
lb
\end{tabular} & \begin{tabular}{|c|} 
Force-Normal \\
lb
\end{tabular} & $\begin{array}{c}\text { Total Force- } \\
\text { Normal lb }\end{array}$ & $\begin{array}{c}\text { Spanwise (cp) } \\
\text { \% Device } \\
\text { span } \\
\end{array}$ \\
\hline 10.0 & 72.5 & 74.7 & 75.1 & 73.4 & 67.4 & 363.1 & 0.494 \\
\hline 20.0 & 59.5 & 59.3 & 59.6 & 55.9 & 61.5 & 295.9 & 0.500 \\
\hline 30.0 & 83.2 & 86.3 & 82.5 & 74.2 & 80.6 & 406.8 & 0.492 \\
\hline 40.0 & 103.0 & 99.1 & 93.7 & 85.5 & 91.9 & 473.2 & 0.485 \\
\hline 50.0 & 129.4 & 122.7 & 112.4 & 101.2 & 108.7 & 574.5 & 0.478 \\
\hline 60.0 & 143.3 & 134.4 & 124.7 & 111.1 & 130.2 & 643.7 & 0.485 \\
\hline & $\begin{array}{l}\text { Blade } \\
\text { Sta. } 15\end{array}$ & $\begin{array}{c}\text { Blade } \\
\text { Sta. } 16\end{array}$ & $\begin{array}{c}\text { Blade } \\
\text { Sta. } 17\end{array}$ & $\begin{array}{c}\text { Blade } \\
\text { Sta. } 18\end{array}$ & $\begin{array}{c}\text { Blade } \\
\text { Sta. } 19\end{array}$ & $\begin{array}{c}\text { DEVICE } \\
\text { totals }\end{array}$ & $\begin{array}{c}\text { DEVICE } \\
\text { totals }\end{array}$ \\
\hline$V_{0}(\mathrm{~m} / \mathrm{sec})$ & $\begin{array}{c}\text { Moment } \\
\text { in- lb }\end{array}$ & $\begin{array}{c}\text { Moment } \\
\text { in- lb }\end{array}$ & $\begin{array}{c}\text { Moment } \\
\text { in-lb }\end{array}$ & $\begin{array}{c}\text { Moment } \\
\text { in-lb }\end{array}$ & $\begin{array}{c}\text { Moment } \\
\text { in-lb }\end{array}$ & $\begin{array}{c}\text { Total M } \\
\text { in-lb }\end{array}$ & $\begin{array}{c}\text { Spanwise } \\
\text { (em) \% } \\
\text { Device span }\end{array}$ \\
\hline 10.0 & 85.3 & 80.1 & 72.1 & 61.7 & 54.3 & 353.6 & 0.454 \\
\hline 20.0 & 25.1 & 22.8 & 24.9 & 20.4 & 19.1 & 112.3 & 0.474 \\
\hline 30.0 & 22.0 & 21.0 & 18.0 & 15.4 & 14.2 & 90.5 & 0.453 \\
\hline 40.0 & 28.8 & 25.2 & 21.0 & 16.8 & 14.7 & 106.5 & 0.431 \\
\hline 50.0 & 35.0 & 30.3 & 22.2 & 17.5 & 18.4 & 123.4 & 0.426 \\
\hline 60.0 & 5.9 & 5.1 & 9.8 & 7.7 & 21.4 & 49.8 & 0.634 \\
\hline
\end{tabular}

\begin{tabular}{|c|c|c|c|}
\multicolumn{1}{c}{$\begin{array}{c}\text { HINGE } \\
\text { Reactions }\end{array}$} & \multicolumn{1}{c}{$\begin{array}{c}\text { HINGE } \\
\text { Reactions }\end{array}$} & \multicolumn{1}{c}{$\begin{array}{c}\text { HINGE } \\
\text { Reactions }\end{array}$} & \multicolumn{1}{c}{$\begin{array}{c}\text { HINGE } \\
\text { Reactions }\end{array}$} \\
\hline $\begin{array}{c}\text { BS 294 } \\
(\text { RHn 294) } \\
(\text { (bs) }\end{array}$ & $\begin{array}{c}\text { BS 294 } \\
(\text { RHc 294) } \\
(\mathbf{b s})\end{array}$ & $\begin{array}{c}\text { BS 210 } \\
(\text { RHn 210) } \\
(\mathbf{l b s})\end{array}$ & $\begin{array}{c}\text { BS 210 } \\
\text { (RHc 210) } \\
(\mathbf{l b s})\end{array}$ \\
\hline 89.69 & 155.35 & 91.87 & 159.12 \\
\hline 73.08 & 126.59 & 74.86 & 129.66 \\
\hline 100.48 & 174.03 & 102.92 & 178.26 \\
\hline 116.89 & 202.46 & 119.73 & 207.38 \\
\hline 141.90 & 245.77 & 145.34 & 251.74 \\
\hline 158.99 & 275.38 & 162.85 & 282.07 \\
\hline Link
\end{tabular}

$$
\text { Reaction }
$$

\begin{tabular}{|c|}
\hline $\begin{array}{c}\text { Reactions } \\
\text { (RMn 240) } \\
\text { (in-lb) }\end{array}$ \\
\hline 354 \\
\hline 112 \\
\hline 90 \\
\hline 107 \\
\hline 123 \\
\hline 50 \\
\hline
\end{tabular}

\begin{tabular}{|c|c|c|c|c|c|c|c|c|c|c|}
\hline$\Omega$ & (cg) position & Device & Centrifugal & Centrifugal & (cg) position & & & ifugal Loads & & \\
\hline $\mathrm{rad} / \mathrm{sec}$ & pivot offset & Mass & Force & Force & 210 offset & (RHc 294) & (RHn 294) & (RHc 210) & (RHn 210) & $(\mathrm{Fz} 210)$ \\
\hline & $\mathbf{m}$ & $\mathbf{k g}$ & Newton & $\mathbf{I b}$ & in & $\mathbf{l b}$ & $\mathbf{l b}$ & $\mathbf{l b}$ & $\mathbf{l b}$ & lb \\
\hline 6.81 & 6.82 & 17 & 5057.3 & 1137.0 & 3.63 & 25 & -43 & -25 & 43 & 1137 \\
\hline
\end{tabular}


THE WIND TURBINE $=$ MICON 65/13

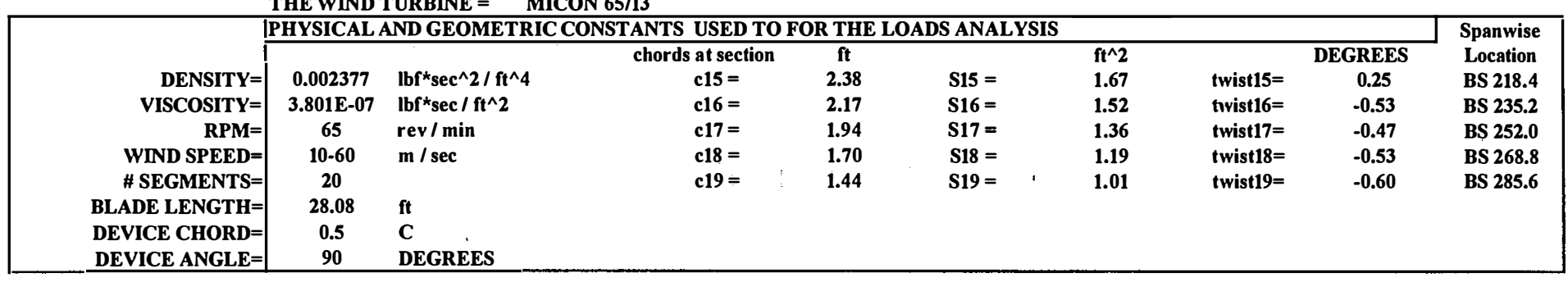

\begin{tabular}{|c|c|c|c|c|c|c|c|}
\hline & $\begin{array}{c}\text { Blade } \\
\text { Sta. } 15\end{array}$ & $\begin{array}{c}\text { Blade } \\
\text { Sta. } 16\end{array}$ & $\begin{array}{l}\text { Blade } \\
\text { Sta. } 17\end{array}$ & $\begin{array}{c}\text { Blade } \\
\text { Sta. } 18\end{array}$ & $\begin{array}{c}\text { Blade } \\
\text { Sta. } 19\end{array}$ & $\begin{array}{c}\text { DEVICE } \\
\text { totals }\end{array}$ & $\begin{array}{c}\text { DEVICE } \\
\text { totals }\end{array}$ \\
\hline$V_{0}(\mathrm{~m} / \mathrm{sec})$ & $\begin{array}{c}\begin{array}{c}\text { Force- } \\
\text { Normal lb }\end{array} \\
\end{array}$ & \begin{tabular}{|c} 
Force-Normal \\
$\mathbf{l b}$
\end{tabular} & $\begin{array}{c}\text { Force-Normal } \\
\text { lb }\end{array}$ & \begin{tabular}{|c} 
Force-Normal \\
lb
\end{tabular} & \begin{tabular}{|c|} 
Force-Normal \\
$\mathbf{l b}$
\end{tabular} & $\begin{array}{c}\text { Total Force- } \\
\text { Normal lb } \\
\end{array}$ & $\begin{array}{c}\text { Spanwise (cp) } \\
\text { \% Device } \\
\text { span } \\
\end{array}$ \\
\hline 10.0 & 134.1 & 138.2 & 139.0 & 135.8 & 133.3 & 680.4 & 0.499 \\
\hline 20.0 & 104.2 & 103.9 & 103.2 & 96.8 & 106.5 & 514.7 & 0.499 \\
\hline 30.0 & 78.6 & 75.2 & 71.9 & 61.8 & 67.1 & 354.6 & 0.479 \\
\hline 40.0 & 81.3 & 78.2 & 79.9 & 72.8 & 86.9 & 399.2 & 0.503 \\
\hline 50.0 & 93.7 & 88.9 & 81.7 & 73.6 & 85.8 & 423.7 & 0.485 \\
\hline \multirow[t]{2}{*}{60.0} & 124.9 & 117.1 & 108.6 & 96.7 & 94.3 & 541.6 & 0.470 \\
\hline & $\begin{array}{l}\text { Blade } \\
\text { Sta. } 15\end{array}$ & $\begin{array}{l}\text { Blade } \\
\text { Sta. } 16\end{array}$ & $\begin{array}{c}\text { Blade } \\
\text { Sta. } 17\end{array}$ & $\begin{array}{l}\text { Blade } \\
\text { Sta. } 18\end{array}$ & $\begin{array}{c}\text { Blade } \\
\text { Sta. } 19\end{array}$ & $\begin{array}{c}\text { DEVICE } \\
\text { totals }\end{array}$ & $\begin{array}{c}\text { DEVICE } \\
\text { totals }\end{array}$ \\
\hline$V_{0}(\mathrm{~m} / \mathrm{sec})$ & $\begin{array}{c}\text { Moment } \\
\text { in- lb }\end{array}$ & $\begin{array}{c}\text { Moment } \\
\text { in- lb }\end{array}$ & $\begin{array}{c}\text { Moment } \\
\text { in- lb }\end{array}$ & $\begin{array}{c}\text { Moment } \\
\text { in- lb }\end{array}$ & $\begin{array}{c}\text { Moment } \\
\text { in-lb }\end{array}$ & $\begin{array}{c}\text { Total M } \\
\text { in- lb }\end{array}$ & \begin{tabular}{|c|} 
Spanwise \\
$(\mathrm{cm}) \%$ \\
Device span
\end{tabular} \\
\hline 10.0 & 170.7 & 160.4 & 144.3 & 123.5 & 107.3 & 706.2 & 0.454 \\
\hline 20.0 & 77.3 & 70.2 & 71.9 & 59.1 & 55.2 & 333.7 & 0.467 \\
\hline 30.0 & -27.1 & -27.9 & -23.9 & -16.1 & -14.8 & -109.7 & 0.434 \\
\hline 40.0 & -60.4 & -52.9 & -36.2 & -28.9 & -18.2 & -196.5 & 0.390 \\
\hline 50.0 & -103.1 & -89.2 & -69.6 & -54.9 & .38 .7 & -355.5 & 0.408 \\
\hline 60.0 & -103.4 & -88.4 & -79.8 & -62.2 & -63.0 & -396.7 & 0.446 \\
\hline
\end{tabular}

\begin{tabular}{|c|c|c|c|}
\multicolumn{1}{c}{$\begin{array}{c}\text { HINGE } \\
\text { Reactions }\end{array}$} & \multicolumn{1}{c}{$\begin{array}{c}\text { HINGE } \\
\text { Reactions }\end{array}$} & \multicolumn{1}{c}{$\begin{array}{c}\text { HINGE } \\
\text { Reactions }\end{array}$} & \multicolumn{1}{c}{$\begin{array}{c}\text { HINGE } \\
\text { Reactions }\end{array}$} \\
\hline $\begin{array}{c}\text { BS 294 } \\
\text { (RHn 294) } \\
(\mathbf{l b s})\end{array}$ & $\begin{array}{c}\text { BS 294 } \\
\text { (RHc 294) } \\
\text { (lbs) }\end{array}$ & $\begin{array}{c}\text { BS 210 } \\
\text { (RHn 210) } \\
\text { (lbs) }\end{array}$ & $\begin{array}{c}\text { BS 210 } \\
(\mathbf{R H c} 210) \\
(\mathbf{b s})\end{array}$ \\
\hline 0.00 & 336.12 & 0.00 & 344.29 \\
\hline 0.00 & 254.28 & 0.00 & 260.45 \\
\hline 0.00 & 175.17 & 0.00 & 179.43 \\
\hline 0.00 & 197.19 & 0.00 & 201.98 \\
\hline 0.00 & 209.33 & 0.00 & 214.41 \\
\hline 0.00 & 267.56 & 0.00 & 274.06 \\
\hline Link
\end{tabular}

\begin{tabular}{|c|}
$\begin{array}{c}\text { Link } \\
\text { Reactions }\end{array}$ \\
\hline $\begin{array}{c}\text { BS 240 } \\
\text { (RMn 240) } \\
\text { (in-1b) }\end{array}$ \\
\hline 706 \\
\hline 334 \\
\hline-110 \\
\hline-197 \\
\hline-356 \\
\hline-397 \\
\hline
\end{tabular}

\begin{tabular}{|c|c|c|c|c|c|c|c|c|c|c|}
\hline$\Omega$ & (cg) position & Device & Centrifugal & Centrifugal & (cg) position & & & ifugal Loads & & \\
\hline $\mathrm{rad} / \mathrm{sec}$ & pivot offset & Mass & Force & Force & 210 offset & (RHc 294) & (RHn 294) & (RHc 210) & (RHn 210) & (Fz 210) \\
\hline & $\mathbf{m}$ & $\mathrm{kg}$ & Newton & lb & in & lb & lb & $\mathbf{l b}$ & $\mathbf{l b}$ & $\mathbf{l b}$ \\
\hline 6.81 & 6.82 & 17 & 5057.3 & 1137.0 & 3.63 & 0 & -49 & 0 & 49 & 1137 \\
\hline
\end{tabular}


THE WIND TURBINE $=\quad$ MICON 65/13

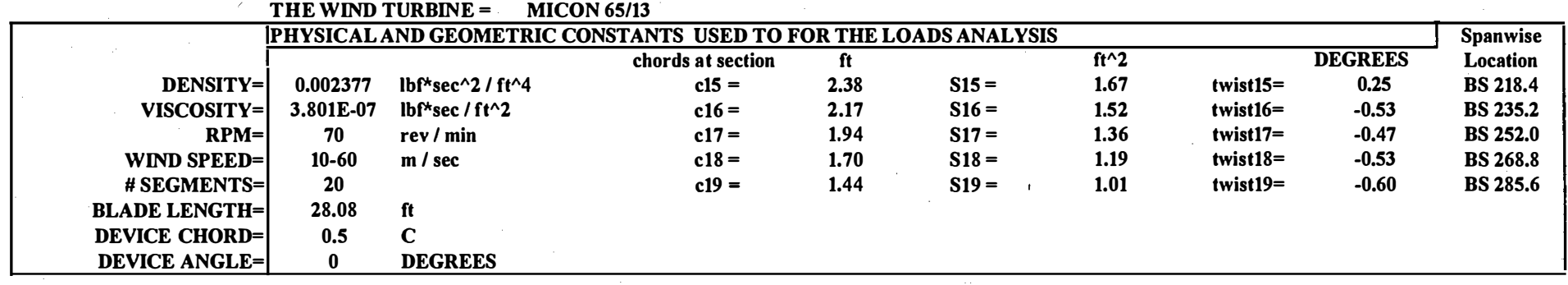

\begin{tabular}{|c|c|c|c|c|c|c|c|}
\hline & $\begin{array}{l}\text { Blade } \\
\text { Sta. } 15\end{array}$ & $\begin{array}{c}\text { Blade } \\
\text { Sta. } 16\end{array}$ & $\begin{array}{l}\text { Blade } \\
\text { Sta. } 17\end{array}$ & $\begin{array}{c}\text { Blade } \\
\text { Sta. } 18\end{array}$ & $\begin{array}{c}\text { Blade } \\
\text { Sta. } 19\end{array}$ & $\begin{array}{c}\text { DEVICE } \\
\text { totals }\end{array}$ & $\begin{array}{c}\text { DEVICE } \\
\text { totals }\end{array}$ \\
\hline$V_{0}(\mathrm{~m} / \mathrm{sec})$ & $\begin{array}{c}\text { Force- } \\
\text { Normal lb }\end{array}$ & \begin{tabular}{|c} 
Force-Normal \\
lb
\end{tabular} & $\begin{array}{c}\text { Force-Normal } \\
\text { lb }\end{array}$ & $\begin{array}{c}\text { Force-Normal } \\
\text { lb }\end{array}$ & $\begin{array}{c}\text { Force-Normal } \\
\text { lb }\end{array}$ & $\begin{array}{c}\text { Total Force- } \\
\text { Normal lb }\end{array}$ & \begin{tabular}{|c|} 
Spanwise (cp) \\
\% Device \\
span
\end{tabular} \\
\hline 10.0 & 49.2 & 50.8 & 51.1 & 49.9 & 47.1 & 248.1 & 0.496 \\
\hline 20.0 & 50.7 & 50.7 & 49.3 & 46.3 & 51.0 & 248.0 & 0.497 \\
\hline 30.0 & 68.5 & 67.3 & 57.7 & 53.5 & 57.5 & 304.4 & 0.477 \\
\hline 40.0 & 100.6 & 97.2 & 91.8 & 78.9 & 84.9 & 453.5 & 0.478 \\
\hline 50.0 & 146.2 & 133.1 & 124.1 & 107.8 & 114.7 & 625.9 & 0.472 \\
\hline 60.0 & 193.4 & 182.1 & 156.6 & 140.1 & 141.1 & 813.4 & 0.464 \\
\hline & $\begin{array}{c}\text { Blade } \\
\text { Sta. } 15\end{array}$ & $\begin{array}{c}\text { Blade } \\
\text { Sta. } 16\end{array}$ & $\begin{array}{c}\text { Blade } \\
\text { Sta. } 17\end{array}$ & $\begin{array}{c}\text { Blade } \\
\text { Sta. } 18\end{array}$ & $\begin{array}{c}\text { Blade } \\
\text { Sta. } 19\end{array}$ & $\begin{array}{c}\text { DEVICE } \\
\text { totals }\end{array}$ & $\begin{array}{c}\text { DEVICE } \\
\text { totals }\end{array}$ \\
\hline$V_{0}(\mathrm{~m} / \mathrm{sec})$ & $\begin{array}{c}\text { Moment } \\
\text { in-lb }\end{array}$ & $\begin{array}{c}\text { Moment } \\
\text { in-lb }\end{array}$ & $\begin{array}{c}\text { Moment } \\
\text { in- lb }\end{array}$ & $\begin{array}{c}\text { Moment } \\
\text { in-lb }\end{array}$ & $\begin{array}{c}\text { Moment } \\
\text { in-lb }\end{array}$ & $\begin{array}{c}\text { Total M } \\
\text { in- Ib }\end{array}$ & \begin{tabular}{|c|} 
Spanwise \\
$(\mathrm{cm}) \%$ \\
Device span
\end{tabular} \\
\hline 10.0 & 136.5 & 128.4 & 115.6 & 99.0 & 79.3 & 558.8 & 0.449 \\
\hline 20.0 & 83.2 & 80.6 & 70.2 & 57.8 & 54.3 & 346.1 & 0.453 \\
\hline 30.0 & 123.7 & 110.8 & 87.0 & 70.6 & 57.9 & 450.0 & 0.424 \\
\hline 40.0 & 195.8 & 172.5 & 145.8 & 106.6 & 97.5 & 718.1 & 0.427 \\
\hline 50.0 & 290.7 & 233.4 & 194.7 & 149.7 & 135.3 & 1003.8 & 0.421 \\
\hline 60.0 & 381.1 & 327.2 & 254.1 & 199.1 & 164.7 & 1326.2 & 0.415 \\
\hline
\end{tabular}

\begin{tabular}{|c|c|c|c|}
\hline $\begin{array}{c}\text { HINGE } \\
\text { Reactions }\end{array}$ & $\begin{array}{c}\text { HINGE } \\
\text { Reactions }\end{array}$ & $\begin{array}{c}\text { HINGE } \\
\text { Reactions }\end{array}$ & $\begin{array}{c}\text { HINGE } \\
\text { Reactions }\end{array}$ \\
\hline $\begin{array}{c}\text { BS 294 } \\
\text { (RHn 294) } \\
\text { (lbs) }\end{array}$ & $\begin{array}{c}\text { BS 294 } \\
\text { (RHc 294) } \\
\text { (lbs) }\end{array}$ & $\begin{array}{c}\text { BS 210 } \\
\text { (RHn 210) } \\
\text { (lbs) }\end{array}$ & $\begin{array}{c}\text { BS 210 } \\
\text { (RHc 210) } \\
\text { (lbs) }\end{array}$ \\
\hline 122.55 & 0.00 & 125.53 & 0.00 \\
\hline 122.49 & 0.00 & 125.47 & 0.00 \\
\hline 150.37 & 0.00 & 154.02 & 0.00 \\
\hline 224.00 & 0.00 & 229.45 & 0.00 \\
\hline 309.19 & 0.00 & 316.70 & 0.00 \\
\hline 401.81 & 0.00 & 411.57 & 0.00 \\
\hline $\begin{array}{c}\text { Magnet } \\
\text { Reactions }\end{array}$ & $\begin{array}{c}\text { Magnet } \\
\text { Reactions }\end{array}$ & $\begin{array}{c}\text { Magnet } \\
\text { Reactions }\end{array}$ & \\
\hline $\begin{array}{c}\text { BS 294 } \\
\text { (RMn 294) } \\
\text { (in-lb) }\end{array}$ & $\begin{array}{c}\text { BS 240 } \\
\text { (RMn 240) } \\
\text { (in-lb) }\end{array}$ & $\begin{array}{c}\text { BS 210 } \\
\text { (RMn 210) } \\
\text { (in-lb) }\end{array}$ & \\
\hline 167.64 & 279.40 & 223.52 & \\
\hline 103.83 & 173.05 & 138.44 & \\
\hline 135.00 & 225.00 & 180.00 & \\
\hline 215.43 & 359.06 & 287.25 & \\
\hline 301.13 & 501.88 & 401.51 & \\
\hline 397.87 & 663.12 & 530.49 & \\
\hline
\end{tabular}

\begin{tabular}{|c|c|c|c|c|c|c|c|c|c|c|}
\hline $\mathbf{\Omega}$ & (cg) position & Device & Centrifugal & Centrifugal & (cg) position & & & ifugal Loads & & \\
\hline $\mathrm{rad} / \mathrm{sec}$ & pivot offset & Mass & Force & Force & 210 offset & (RHc 294) & (RHn 294) & (RHc 210) & (RHn 210) & (Fz 210) \\
\hline & $\mathbf{m}$ & $\mathbf{k g}$ & Newton & $\mathbf{I b}$ & in & lb & lb & lb & $\mathbf{l b}$ & $\mathbf{l b}$ \\
\hline 7.33 & 6.82 & 17 & 5865.2 & 1318.6 & 3.63 & 57 & 0 & -57 & 0 & 1319 \\
\hline
\end{tabular}


THE WIND TURBINE $=\quad$ MICON 65/13

\begin{tabular}{|c|c|c|c|c|c|c|c|c|c|}
\hline & \multicolumn{8}{|c|}{ PHYSICAL AND GEOMETRIC CONSTANTS USED TO FOR THE LOADS ANALYSIS } & $\begin{array}{l}\text { Spanwise } \\
\text { Location }\end{array}$ \\
\hline VISCOSITY= & 3.801E-07 & $\mathbf{l b} \boldsymbol{r}^{\star} \sec / \mathrm{ft}^{\wedge} \mathbf{2}$ & c16 = & 2.17 & $S 16=$ & 1.52 & twist16= & -0.53 & BS 235.2 \\
\hline $\mathbf{R P M}=$ & 70 & $\mathrm{rev} / \mathrm{min}$ & c17 = & 1.94 & $S 17=$ & 1.36 & twist17= & -0.47 & BS 252.0 \\
\hline WIND SPEED $=$ & $10-60$ & $\mathrm{~m} / \mathrm{sec}$ & c18 = & 1.70 & $\mathbf{S 1 8}=$ & 1.19 & twist18= & -0.53 & BS 268.8 \\
\hline \# SEGMENTS= & 20 & & c19 = & 1.44 & $\mathbf{S} 19=$ & 1.01 & twist19= & -0.60 & BS 285.6 \\
\hline BLADE LENGTH= & 28.08 & ft & & & & & & & \\
\hline DEVICE CHORD= & 0.5 & $\mathbf{C}$ & & & & & & & \\
\hline DEVICE ANGLE = & 10 & DEGREES & & & & & & & \\
\hline
\end{tabular}

\begin{tabular}{|c|c|c|c|c|c|c|c|c|c|c|}
\hline & $\begin{array}{l}\text { Blade } \\
\text { Sta. } 15\end{array}$ & $\begin{array}{c}\text { Blade } \\
\text { Sta. } 16\end{array}$ & $\begin{array}{c}\text { Blade } \\
\text { Sta. } 17\end{array}$ & $\begin{array}{c}\text { Blade } \\
\text { Sta. } 18\end{array}$ & $\begin{array}{c}\text { Blade } \\
\text { Sta. } 19\end{array}$ & $\begin{array}{c}\text { DEVICE } \\
\text { totals }\end{array}$ & $\begin{array}{c}\text { DEVICE } \\
\text { totals }\end{array}$ & & $\begin{array}{c}\text { HINGE } \\
\text { Reactions }\end{array}$ & $\begin{array}{c}\text { HINGE } \\
\text { Reactions }\end{array}$ \\
\hline$V_{0}(\mathrm{~m} / \mathrm{sec})$ & $\begin{array}{c}\text { Force- } \\
\text { Normal lb }\end{array}$ & $\begin{array}{c}\text { Force-Normal } \\
\text { lb }\end{array}$ & \begin{tabular}{|c} 
Force-Normal \\
lb
\end{tabular} & \begin{tabular}{|c} 
Force-Normal \\
lb
\end{tabular} & $\begin{array}{c}\text { Force-Normal } \\
\text { lb }\end{array}$ & $\begin{array}{l}\text { Total Force- } \\
\text { Normal lb }\end{array}$ & \begin{tabular}{|c|} 
Spanwise (cp) \\
\% Device \\
span
\end{tabular} & & $\begin{array}{c}\text { BS 294 } \\
\text { (RHn 294) } \\
\text { (lbs) }\end{array}$ & $\begin{array}{c}\text { BS 294 } \\
\text { (RHc 294) } \\
\text { (lbs) }\end{array}$ \\
\hline 10.0 & 23.9 & 24.7 & 21.8 & 21.3 & 20.1 & 111.8 & 0.480 & & 54.41 & 9.59 \\
\hline 20.0 & 48.2 & 45.8 & 44.5 & 41.9 & 42.6 & 223.0 & 0.486 & & 108.48 & 19.13 \\
\hline 30.0 & 68.5 & 67.3 & 57.7 & 53.5 & 53.7 & 300.6 & 0.471 & & 146.22 & 25.78 \\
\hline 40.0 & 100.6 & 97.2 & 91.8 & 78.9 & 84.9 & 453.5 & 0.478 & & 220.60 & 38.90 \\
\hline 50.0 & 146.2 & 133.1 & 124.1 & 107.8 & 114.7 & 625.9 & 0.472 & & 304.49 & 53.69 \\
\hline 60.0 & 193.4 & 182.1 & 156.6 & 140.1 & 141.1 & 813.4 & 0.464 & & 395.70 & 69.77 \\
\hline & $\begin{array}{l}\text { Blade } \\
\text { Sta. } 15 \\
\end{array}$ & $\begin{array}{c}\text { Blade } \\
\text { Sta. } 16 \\
\end{array}$ & $\begin{array}{l}\text { Blade } \\
\text { Sta. } 17 \\
\end{array}$ & $\begin{array}{c}\text { Blade } \\
\text { Sta. } 18 \\
\end{array}$ & $\begin{array}{c}\text { Blade } \\
\text { Sta. } 19 \\
\end{array}$ & $\begin{array}{c}\text { DEVICE } \\
\text { totals }\end{array}$ & $\begin{array}{c}\text { DEVICE } \\
\text { totals }\end{array}$ & & $\begin{array}{c}\text { Link } \\
\text { Reactions } \\
\end{array}$ & \\
\hline$V_{0}(\mathrm{~m} / \mathrm{sec})$ & $\begin{array}{c}\text { Moment } \\
\text { in-lb }\end{array}$ & $\begin{array}{c}\text { Moment } \\
\text { in- lb }\end{array}$ & $\begin{array}{c}\text { Moment } \\
\text { in-lb }\end{array}$ & $\begin{array}{c}\text { Moment } \\
\text { in-lb }\end{array}$ & $\begin{array}{c}\text { Moment } \\
\text { in-lb }\end{array}$ & $\begin{array}{c}\text { Total M } \\
\text { in- lb }\end{array}$ & \begin{tabular}{|c|} 
Spanwise \\
$(\mathrm{cm}) \%$ \\
Device span \\
\end{tabular} & & $\begin{array}{c}\text { BS 240 } \\
\text { (RMn 240) } \\
\text { (in-lb) }\end{array}$ & \\
\hline 10.0 & 35.6 & 33.5 & 24.3 & 20.8 & 16.7 & 131.0 & 0.423 & & 131 & \\
\hline 20.0 & 86.4 & 74.0 & 64.4 & 53.0 & 42.8 & 320.7 & 0.433 & & 321 & \\
\hline 30.0 & 126.6 & 113.4 & 83.8 & 68.0 & 58.2 & 450.0 & 0.419 & & 450 & \\
\hline 40.0 & 187.6 & 165.2 & 139.7 & 104.9 & 95.9 & 693.2 & 0.430 & & 693 & \\
\hline 50.0 & 280.1 & 227.4 & 189.7 & 143.7 & 129.8 & 970.7 & 0.421 & & 971 & \\
\hline 60.0 & 366.6 & 314.7 & 244.8 & 191.8 & 160.5 & 1278.5 & 0.416 & & 1278 & \\
\hline $\mathbf{\Omega}$ & (cg) position & Device & Centrifugal & Centrifugal & (cg) position 1 & & \multicolumn{2}{|c|}{ Centrifugal Loads } & & \\
\hline $\mathrm{rad} / \mathrm{sec}$ & pivot off set & Mass & Force & Force & 210 offset & (RHc 294) & (RHn 294) & (RHc 210) & (RHn 210) & (Fz 210) \\
\hline & $\mathbf{m}$ & $\mathrm{kg}$ & Newton & $\mathbf{l b}$ & in & lb & lb & lb & lb & lb \\
\hline 7.33 & 6.82 & 17 & 5865.2 & 1318.6 & 3.63 & 56 & -10 & -56 & 10 & 1319 \\
\hline
\end{tabular}


THE WIND TURBINE $=$ MICON 65/13

\begin{tabular}{|c|c|c|c|c|c|c|c|c|c|}
\hline & \multicolumn{8}{|c|}{ PHYSICAL AND GEOMETRIC CONSTANTS USED TO FOR THE LOADS ANALYSIS } & \multirow{2}{*}{$\begin{array}{l}\text { Spanwise } \\
\text { Location }\end{array}$} \\
\hline & & & chords a t section & ft & & $\mathrm{ft}^{\wedge} \mathbf{2}$ & & DEGREES & \\
\hline VISCOSITY= & 3.801E-07 & $\mathrm{lbf}^{\star} \sec / \mathrm{ft}^{\wedge} \mathbf{2}$ & $\mathrm{c} 16=$ & 2.17 & $S 16=$ & 1.52 & twist16= & -0.53 & BS 235.2 \\
\hline $\mathbf{R P M}=$ & 70 & $\mathrm{rev} / \mathrm{min}$ & c17 = & 1.94 & $\mathrm{~S} 17=$ & 1.36 & twist17= & -0.47 & BS 252.0 \\
\hline \# SEGMENTS= & 20 & & c19 $=$ & 1.44 & $\mathbf{S 1 9}=$ & 1.01 & twist19= & -0.60 & BS 285.6 \\
\hline BLADE LENGTH= & 28.08 & $\mathrm{ft}$ & & & & & & & \\
\hline DEVICE CHORD= & 0.5 & C & & & & & & & \\
\hline DEVICE ANGLE $=$ & 60 & DEGREES & e & & & & & & \\
\hline
\end{tabular}

\begin{tabular}{|c|c|c|c|c|c|c|c|c|c|c|c|}
\hline & & $\begin{array}{l}\text { Blade } \\
\text { Sta. } 15\end{array}$ & $\begin{array}{l}\text { Blade } \\
\text { Sta. } 16\end{array}$ & $\begin{array}{l}\text { Blade } \\
\text { Sta. } 17\end{array}$ & $\begin{array}{l}\text { Blade } \\
\text { Sta. } 18\end{array}$ & $\begin{array}{l}\text { Blade } \\
\text { Sta. } 19\end{array}$ & $\begin{array}{c}\text { DEVICE } \\
\text { totals }\end{array}$ & $\begin{array}{c}\text { DEVICE } \\
\text { totals }\end{array}$ & & $\begin{array}{c}\text { HINGE } \\
\text { Reactions }\end{array}$ & $\begin{array}{c}\text { HINGE } \\
\text { Reactions }\end{array}$ \\
\hline & $V_{o}(\mathrm{~m} / \mathrm{sec})$ & $\begin{array}{c}\text { Force- } \\
\text { Normal lb }\end{array}$ & \begin{tabular}{|c|} 
Force-Normal \\
lb
\end{tabular} & \begin{tabular}{|c|} 
Force-Normal \\
lb
\end{tabular} & \begin{tabular}{|c|} 
Force-Normal \\
lb
\end{tabular} & \begin{tabular}{|} 
Force-Normal \\
lb
\end{tabular} & $\begin{array}{l}\text { Total Force- } \\
\text { Normal lb }\end{array}$ & \begin{tabular}{|c|} 
Spanwise (cp) \\
\% Device \\
span
\end{tabular} & & $\begin{array}{c}\text { BS 294 } \\
\text { (RHn 294) } \\
\text { (lbs) }\end{array}$ & $\begin{array}{c}\text { BS 294 } \\
\text { (RHc 294) } \\
\text { (lbs) }\end{array}$ \\
\hline & 10.0 & 83.5 & 86.1 & 84.3 & 82.4 & 77.8 & 414.1 & 0.493 & & 102.29 & 177.17 \\
\hline & 20.0 & 67.4 & 69.7 & 67.8 & 63.7 & 76.6 & 345.2 & 0.507 & & 85.26 & 147.67 \\
\hline & 30.0 & 97.8 & 96.1 & 89.6 & 83.1 & 89.6 & 456.2 & 0.487 & & 112.69 & 195.18 \\
\hline & 40.0 & 112.6 & 108.8 & 102.8 & 94.4 & 101.6 & 520.2 & 0.486 & & 128.48 & 222.53 \\
\hline & 50.0 & 138.4 & 130.1 & 121.3 & 111.2 & 118.3 & 619.1 & 0.481 & & 152.93 & 264.88 \\
\hline & 60.0 & 152.8 & 144.0 & 148.2 & 132.7 & 137.9 & 715.6 & 0.488 & & 176.75 & 306.14 \\
\hline & & $\begin{array}{l}\text { Blade } \\
\text { Sta. } 15\end{array}$ & $\begin{array}{l}\text { Blade } \\
\text { Sta. } 16\end{array}$ & $\begin{array}{l}\text { Blade } \\
\text { Sta. } 17\end{array}$ & $\begin{array}{l}\text { Blade } \\
\text { Sta. } 18\end{array}$ & $\begin{array}{l}\text { Blade } \\
\text { Sta. } 19\end{array}$ & $\begin{array}{c}\text { DEVICE } \\
\text { totals }\end{array}$ & $\begin{array}{c}\text { DEVICE } \\
\text { lotals }\end{array}$ & & $\begin{array}{c}\text { Link } \\
\text { Reactions }\end{array}$ & \\
\hline & $\mathrm{V}_{0}(\mathrm{~m} / \mathrm{sec})$ & $\begin{array}{l}\text { Moment } \\
\text { in-lb }\end{array}$ & $\begin{array}{l}\text { Moment } \\
\text { in- lb }\end{array}$ & $\begin{array}{c}\text { Moment } \\
\text { in-lb }\end{array}$ & $\begin{array}{l}\text { Moment } \\
\text { in- lb }\end{array}$ & $\begin{array}{c}\text { Moment } \\
\text { in- lb }\end{array}$ & $\begin{array}{c}\text { Total } \mathbf{M} \\
\text { in- lb }\end{array}$ & \begin{tabular}{|c|} 
Spanwise \\
(cm) \% \\
Device span
\end{tabular} & & $\begin{array}{c}\text { BS 240 } \\
\text { (RMn 240) } \\
\text { (in-lb) }\end{array}$ & \\
\hline & 10.0 & 98.3 & 92.4 & 91.3 & 78.2 & 62.7 & 422.8 & 0.460 & & 423 & \\
\hline & 20.0 & 28.5 & 32.5 & 28.3 & 23.3 & 27.8 & 140.2 & 0.485 & & 140 & \\
\hline & 30.0 & 26.1 & 23.4 & 21.2 & 17.2 & 19.5 & 107.4 & 0.464 & & 107 & \\
\hline & 40.0 & 31.0 & 27.3 & 23.1 & 17.8 . & 16.3 & 115.3 & 0.433 & & 115 & \\
\hline & 50.0 & 37.4 & 28.8 & 24.0 & 22.2 & 20.0 & 132.4 & 0.438 & & 132 & \\
\hline & 60.0 & 14.8 & 12.7 & 32.7 & 25.6 & 20.3 & 106.0 & 0.545 & & 106 & \\
\hline & $\boldsymbol{\Omega}$ & (cg) position & Device & Centrifugal & Centrifugal & (cg) position & & Cen & rifugal Loads & & \\
\hline & $\mathrm{rad} / \mathrm{sec}$ & pivot offset & Mass & Force & Force & 210 off set & (RHc 294) & (RIIn 294) & (RHc 210) & (RHn 210) & (Fz 210) \\
\hline & & $\mathbf{m}$ & $\mathbf{k g}$ & Newton & Ib & in & $\mathbf{l b}$ & lb & $\mathbf{l b}$ & lb & $\mathbf{l b}$ \\
\hline & 7.33 & 6.82 & 17 & 5865.2 & 1318.6 & 3.63 & 28 & -49 & -28 & 49 & 1319 \\
\hline
\end{tabular}


THE WIND TURBINE $=\quad$ MICON 65/13

\begin{tabular}{|c|c|c|c|c|c|c|c|c|c|}
\hline \multirow{2}{*}{ DENSITY $=$} & \multicolumn{8}{|c|}{ PHYSICAL AND GEOMETRIC CONSTANTS USED TO FOR THE LOADS ANALYSIS } & \multirow{2}{*}{$\begin{array}{l}\text { Spanwise } \\
\text { Location }\end{array}$} \\
\hline & & & chords at section & ft & & $\mathrm{ft}^{\wedge} \mathbf{2}$ & & DEGREES & \\
\hline VISCOSITY $=$ & 3.801E-07 & $\mathrm{lbf}^{\star} \sec / \mathrm{ft}^{\wedge} \mathbf{2}$ & c16 = & 2.17 & $S 16=$ & 1.52 & twist16= & -0.53 & BS 235.2 \\
\hline $\mathbf{R P M}=$ & 70 & $\mathrm{rev} / \mathrm{min}$ & c17 = & 1.94 & S17 $=$ & 1.36 & twist17= & -0.47 & BS 252.0 \\
\hline \# SEGMENTS= & 20 & & c19= & 1.44 & $S 19=$ & 1.01 & twist19= & -0.60 & BS 285.6 \\
\hline BLADE LENGTH= & 28.08 & ft & & & & & & & \\
\hline DEVICE CHORD= & 0.5 & C & & & & & & & \\
\hline DEVICE ANGLE= & 90 & DEGREES & & & & & & & \\
\hline
\end{tabular}

\begin{tabular}{|c|c|c|c|c|c|c|c|c|c|c|}
\hline & $\begin{array}{l}\text { Blade } \\
\text { Sta. } 15\end{array}$ & $\begin{array}{l}\text { Blade } \\
\text { Sta. } 16\end{array}$ & $\begin{array}{l}\text { Blade } \\
\text { Sta. } 17\end{array}$ & $\begin{array}{c}\text { Blade } \\
\text { Sta. } 18\end{array}$ & $\begin{array}{c}\text { Blade } \\
\text { Sta. } 19\end{array}$ & $\begin{array}{c}\text { DEVICE } \\
\text { totals }\end{array}$ & $\begin{array}{c}\text { DEVICE } \\
\text { totals }\end{array}$ & & $\begin{array}{c}\text { HINGE } \\
\text { Reactions }\end{array}$ & $\begin{array}{c}\text { HINGE } \\
\text { Reactions }\end{array}$ \\
\hline$V_{0}(\mathrm{~m} / \mathrm{sec})$ & $\begin{array}{c}\text { Force- } \\
\text { Normal lb }\end{array}$ & \begin{tabular}{|c|} 
Force-Normal \\
lb
\end{tabular} & $\begin{array}{c}\text { Force-Normal } \\
\text { lb }\end{array}$ & \begin{tabular}{|c|} 
Force-Normal \\
lb
\end{tabular} & \begin{tabular}{|c} 
Force-Normal \\
lb
\end{tabular} & $\begin{array}{c}\text { Total Force- } \\
\text { Normal lb }\end{array}$ & $\begin{array}{c}\text { Spanwise (cp) } \\
\text { \% Device } \\
\text { span }\end{array}$ & & $\begin{array}{c}\text { BS 294 } \\
\text { (RHn 294) } \\
\text { (lbs) }\end{array}$ & $\begin{array}{c}\text { BS 294 } \\
\text { (RHc 294) } \\
\text { (lbs) }\end{array}$ \\
\hline 10.0 & 154.5 & 159.3 & 166.7 & 163.1 & 153.9 & 797.5 & 0.501 & & 0.00 & 393.95 \\
\hline 20.0 & 118.0 & 120.7 & 117.4 & 110.3 & 133.7 & 600.1 & 0.507 & & 0.00 & 296.45 \\
\hline 30.0 & 85.2 & 83.7 & 74.6 & 69.2 & 126.1 & 438.8 & 0.531 & & 0.00 & 216.77 \\
\hline 40.0 & 95.9 & 92.7 & 87.6 & 89.2 & 96.0 & 461.5 & 0.499 & & 0.00 & 227.98 \\
\hline 50.0 & 100.2 & 94.6 & 88.1 & 87.8 & 93.4 & 464.1 & 0.491 & & 0.00 & 229.25 \\
\hline 60.0 & 133.1 & 125.4 & 107.4 & 96.1 & 100.3 & 562.2 & 0.466 & & 0.00 & 277.70 \\
\hline & $\begin{array}{l}\text { Blade } \\
\text { Sta. } 15\end{array}$ & $\begin{array}{l}\text { Blade } \\
\text { Sta. } 16\end{array}$ & $\begin{array}{l}\text { Blade } \\
\text { Sta. } 17\end{array}$ & $\begin{array}{l}\text { Blade } \\
\text { Sta. } 18\end{array}$ & $\begin{array}{l}\text { Blade } \\
\text { Sta. } 19\end{array}$ & $\begin{array}{c}\text { DEVICE } \\
\text { totals }\end{array}$ & $\begin{array}{c}\text { DEVICE } \\
\text { totals }\end{array}$ & & $\begin{array}{c}\text { Link } \\
\text { Reactions }\end{array}$ & \\
\hline$V_{0}(\mathrm{~m} / \mathrm{sec})$ & $\begin{array}{c}\text { Moment } \\
\text { in-lb }\end{array}$ & $\begin{array}{c}\text { Moment } \\
\text { in-lb }\end{array}$ & $\begin{array}{c}\text { Moment } \\
\text { in-lb }\end{array}$ & $\begin{array}{c}\text { Moment } \\
\text { in-lb }\end{array}$ & $\begin{array}{c}\text { Moment } \\
\text { in-lb }\end{array}$ & $\begin{array}{c}\text { Total M } \\
\text { in-lb }\end{array}$ & $\begin{array}{c}\text { Spanwise } \\
(\mathrm{cm}) \% \\
\text { Device span }\end{array}$ & & $\begin{array}{c}\text { BS 240 } \\
\text { (RMn 240) } \\
\text { (in-lb) }\end{array}$ & \\
\hline 10.0 & 196.6 & 184.9 & 180.4 & 154.5 & 123.8 & 840.3 & 0.458 & & 840 & \\
\hline 20.0 & 87.5 & 93.9 & 81.8 & 67.3 & 78.9 & 409.4 & 0.479 & & 409 & \\
\hline 30.0 & -34.7 & -31.1 & -22.2 & -18.0 & 48.0 & -57.9 & -0.117 & & -58 & \\
\hline 40.0 & -53.3 & -46.9 & -39.7 & -22.0 & -20.1 & -181.8 & 0.400 & & -182 & \\
\hline 50.0 & -110.3 & -90.1 & -75.1 & -46.5 & -42.1 & -364.1 & 0.401 & & -364 & \\
\hline 60.0 & -119.9 & -102.9 & -96.4 & -75.5 & -63.6 & -458.2 & 0.439 & & -458 & \\
\hline $\bar{\Omega}$ & (cg) position & Device & Centrifugal & Centrifugal & (cg) position ! & & \multicolumn{2}{|c|}{ Centrifugal Loads } & & \\
\hline $\mathrm{rad} / \mathrm{sec}$ & pivot offset & Mass & Force & Force & 210 of fset & (RHc 294) & (RHn 294) & (RHc 210) & (RHn 210) & (Fz 210) \\
\hline & $\mathbf{m}$ & $\mathbf{k g}$ & Newton & $\mathbf{I b}$ & in & lb & lb & lb & lb & lb \\
\hline 7.33 & 6.82 & 17 & 5865.2 & 1318.6 & 3.63 & 0 & -57 & 0 & 57 & 1319 \\
\hline
\end{tabular}




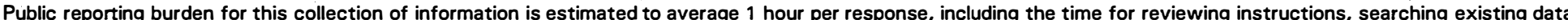

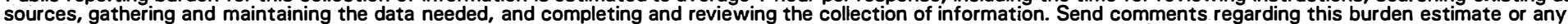

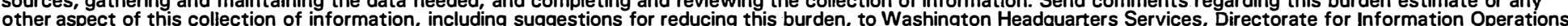

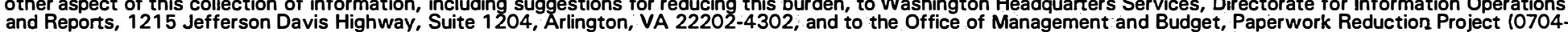
and Reports, 1215 Jefferson Davis
0188 ), Washington, DC 20503.

1.

2. REPORT DATE

January 1996

4. TITLE AND SUBTITLE

Wind Turbine Trailing-Edge Aerodynamic Brake Design

6. AUTHOR(S)

Gene Quandt

7. PERFORMING ORGANIZATION NAME(S) AND ADDRESS(ES)

Gene Quandt $Z$

PO Box $4398 \mathrm{z}$

Pocatello, Idaho $83205 \mathrm{z}$

9. SPONSORING/MONITORING AGENCY NAME(S) AND ADDRESS(ES)

National Renewable Energy Laboratory

1617 Cole Blvd. $z$

Golden, CO 80401-3393 z
3. REPORT TYPE AND DATES COVERED

Subcontract Report

5. FUNDING NUMBERS

C: TAD-3-13400

TA: WE518330

8. PERFORMING ORGANIZATION REPORT NUMBER
10. SPONSORING/MONITORING AGENCY REPORT NUMBER

TP-441-7389

DE96000525

11. SUPPLEMENTARY NOTES

NREL Technical Monitor: Paul Migliore

12a. DISTRIBUTION/AVAILABILITY STATEMENT

National Technical Information Service

U.S. Department of Commerce $z$

5285 Port Royal Road

Springfield, VA 22161 12b. DISTRIBUTION CODE

UC-1213

13. ABSTRACT (Maximum 200 words)

This report describes the design of a centrifugally actuated aerodynamic-overspeed device for a horizontal-axis wind turbine. The device will meet the following criteria:

o It will be effective for airfoil angles of attack $0^{\circ}$ to $45^{\circ}$.

o It will be stowed inside the blade profile prior to deployment.

o It will be capable of offsetting the positive torque produced by the overall blade.

o Hinge moments will be minimized to lower actuator loads and cost.

- It will be evaluated as a potential power modulating active rotor-control system.

A literature review of aerodynamic braking devices was conducted. Information from the literature review was used to conceptualize the most effective devices for subsequent testing and design. Wind-tunnel test data for several braking devices are presented in this report. Using the data for the most promising configuration, a preliminary design was developed for a MICON $65 / 13$ wind turbine with Phoenix 7.9-m rotor blades.

14. SUBJECT TERMS wind turbine design
15. NUMBER OF PAGES

16. PRICE CODE

20. LIMITATION OF ABSTRACT OF THIS PAGE Unclassified
19. SECURITY CLASSIFICATION OF ABSTRACT Unclassified
UL

\section{OF REPORT}

Unclassified 